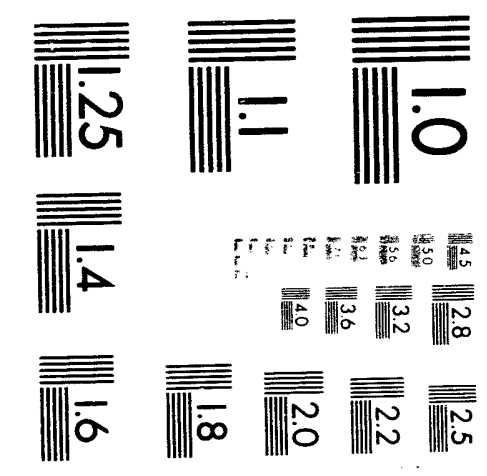



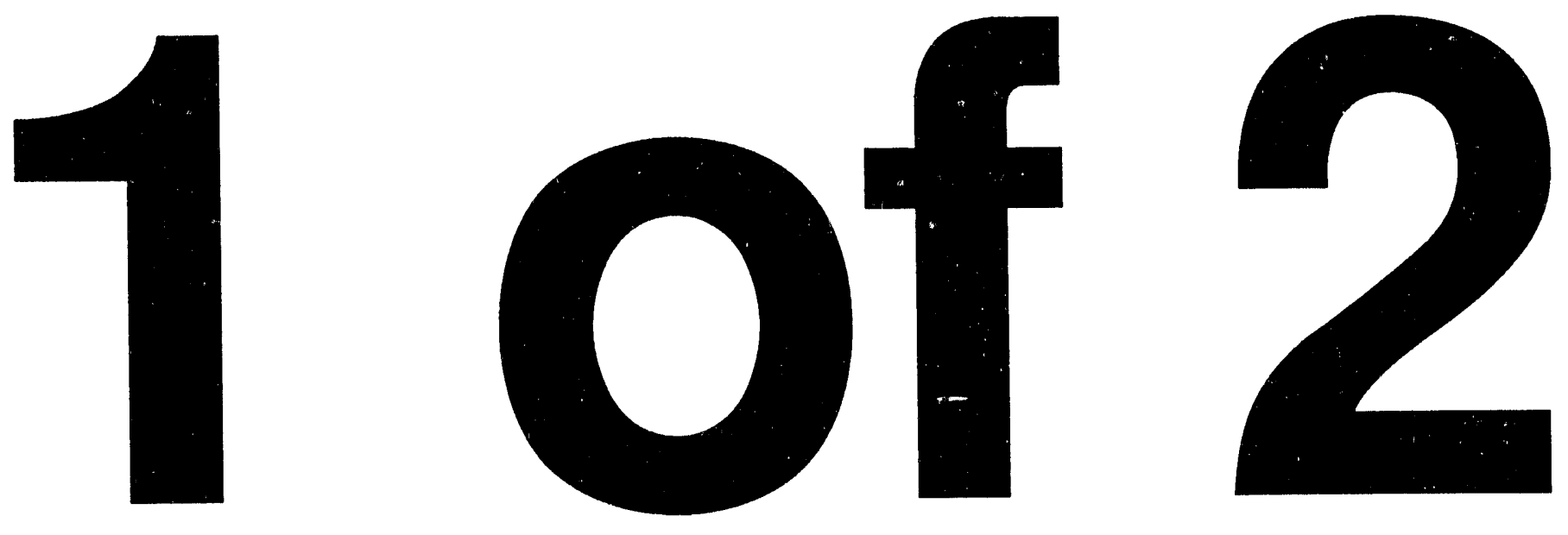


\title{
CHAWS User's Guide: System Description and Standard Operating Procedures Lexington-Blue Grass Army Depot
}

\author{
S.A. Martins \\ J.H. Shinn \\ Editors
}

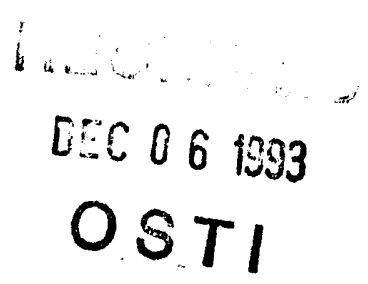

May, 1993

'This is an informal report intended primarily for internal or limited external distribution. The opinions and conclusions stated are those of the author and may or may not be those of the Laboratory.

Work performed under the auspices of the U.S. Department of Energy by the Lawrence Livermore National Laboratory under Contract W-7405-Eng-48. 


\section{DISCLAIMER}

This dreument was prepared as an account of work sponsosed by an agency of the United States Covernment. Neither the United States Government nor the University of California nor any of their employees, makes any warranty, express or implied, or assumes any legal liability or responsibility for the accuracy, completeness, or usefulness of any information, apparatus, product, or process disclosed, or represents that its use would not infringe privately owned rights. Reference herein to any specific commercial products, process, or service by Irade name, trademark, manufacturer, or otherwise, does not necessarily constitute or imply its endorsement, recommendation, of favoring by the United States Government or the University of California. The views and opinions of authors expressed herein do not necessarily state or reflect those of the United States Government or the University of California, and shall not be used for advertising or product endorsement purposes.

This report has been re.

directly from the best araitaliz topy.

Available to DOE and DOE contractors from the Office of Scientific and Technical Information

P.O. Box 62, Oak Ridge, TN 37831

Prices available from 1615) 576-8401, FTS 626-8401.

Available 10 the public from the

National Technical Information Service

US. Department of Commerce

3285 Port Royal Rd.

Springfield, VA 22161 
UCID-21336, Rev. 1

\title{
CHAWS User's Guide: \\ System Description and Standard Operating Procedures \\ Lexington-Blue Grass Army Depot
}

\author{
S.A. Martins \\ J.H. Shinn \\ Editors
}

May, 1993 


\section{Contents}

Preface ................................................................................................... vi

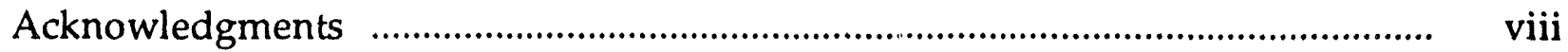

I Daily Operations Guide .................................................................... I- 1

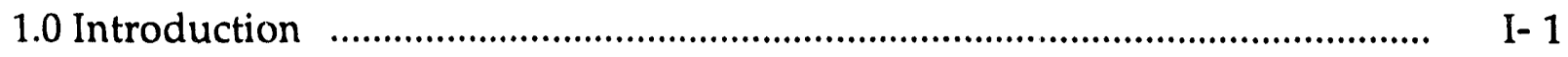

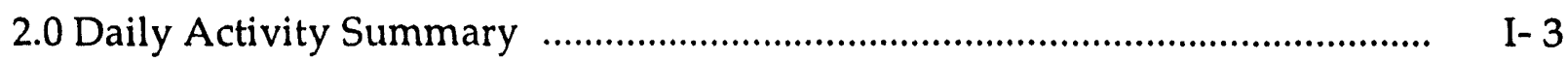

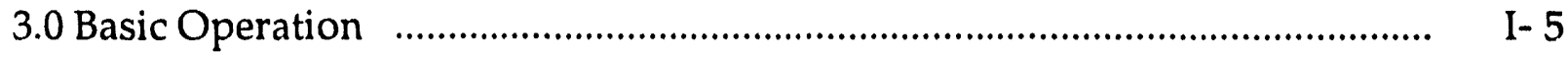

3.1 Power-On Check ......................................................................... 5

3.2 Cold Start-Up .......................................................................... I- 5

3.3 Warm Re-Start ........................................................................ I- 6

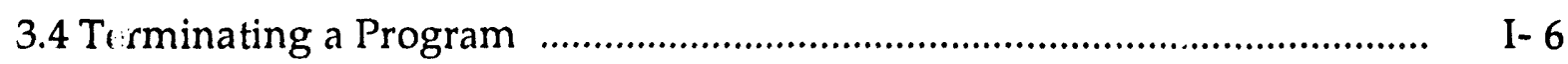

3.5 Alloy Screens ..................................................................................... I- 7

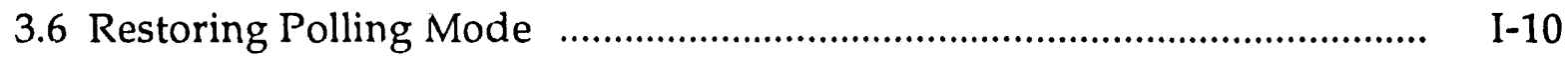

4.0 Graphic display mode ................................................................... I-10

4.1 Entry into Graphic Display Mode .................................................... I-10

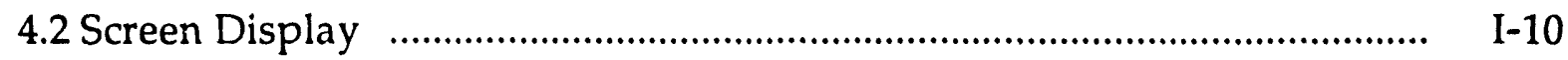

5.0 Modeling and Data Processing Software ................................................ I-11

5.1 Downwind Hazard Prediction Model -- D2PC ..................................... I-I1

5.2 Data Processing and Editing Software ................................................. I-11

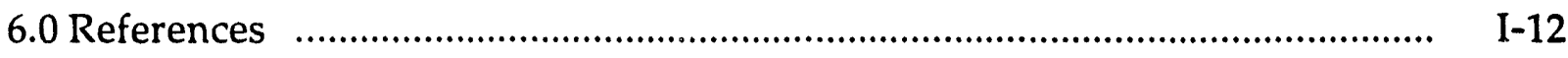

Appendix I-A: Glossary of Terms ............................................................. I-13

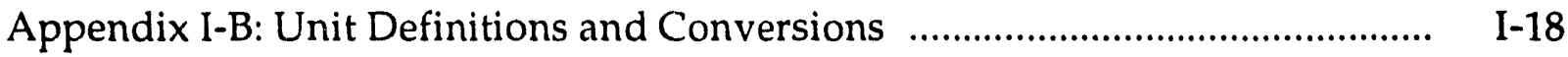

Appendix I-C: Julian Calendar ............................................................... I-19

II Rewired HANDAR Instruments and Towers $\quad$.............................................. II- 1

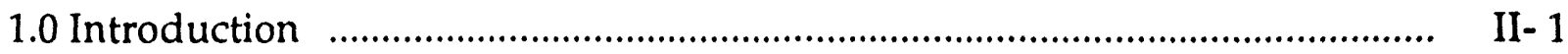

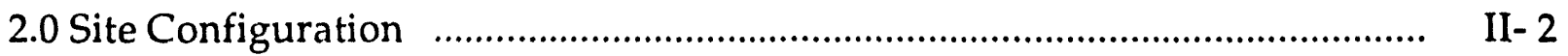

2.1 Tower and Sensor Configuration ...................................................... II- 2

2.2 Meteorological Sensor Description ...................................................... II- 2

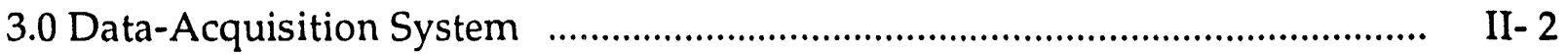

Appendix II-A: Glossary of Terms ............................................................... II- 8

III CHAWS Sound Detection and Ranging (SODAR) Systems ......................... III- 1

IV HANDAR Interrogated Radio System ................................................. IV- 1

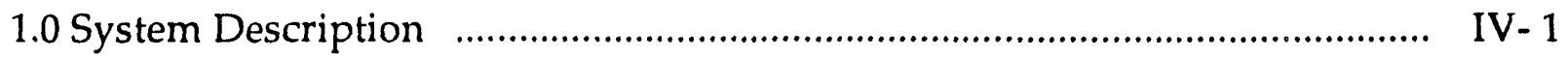




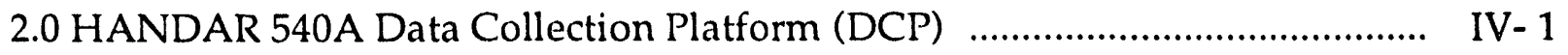

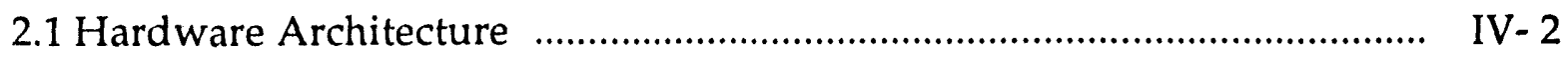

2.2 Programming the 540A ....................................................................... IV-

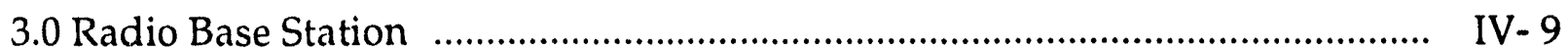

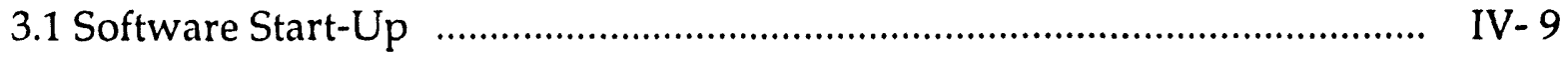

3.2 Termination of BASE. BAT Execution …................................................ IV-10

3.3 Interactive Communications …........................................................... IV-11

3.4 External Mode ..................................................................................... IV-12

3.5 The Poll/Monitor Mode …................................................................. IV-12

4.0 Troubleshooting Guide ........................................................................ IV-12

4.1 None of the 540A's Respond to the Radio Base Station ............................ IV-12

4.2 Individual 540A's Do Not Respond to the Base Station ............................ IV-13

4.3 After Reestablishment of Communications …......................................... IV-15

5.0 List of Manuals Needed for Chapter IV ................................................ IV-15

Appendix IV-A: 540A Quick Programming Reference .................................... IV-16

Appendix IV-B: 540A Program List ............................................................. IV-21

Appendix IV-C: WAITDATA Program Description ……................................. IV-35

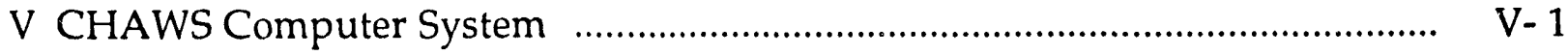

1.0 Introduction

1.1 Hardware Architecture ............................................................................ V-1

1.2 System Software .......................................................................... V-

1.3 System Functions …......................................................................... V-

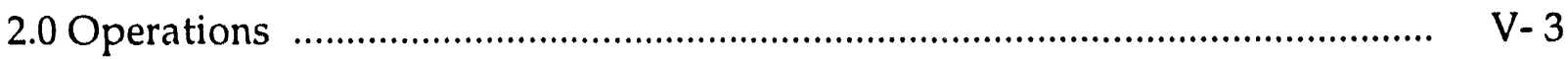

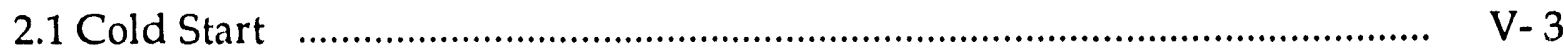

2.2 The Spear PC/AT Host Computer ………................................................... V- V

2.3 Routine Weather-Data Logging ………...................................................... V-

2.4 Telephone Communications …………..................................................... V- 5

2.5 SODAR Data Logging ...................................................................... V-5

2.6 Using the Printer ................................................................................... V-

3.0 Troubleshooting Guide ........................................................................... V-6

3.1 System Power Problems ……............................................................ V-

3.2 Default Software Does Not Start When System Is

Powered-Up or Rebooted ..................................................................... V-7

3.3 Hard-Disk Problems ................................................................................ V-

3.4 Telephone Communications …......................................................... V-9 
4.0 System Installation and Specifications …….............................................. V-10

4.1 Uninterruptible Power Supply (UPS) ……............................................ V-10

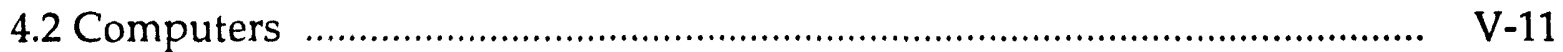

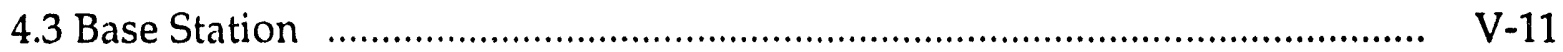

4.4 PC/Slave Card Installation ................................................................... V-12

4.5 Telephone Modem ............................................................................. V-13

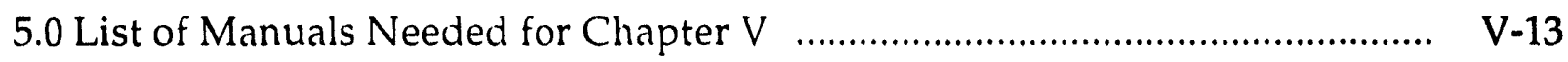

Appendix V-A: EOC/AOC Telephone Link ……............................................. V-14

Appendix V-B: Computer System Time-Keeping ……......................................... V-15

VI Graphic Display and Data-Processing Software ........................................... VI- 1

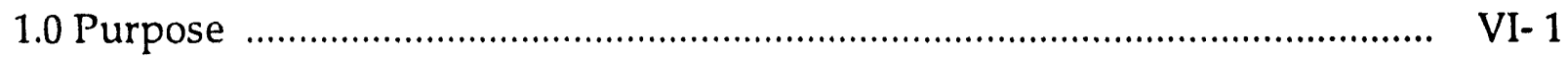

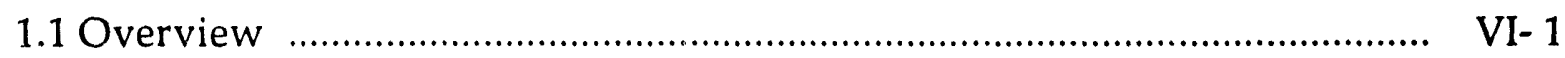

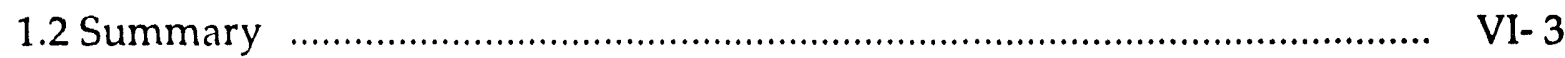

2.0 Data File and Program Descriptions ……................................................... VI- 3

2.1 Data Files .

2.2 Configuration and Initialization Files ………...................................... VI- 5

2.3 Continuous Data-Collection Programs ………......................................... VI- 7

2.4 Data Examination and Summary Programs ……...................................... VI-11

3.0 Program Operation …......................................................................... VI-13

3.1 Continuous Data-Collection Programs …….............................................. VI-16

3.2 Data-Examination and Summary Programs .............................................. VI-24

3.3 Disk Operating System (DOS) Primer ................................................. VI-37

3.4 Examination and Editing of ASCII Files (PE2) ....................................... VI-40

4.0 Data Tabulation, Interpretation, and Archiving ……................................... VI-46

4.1 Data Processing and Quality Assurance ………...................................... VI-46

4.2 Interpretation of the Tabular Data ........................................................ VI-47

4.3 Archiving of Tables ............................................................................ VI-48

4.4 Archiving of Data Files (*.WX, * . HR) ………...................................... VI-49

4.5 Data Recovered (RECOV) ...................................................................... VI

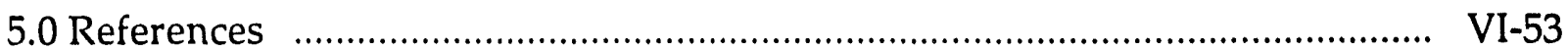




\section{PREFACE}

The Chemical Hazard Warning System (CHAWS) has been designed to collect meteorological data and to display, in real time, hazardous chemical dispersion as a result of an accidental release. Meteorological sensors are placed strategically around each installation and are used to calculate direction and hazard distance for the release. These data are then graphically displayed on a computer screen showing a site map and arrows depicting the release direction and distance traveled.

The objectives of CHAWS are as follows:

- To determine the trajectory of the center of mass of released material from the measured wind field.

- To calculate the dispersion based on the measured lateral turbulence intensity (sigma theta).

- To determine the height of the mixing zone by measurement of the inversion height and wind profiles up to an altitude of about $1 \mathrm{~km}$.

- To archive meteorological data for potential use in climatological descriptions for emergency planning.

- To archive air-quality data for preparation of compliance reports.

- To provide access to the data for near real-time hazard analysis purposes.

The last function is provided at a minimum by the PC-version of the Army code D2 PC, which is resident in the central computer. Although D2PC has limited capability to use the full power of CHAWS meteorological data, it is noted for its variety of source-term scenarios that can be selected by an operator to estimate the downwind distance to a hazardous concentration limit.

The CHAWS system has been made as easy to use as possible, but because it has a wide variety of functions, learning to use it correctly may take some time. All operators should

- Have a basic knowledge of the Microsoft Disk Operating System (MS-DOS) and an understanding of how to use computers.

- Read each chapter carefully before attempting to use the system.

- Work through the steps explained in each section to learn the correct techniques to fully use all the capabilities of CHAWS.

Operators probably will need to go through the manuals more than once to have a good understanding of how the system works. Moreover, the more an operator uses 
the system, the easier it becomes. However, the manuals should always be kept within easy reach as a reference. Summary documents have been provided here for some of the systems, and trained personnel, after learning system operations from the appropriate manual, may find these to be all they need to carry on day-to-day operations.

Because the systems installed at the various Army sites have different configurations, we have written six similar volumes, each tailored to a specific site. They are as follows:

- UCID-20988 - Tooele Army Depot Air Quality Monitoring Systems User's Guide: Description, Standard Operating Procedures, and Installation Report. (In addition to the Tooele Depot, Pine Bluff Arsenal also uses this volume.)

- UCID-21333 - CHAWS User's Guide: System Description and Standard Operating Procedures-Pine Bluff Arsenal.

- UCID-21334 - CHAWS User's Guide: System Description and Standard Operating Procedures-Toocle Army Depot.

- UCID-21335 - CHAWS User's Guide: System Description and Standard Operating Procedures-Edgewood Area, Aberdeen Proving Ground.

- UCID-21336 - CHAWS User's Guide: System Description and Standard Operating Procedures-Lexington-Blue Grass Army Depot.

- UCRL-CR-105263 - CHAWS User's Guide: System Description and Standard Operating Procedures-Johnston Island JCAD Facility.

The major components of CHAWS are listed below along with the chapters (or volumes) in which they are discussed:

- The Emergency Operations Center (EOC) central computer (Chapters I and V).

- The network of meteorological towers (Chapter II).

- The network of air-quality monitors (UCRL-CR-105428).

- The SODAR meteorological sounding system (Chapter III). (This chapter applies only to the Edgewood and Pine Bluff manuals.)

- The data-acquisition radio system (Chapter IV).

- The specialized data-processing and display software (Chapter VI). 


\section{ACKNOWLEDGMENTS}

The CHAWS system was developed by the Environmental Sciences Division at Lawrence Livermore National Laboratory under the direction of Dr. Joseph H. Shinn. The development was made possible through an Interagency Agreement between the U.S. Army Atmospheric Sciences Laboratory at White Sands Missile Range, New Mexico, and the U.S. Department of Energy, San Francisco Operations Office. The Technical Representative for the U.S. Army was Mr. Ron Meyers. The development was greatly facilitated by the coordination with users made possible by Lieutenant Colonel Larry James and Master Sergeant Ray Dennis of the Atmospheric Sciences Laboratory. We wish to express our thanks to Mr. Ed Parham of Pine Bluff Arsenal for his guidance from the operator's point of view and his interest in the success of the system. 


\title{
Chapter I \\ DAILY OPERATIONS GUIDE
}

\author{
Michael H. Merry \\ Certified Consulting Meteorologist \\ Stan Martins \\ Kaiser Engineers, Livermore
}

\subsection{INTRODUCTION}

The Chemical Hazard Warning System (CHAWS) is designed to collect meteorological data and to display, in real time, the dispersion of hazardous chemicals that may result from an accidental release. Meteorological sensors have been placed strategically around the Lexington-Blue Grass Army Depot and are used to calculate direction and hazard distance for the release. Based on these data, arrows depicting the release direction and distance traveled are graphically displayed on a computer screen showing a site map of the facility.

The objectives of CHAWS are as follows:

- To determine the trajectory of the center of mass of released material from the measured wind field

- To calculate the dispersion of the released material based on the measured lateral turbulence intensity (sigma theta).

- To determine the height of the mixing zone by measurement of the inversion height and wind profiles up to an altitude of about $1 \mathrm{~km}$ at sites that have SODAR units installed.

- To archive meteorological data for potential use in climatological descriptions for emergency planning.

- To archive air-quality data for preparation of compliance reports.

- To provide access to the data for near real time hazard analysis purposes.

CHAWS sites are located at the Pine Bluff Arsenal, Arkansas, Edgewood area of Aberdeen Proving Ground, Maryland, Tooele Depot, Utah, Lexington-Blue Grass Depot, Kentucky, and Johnston Island in the Pacific. The systems vary between sites with different features and various types of hardware. The basic system, however, is the same. Nonetheless, we have tailored the manuals to the equipment found at each site. 


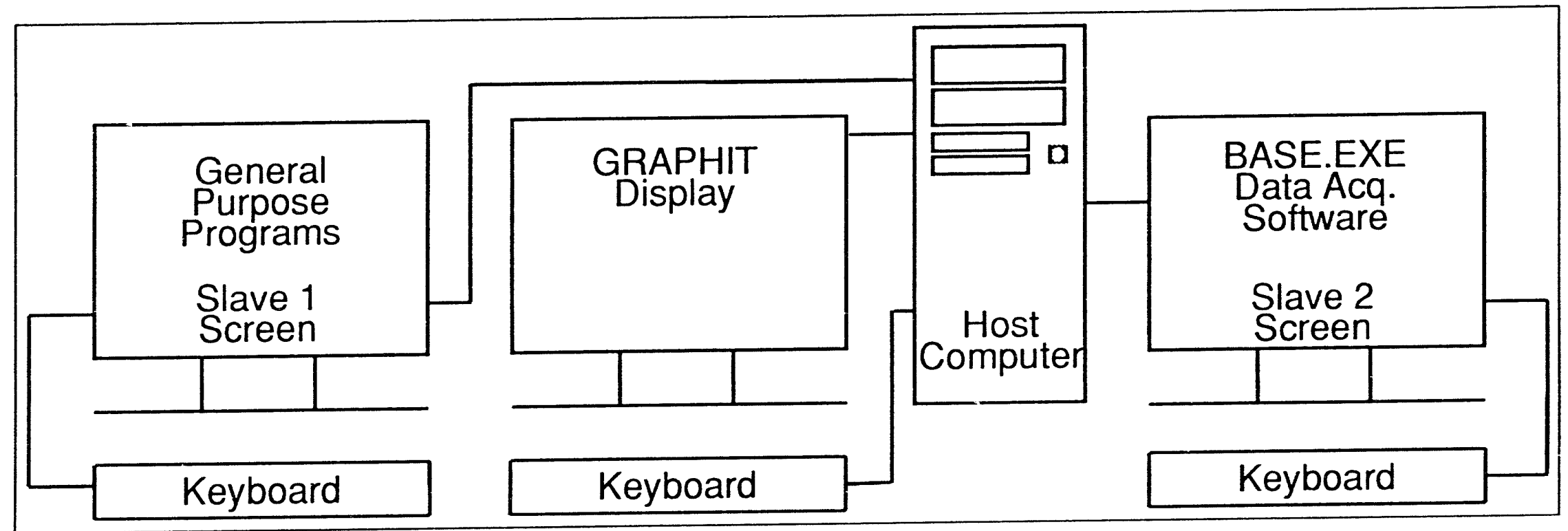

Figure I-1. Data and model display hardware. 
CHAWS consists of a host Spear PC/AT computer and two or more Alloy terminals, which are connected to internal slave computers (see Figure 1-1). The primary function of the host computer is to log and process data from the meteorological and air-quality (where applicable) systems.

The CHAWS system has been made as easy to use as possible, but because it has a wide variety of functions, learning to use it correctly may take some time. Users should have a basic knowledge of the Microsoft Disk Operating System (MS-DOS) and an understanding of how to use computers. Users should also read each chapter carefully before attempting to use the system and work through the steps explained in each section to learn the correct techniques to fully use all the capabilities of CHAWS.

Manuals hav'e been provided that instruct the user in DOS commands and procedures. Also, manuals have been provided for the hardware that has been manufactured by HANDAR and the computer companies. This manual is meant to serve as a supplement to those hardware manuals. To obtain a good understanding of how the system works, the users probably will need to go through the manuals more than once. Summary documents have been provided for some of the systems, and trained personnel, after learning system operations from the manual, may find these to be all they need to carry on day-to-day operations. However, the manuals should always be kept within easy reach as a reference.

\subsection{ROUTINE ACTIVITY SUMMARY}

A regular workday using CHAWS consists of many activities. This section gives a brief overview oi daily and other routine actions necessary to run the system. The following sections of this chapter describe system startup, either with or without graphic display, and list software. Other chapters of this manual present more detail about the hardware and software so the user can perform troubleshooting and maintenance on the system. All technical terms are defined in the Glossary at the end of this chapter (Appendix A). Parameters and units are described in Appendix B.

It is important for the user to note that often a command will be entered and the system will appear to not be performing the operation. Please be patient; the system may be busy running another operation. Occasionally the operation will take 30 to 60 seconds.

ON ARRIVAL: Check the screens to see that the host and slave computers are performing properly. The host should be running LOGIT with the Slave 2 screen 
showing current data as described in Section 3.5. Shortly after the end of a data poll, reboot the system by hitting the $\langle\mathrm{Ctrl}>,<\mathrm{Al} t\rangle$ and $<$ Del $>$ keys simultaneously on the host computer (do this twice if necessary). $<\mathrm{Ctrl}>$ and $<\mathrm{Al} t>$ are on the left side of the main keyboard, while $<D e l>$ is in the lower right corner of the numeric keyboard. [Booting (or starting) is recommended once or preferably twice a day; booting the system corrects for any time drift and ensures that any accumulated errors are eliminated.] Then strike $\langle\mathrm{Ctr} l>$ and " $\mathrm{C}$ " simultaneously. After the message "Terminate batch job ( $\mathrm{Y} / \mathrm{N})$ ?" appears, type " $\mathrm{Y}$ ". Make sure you are in the HANDAR subdirectory. After LOGIT stops running, the graphics may be started by typing "GRAPHIT" after obtaining a DOS prompt (see Section 4.1). The screen will then display a map and graphs.

DURING THE WORKDAY: Check the Alloy Slave 2 terminal screen to make sure it is displaying data from the most recent period and that the clock in the upper right-hand corner is running. Check the host computer screen to make sure the wind trajectory and other meteorological conditions are also being updated regularly; with data from the most recent 2 hours shown on the graphic display.

DAILY: Copy only the * . WX files to a $1.44-\mathrm{M}$ or $1.2-\mathrm{M}$ byte floppy disk. About 10 to 20 days of data should fit on one disk. Chapter VI, Section 4.0 of this CHAWS Manual provides the correct archiving procedures. The * . HR, * . HLY and raw data files can also be saved if the user wants to calculate 5-minute averages or is undecided on what data to archive.

UPON DEPARTURE: While a data poll is in progress, or shortly after a poll, bring the host monitor out of the GRAPHIT mode by hitting the $<\mathrm{Ctrl}>$ and $<$ Brk $>$ keys simultaneously. "Terminate Batch Job? $\mathrm{Y} / \mathrm{N}$ " should appear in the upper left portion of the screen; type " $Y$ ". To clear the graphics off the screen, type " $C$ lear" $<$ Enter $>$, then "CD $\backslash$ HANDAR". At the DOS prompt, type "LOGIT". Do not strike the $<$ Enter $>$ key at this time (if a poll is in progress). After the current poll is complete, the words " 1 file copied" will appear three times in the lower left corner of the Slave 2 screen. At this time strike <Enter $>$ to start LOGIT on the host. The red light should start flashing almost immediately-if does not, press $<\mathrm{Ctrl}>$ and " $\mathrm{C}$ " simultaneously, answer " $\mathrm{Y}$ " to the terminate question, and retype "LOGIT" <Enter>. After a few seconds the words " 1 file copied" should appear twice on the host screen, then the screen should go blank. When the hard disk stops working, a blinking 
cursor should appear on the host monitor. When this occurs, LOGIT is running. Turn the brightness controls down after watching one more poll to ensure that LOGIT is running properly.

\subsection{BASIC OPERATION (WITHOUT GRAPHIC DISPLAY)}

Any type of boot-up (warm or cold) should result in the host computer entering the LOGIT mode automatically. This mode runs the RDCATCH program, which transforms short-term data from the form shown on the Slave 2 screen to *. WX files for more efficient storage.

For a graphic display on the host computer screen, the GRAPHIT mode is used to run WXGRAPH. Before entering this mode, start the system and check its operation. Follow the procedures given below and if the system does not respond as described, consult the Troubleshooting section in Chapter V of this manual.

\subsection{Power-On Check}

Check the green LED light on the upper left front panel of the host. If the LED is lit but the screens do not respond as described, try the warm re-start $(\langle\mathrm{Ctrl}\rangle,\langle\mathrm{A} l t\rangle$, $<$ Del $>$ ) described in Section 3.3. If this fails, or the green light is not lit, proceed to the cold start-up procedure in Section 3.2. If the light is on, check the screens to see if they appear as described in Section 3.5.

\subsection{Cold Start-Up}

If the green front-panel light is out, the system is started cold ("cold-booted") without graphic display by the following procedure:

1. Turn on the host computer (power switch is on the right side rear of the Spear-PC/AT);

2. Turn on each of the 3 screens (if the power switch is not on the front panel, it is usually on the back near the power cord) and the printer.

The green light should now be lit. The number of kilobytes of memory tested will appear in the host's upper left screen. The slave memories will also be tested before the host starts running the LOGIT program. While program and data files are being loaded, the red LED hard-disk access light will flash on and off. (This light is on 
the front panel just to the right of the green power-on light.) Any file-copy messages on the screen will disappear when LOGIT starts running, leaving only the cursor in the upper left corner.

\subsection{Warm Re-Start}

If the green front-panel light on the host computer is on, the system can be restarted warm ("warm-booted") to enter or re-enter LOGIT mode (without graphic display). This will terminate any programs currently running on the host or any slave terminal and thus should be done only between data polls. (WARNING-All volatile internal memory will be erased).

Reboot the system by simultaneously hitting the $\langle\operatorname{Ct} r l\rangle,\langle A l t\rangle$, and $\langle$ Del $\rangle$ keys on the host computer keyboard (twice if necessary). $\langle\operatorname{Ctr} l\rangle$ and $\langle A l t\rangle$ are on the left side of the main keyboard while $<D e l>$ is in the lower right corner of the numeric keyboard. The screen will clear and a flashing cursor will appear in the upper left corner of the screen. The reboot process will display file-copy messages on the screen while the red hard-disk access light on the front panel flashes on and off. When the host runs LOGIT, the file-copy messages will disappear, leaving only the cursor. Confirm that LOGIT is running by comparing the Slave 2 Alloy screen with the figures and discussion in Section 3.5. Note: If the system is locked up, the warm-boot process will not work. Turn the power off, and turn the brightness controls down on the monitors prior to turning the power back on.

\subsection{Terminating a Program}

Normally, a program should be terminated by following the instructions for that program (see Chapter VI, Section 3 of this manual). Continuous programs such as LOGIT or GRAPHIT should not be terminated; the system may lock up or data might be lost. However, if necessary, these programs (but not the base station software) can be stopped by hitting the <Ctrl> and <Break> (Scroll Lock) keys simultaneously. This may need to be done several times. The DOS prompt character (ending with " $>$ ") will appear on the left side of the screen after a successful termination.

This procedure may be used to exit LOGIT and enter DOS in order to start the graphic display with GRAPHIT.

\subsection{Alloy Screens}


Figure I-2 shows the Alloy Slave 1 screen display. The Slave 1 has a keyboard, and in addition to its use for running the U.S. Army's D2PC dispersion modeling program, it is also to be used for data processing, file editing, and other programs. Operation of these programs is mentioned in Section 5.0 of this chapter, and data processing programs are described in Chapter VI of this manual. The manuals for these programs should be consulted for details about their operation.

Figure I-3 shows the Slave 2 screen as it appears when the base station software, BASE.EXE, is polling data. Text in the square brackets " [ ]" does not appear on the screen but is presented in the tigure to explain what the lines of data represent. The top line in the box appears in brackets " \{\} " to indicate that it appears before a poll starts, whereas the data that follow do not.

Before the polling begins, the top 3 lines appear as in the Figure I-3. If "Polling enabled" appears, the system is ready to collect the data for the next 15-minutes. Check the Julian date and time at the upper right to make sure they are current. A table of Julian dates appears as Appendix $C$ of this chapter.

Polling is scheduled to begin at the "-- Next poll time:" shown in the upper or lower center of the boxed area (always on a 15-minute interval). The "DCP 00000001 -.." represents the next station (Data Collection Platform) to be polled (in this example, Station No. 1).

The rest of Figure I-3 shows how the screen appears at the end of a poll, at which time the "Next Poll Time ..." line at the bottom of the boxed aren shows the time of the next scheduled poll. Note: Data shown were taken inside a labor atory and do NOT represent a real atmospheric scenario. Moreover, station and channel numbers vary from site to site. 


NTNX Slave Processor -- Version 1.68f
Copyright (C) 1985,1986,1987 by Alloy Computer Products, Inc.
User: 1
Mem Size: $651 \mathrm{~K}$ Shared Drives: C: $2158 \mathrm{~K}$
Single Address Space
C> prompt $\$ \mathrm{p} \$ g$
C: $\backslash>$ HISTORY
C: $\backslash>$
$C: \backslash>$

Figure I-2. Slave 1 terminal screen display.

As the data representing 5- and 15-minute averages move up the Alloy Slave 2 terminal screen, the "Polling Enabled" remark at the top will change to "Polling DCP 00000001 (2, 3, etc.)" as each station is polled. To the right of this remark will be either "Transmitting", "Awaiting Response", or "Receiving", indicating the current activity of the HANDAR 542 Base Station.

Figure I-3 shows the Slave 2 screen as it should appear displaying current data. Make sure the clock in the upper right displays the current time and that the display follows the format given. If BASE.EXE does not appear to be running and displaying a screen as in the figure, reboot the system (Section 3.3) or consult the Troubleshooting Chapter (Chapter V) of this manual. The line below the boxed-in area in Figure I-3 is explained in the HANDAR Base Station Software Manual.

\subsection{Restoring Polling Mode}

If the radio base station software is in a menu other than "Poll/Monitor mode", press $<F 10>$ until the main menu appears. Now select $<F 2>$ from the Main Menu. The polling menu should now be on the screen. If the message "Polling 


\begin{tabular}{|c|c|c|c|c|c|}
\hline & --- & Next poll time & 022 & $08: 30: 00$ & DCP $00000001 \ldots$ \\
\hline 64 & $02208: 19: 59$ & $00: 05: 00 \quad 001.5$ & 001.5 & 001.6 & [5-min wind speeds] \\
\hline \multirow[t]{2}{*}{66} & $02208: 29: 40$ & $00: 15: 00 \quad 021.3$ & & & [15-min temperature] \\
\hline & -- & - Next poll time & Now & 1 pol1 & waiting. . - \\
\hline & --- Polled da & ata from DCP 000 & 10006- & from 022 & $08: 15: 00$ to $02208: 30: 00$ \\
\hline 000 & $00000702208:$ & $: 35: 05$ & & & [Station 7, Jul date, time] \\
\hline 01 & $02208: 29: 00$ & $00: 15: 00 \quad 13.3$ & & & [15-min battery voltage] \\
\hline 02 & $02208: 29: 50$ & $00: 15: 00 \quad 0.000$ & & & [15-min air qual CAL voltage] \\
\hline 03 & $02208: 19: 50$ & $00: 05: 00 \quad 0.000$ & 0.000 & 0.000 & 5 -min voltages] \\
\hline 07 & $02208: 19: 50$ & $00: 05: 00 \quad 0.001$ & 0.001 & 0.001 & [03 5-min voltages] \\
\hline 08 & $02208: 19: 50$ & $00: 05: 00 \quad 0.001$ & 0.000 & 0.000 & [SO2 5-min voltages] \\
\hline 09 & $02208: 19: 50$ & $00: 05: 00 \quad 0.000$ & 0.000 & 0.000 & [NO $\mathrm{N}_{\mathrm{x}}$-min voltages] \\
\hline 61 & $02208: 19: 57$ & $00: 05: 00 \quad 0.009$ & 0.009 & 0.009 & [5-min wind speeds] \\
\hline 63 & $02208: 19: 59$ & $00: 05: 00 \quad 179 \quad 17$ & 9 179 & & [5-min wind directions] \\
\hline 64 & $02208: 19: 59$ & $00: 05: 00 \quad 001.6$ & 001.5 & 001.8 & [5-min sigma theta] \\
\hline 66 & $02208: 29: 40$ & $00: 15: 00 \quad 021.4$ & & & [15-min temperature] \\
\hline
\end{tabular}

1 Enable polling 2 Display status 3 Reset poll 4 Disable polling 10 Return

Explanations :

$$
\text { (Data Description Line) }
$$

[CH|JUL|HR MN SC|HR MN SC|AV \#1 AV \#2 AV \#31]

[DATA|DAY|TIME |AVG .PER/5 OR 15-MIN. AVG.1]

FIRST LINE :

$\mathrm{CH}$ : Channel number for data

JUL: Julian date (see Appendix C for Julian dates)

HR : Hours

$\mathrm{MN}$ : Minutes

SC : Seconds

$\mathrm{AV} \# 1, \mathrm{AV} \# 2, \mathrm{AV} \# 3$ : Averages for first, second, and third 5-min periods (Only AV \#1 appears for a 15-min period)

SECOND LINE:

DATA : Refers to data-channel-type number above

DAY : Refers to Julian date above

TIME : Refers to local standard time

AVG. PER : Averaging period (Columns specify periods in $H R, M N, S C$ )

5 or 15-MIN AVG. : Refers to averages given above

Figure I-3. Slave 2 terminal screen display (from Pine Bluff instruments). Note: The data shown are not real-time. 
enabled" does not appear in the upper center screen, consult Troubleshooting in Chapter V of this manual.

\subsection{GRAPHIC DISPLAY MODE}

This mode employs the batch file GRAPHIT that runs WXGRAPH to obtain a graphic display of the meteorological parameters. GRAPHIT will also run RDCATCH to create the *. Wx files for efficient storage of the 15-minute data periods.

This mode must be entered after the system is started and data are properly being collected (see Section 3). If the Alloy Slave 2 screen is operating with data collection as prescribed in Section 3.5, you are ready to enter GRAPHIT mode.

\subsection{Entry into Graphic Display Mode}

If the computer is not running, start it by the procedure described in Section 3.2 above. If LOGIT is already running, terminate its operation (between polls ONLY) by striking $\langle C t r l>$ and $<$ Break $>$ simultaneously. When a prompt appears (" $>$ "), type "GRAPHIT" on the host computer's keyboard followed by <Enter $>$. This should start GRAPHIT whether it is in the HANDAR directory (after LOGIT) or the root directory (after startup).

\subsection{Screen Display}

The above procedure enters the GRAPHIT batch file commands to the host computer and starts the operation of WXGRAPH. The parameters described below are assigned by the WXGRAPH.INI file. They can be changed by editing this file following the instructions given in Chapter V, Section 3.1.6 of this manual.

Upon completion of the steps in Section 4.1, the host screen will draw the map and show wind direction arrows and trajectories. It will also plot time-series graphs of wind and temperature on the right-hand side of the screen as explained in Chapter V, Section 3.1.7 of this manual. The plots typically show the values of four different meteorological parameters over a 2-hour period; these include wind speed, wind direction, standard deviation of wind direction (sigma-theta), and temperature. The times appear to the right of their respective tic marks along the bottom axis of these time-series graphs. 
The display is easily understood. Arrows at each CHAWS monitoring station point downwind (in the direction the wind is blowing). For definitions of parameters and units, see Appendices $A$ and $B$ of this chapter. It is important to remember that the trajectories are based on past data (with the latest wind direction at the far end of the trajectory). They are not snapshot plumes or projections of future air parcel trajectories. A detailed explanation of the trajectories appears in Chapter VI, Section 3.1.5.4 of this manual.

\subsection{MODELING AND DATA PROCESSING SOFTWARE}

This section lists the software that can be run on the Slave 1 terminal. For more complete descriptions of these programs, turn to Chapter VI of this Manual.

\subsection{Downwind Hazard Prediction Model -- D2PC}

For emergency purposes, the Slave 1 Alloy terminal is set up to run D2PC immediately as long as the subdirectory containing D2PC is active. (The subdirectory can be either D2 or D2PC, depending on the site.) Simply type "D2 PC" <Enter $>$ and follow the instructions on the screen. Familiarity with the program is required. Consult the D2PC manual, Personal Computer Program for Chemical Hazard Prediction $(D 2 P C)^{1}$ (or a later edition) for operational details as well as a technical description of the program.

\subsection{Data-Processing and Editing Software}

Data-processing software should all be run on Slave 1. This includes WXSUM, AQHRS, AQCAL, AQHTAB, and RECOV. Editing and spreadsheet software such as PE2 and LOTUS may also be operated from this screen. Consult the manuals for these programs for details about their operation. 


\subsection{REFERENCES}

1. Whitacre et al., Personal Computer Program for Chemical Hazard Prediction (D2PC), No. CRDEC-TR-87021 (1987). 


\section{Appendix I-A \\ Glossary of Terms}

Alloy: Brand name for the terminal screens used as displays for the Slave computer cards in the host computer.

Ambient: Characteristic of the air surrounding a site or station.

AQ-Air Quality: A measurement representing ambient air quality. Those measurements observed from the CHAWS analyzers include the CAL value (Channel 2), $\mathrm{NO}$ (Channel 3), $\mathrm{O}_{3}$ (Channel 7), $\mathrm{SO}_{2}$ (Channel 8) and $\mathrm{NO}_{x}$ (Channel 9). Each of these is defined below.

ASCII-American Standard Code for Information Interchange: The standard code used by most computers consisting of 8-bit characters ( 7 bits plus parity check). The characters may be alphanumeric (letters or numbers), symbols, punctuation, graphic or device-control characters. They can be sent to a device such as a scrcen, printer, etc. and are easily read by a user.

Baud rate: The number of bits per second being transmitted by computer equipment.

Binary: The common denominator of all computer code; it is the language actually used by the computer. Binary consists of nothing but open or closed circuits representing " 0 ' $s$ " and " 1 's," which are translated by the computer from base 2 to base 10 numbers, or to "yes" or "no" or "true" or "false" depending on the frame of reference. Binary is the most efficient language for computer speed and data storage but cannot easily be read by a user. *.WX and *.HR files are stored in Direct Access Binary code.

Bit: The smallest piece of computer information. One binary element, i.e., 0 or 1 .

Boot: To start a computer system.

Byte: Eight bits. Equal to one ASCII character.

CAL-Calibration mode: The mode where an air-quality analyzer is checking a ZERO or SPAN value instead of reading ambient concentration. A CAL value can represent the ZERO or SPAN value for an analyzer or the voltage for Channel 2.

Character: A single symbol appearing on a screen (usually 1 byte).

Code: A programming language (such as BASIC, FORTRAN or COBOL).

Cold boot: Starting the computer from a power-off position by turning the power on.

Concentration: Volume or mass of air pollutant per volume of air.

Criteria pollutant: Any atmospheric contaminant regulated under the Clean Air Act. These include sulfur dioxide, oxides of nitrogen, non-methane hydrocarbons, ozone, carbon monoxide, and particles (including lead).

Cursor: The character-sized spot of flashing light on the screen that shows where data entered from the keyboard will appear. 
Data: Any information obtained from or used by CHAWS.

DCP-Data collection platform: Any CHAWS monitoring station.

Degrees: Used to define temperature or wind direction. CHAWS system uses centigrade for temperature (see Appendix B).

Deposition: Rate or total amount of airborne emission material deposited on a unit area of land.

Device: Anything attached to a computer to which it directs or from which it obtains data, such as a screen, keyboard, printer, disk drive, modem, etc. Also called a peripheral.

Diffusion: The spreading out of a puff or plume of pollutants due to molecular (or sometimes including turbulent eddy) motions.

Directory: A series of files organized onto a common source. To access the files in a directory, the directory must be "active" or the directory name is required in addition to the filename from the main directory.

Dispersion: The spreading out of a puff or plume of pollutants due to mixing by turbulent eddies.

DOS-Disk Operating System: The command-data-handling program used by the Spear computer.

Emission: The release of a substance into the atmosphere.

Firmw. ،e: A set of instructions stored in read only memory (ROM).

Floppy disk: A round, flexible disk in a packet containing digitally encoded data stored magnetically. For PC-based microcomputers, the disk packet may be $51 / 4$ inches square and hold either 360$\mathrm{K}$ byte (double sided, double density) or 1200 kilobytes (high density, also called 1.2-M byte). A 3.5 -inch diskette will hold either 720 kilobytes or $1.44-\mathrm{M}$ bytes.

Floppy disk-drive: A device for reading data from or writing data to a floppy disk. When the red light is on, data are being read or written. The drive is usable when a floppy disk is inserted into the slot and the gate (an arm about an inch long) is pointed in a vertical direction (CLOSED). It cannot read data if the arm is OPEN (horizontal).

Function keys: Keys that perform pre-defined functions on the keyboard, such as help, save, file or quit $(\mathrm{F} 1, \mathrm{~F} 2, \mathrm{~F} 3, \mathrm{~F} 4 \ldots)$

Gradient: The rate of change of a parameter with distance along a vertical or horizontal axis.

Hard disk: A mass-storage device that can hold much more data than a floppy disk (usually 20 to $30-\mathrm{M}$ byte). For the PC computer, it may have its own dedicated drive-usually with a red light that comes on when it is turned on. When data are being accessed (read or written), the red light on the left front panel of a PC/AT (next to the green power-on light) flashes.

Hardware: Any piece of equipment that exists physically in a tangible sense (instruments, wiring, circuits, circuit boards, computers, etc.)

Impact: The amount of a downwind ambient concentration or deposition that is attributable to a given emission source. 
Increment: Allowable increase in ambient air-quality concentration permitted under the Prevention of Significant Deterioration Regulations in the Clean Air Act.

Interactive: Program that requests data from a keyboard.

Inversion: An atmospheric layer in which the temperature actually increases with height. (The SODAR reports any discontinuity in temperature change with height as an "INV"ersion. This could simply be a more stable layer than the layer below it.)

Julian date: The number of days since the start of the year, starting with Jan. 1. Julian day 25 is Jan. 25, day 50 is Feb. 19, etc. Starting with March, leap years have 1 day added. A table of Julian dates appears in Appendix I-C.

Kilobyte: 1024 bytes of data storage.

LLNL: Lawrence Livermore National Laboratory - a campus of the University of California.

Megabyte: $1,048,576$ bytes of data storage.

Memory: Any means of data storage accessed by a computer.

MET-Meteorology: Weather parameters such as wind direction, wind speed, sigma-theta, temperature, and relative humidity.

Mixing Height: The height to which airborne material will rise due to mixing when released at ground level.

Modem: A device that allows computers to exchange information over telephone lines.

Modified sigma-theta: The method used by the CHAWS system to determine atmospheric stability class. Incorporates sigma-theta values, vertical temperature gradient, and wind speed.

NO-Nitric oxide: A colorless gas created by chemical combination of oxygen and nitrogen in intense heat. Monitored by CHAWS Channel No. 3.

$\mathrm{NO}_{2}-$ Nitrogen dioxide: A light-brown colored gas. Toxic in high concentrations over long periods. Obtained from the CHAWS system by subtracting NO from $\mathrm{NO}_{x}$ (Channel 3 from Channel 9).

$\mathrm{NO}_{x}$-Oxides of nitrogen: The total concentration of all gaseous compounds of oxygen and nitrogen. CHAWS Channel No. 9.

$\mathrm{O}_{3}$-Ozone: A somewhai volatile gas whose molecules consist of 3 oxygen atoms (most atmospheric oxygen has 2 atoms). Responsible for eye irritation and minor crop damage. Formed in the lower atmosphere by lightning or complex chemical reactions involving $\mathrm{NO}_{2}$ and hydrocarbons in sunlight. CHAWS Channel No. 8.

Parcel: A volume of air small enough to have essentially uniform characteristics, considered in comparison to and in isolation from its surroundings (i.e., as if in a bag).

- Path: Computer term for the device, directory, and subdirectory. 
PE2-Personal Editor version II: The editing (word processing) software used for the CHAWS system. It can be used to edit any ASCII file. A manual of all the PE2 commands is available.

Peripheral: A device used by a computer but not installed inside the main box, such as a keyboard, monitor, or printer.

Plume: The trail of smoke or other air pollutant emitted by a source. Usually elongated in the direction the wind was blowing when it passed the source. Not equivalent to a trajectory.

Polling: Scanning of all data-collection platforms (DCP's) for the latest 5- or 15-minute average data. Done by BASE.EXE in the Alloy Slave 2 terminal.

Pollutant: Any substance considered harmful or detrimental to the ecosystem.

Program: A set of instructions for a computer. Usually saved on a device for easy operation. (Most programs can be started by simply typing the main program name while in DOS command mode.)

Prompt: A character (or set of characters) appearing on a screen when it is ready for data entry. In MS DOS, it is a greater than sign ("::").

Quality assurance: Any method employed for filtering out bad data and correcting a data base. It includes deleting values that are outside certain limits (done using WXCONF.CNF), correction after calibration, and a number of other techniques.

RAM-Random Access Memory: The internal memory storage space available inside a computer for data entered from a device. This memory is lost if the computer is turned off or rebooted.

Resultant wind: The total wind vector obtained by connecting the rear of the first wind vector for a given period to the front (arrow part) of the latest wind vector for that period, provided all the intervening wind vectors are lined up in between. The trajectory follows the individual wind vectors, not the resultant wind vector.

Reboot: See "Warm boot"

RH, RHum-Relative humidity: The percent saturation of the air. 100 percent means totally saturated, at which point clouds form.

ROM-Read Only Memory: The internal memory storage space in a computer that cannot be changed. This memory is not normally erased.

SigThe-sigma theta: A statistical parameter relating to the horizontal crosswind motion of the air. Used in D2PC and other dispersion models to predict the spreading of a plume. The CHAWS system obtains this value by calculating the standard deviation (sigma) of the 300 samples of crosswind component vector angle to the mean wind (theta) in a given 5-minute period.

Slave 1: The data-processing terminal used for running the long-term data handling programs. Currently operates D2PC when required.

Slave 2: The data-processing terminal used for data collection. Operates the base station software BASE.EXE in normal mode. 
Slave 3: The data-processing terminal in the host computer used for SODAR data collection.

Software: Any set or sets of instructions telling a computer how to process data. Also called program(s) and subroutine(s).

SPAN: The reference value displayed on an air-quality analyzer to monitor the high end of the operational range during calibrations.

Stability: The tendency for a parcel of air to return to its original level when displaced vertically. A layer is stable when a parcel displaced upwards will be colder and heavier than the surrounding air. Related to the thermal structure of the layer. Vertical dispersion potential is inversely related to stability.

T-Temp: Temperature. The warmth of the air, i.e., the heat contained per unit (mass $\infty$ heat capacity). Proportional to the kinetic energy of the molecular motions. 
$\mathrm{T}^{*}$-T-Star: Characteristic mean temperature gradient. Atmospheric stability expressed in terms of the vertical temperature gradient per $\log$ of height $(d T / d(\ln z)$, where $z$ is the height above the ground). Used as a measure of thermal turbulence, which varies inversely with $T^{*}$. Stability varies directly with $\mathrm{T}^{*}$ (when offset by a constant representing the dry adiabatic lapse rate).

Trajectory: The path of a particle or parcel downwind (away from the wind direction) over a given time period. (During WXGRAPH, trajectories start at the position of origin and travel downwi i). (Not to be confused with an instantaneous snapshot of a plume.)

$U^{*}-U-S t a r:$ Friction velocity. Horizontal wind speed shear per $\log$ of height $(d U / d(\log z)$, where $z$ is the height above the ground). U-Star increases as mechanical turbulence decreases.

Vector: An arrow drawn to represent the motion of the wind, the trajectory of a parcel or another directional quantity. A wind vector points in the opposite direction from the wind direction.

Warm boot-Also called a reboot: Restarting the computer while leaving the main power supply turned on. On a PC/AT or XT, this is done by hitting the $\langle\operatorname{Ctr} 1\rangle,\langle A 1 t\rangle$, and $\langle$ Del $>$ keys simultaneously. (Although the power remains on, all RAM memory is erased.)

WD-WDir-Wind direction: The direction from which the wind is blowing. (Wind arrows in the CHAWS graphic display (WXGRAPH) point in the direction toward which it is blowing-i.e., they point downwind, toward the direction in which the wind will carry airborne material, opposite the observed wind direction).

WS-WSpd-Wind speed: The speed with which the air is blowing past a point. A 5-minute average represents the average speed of all the air parcels that pass a point in the 5-minute period.

ZERO: The reference value displayed on an air-quality analyzer to monitor the low end of the operational range during calibration. 
Appendix I-B

Unit Definitions and Conversions

\begin{tabular}{|c|c|c|c|c|}
\hline $\begin{array}{l}\text { Parameter } \\
\text { (abbrev.) }\end{array}$ & Definition & $\begin{array}{c}\text { Units } \\
\text { (abbrev.) }\end{array}$ & Conversion & $\begin{array}{c}\text { Units } \\
\text { (abbrev.) }\end{array}$ \\
\hline $\begin{array}{l}\text { Concentration } \\
\text { (Conc., X) }\end{array}$ & $\begin{array}{l}\text { Volume or mass of } \\
\text { air pollutant per } \\
\text { volume of air }\end{array}$ & $\begin{array}{l}\text { Parts per billion by } \\
\text { volume (ppbv) }\end{array}$ & (none needed) & \\
\hline $\begin{array}{l}\text { Sigma Theta } \\
\text { (SigThe, } \sigma_{\theta} \text { ) }\end{array}$ & $\begin{array}{l}\text { Wind direction } \\
\text { variation }\end{array}$ & Degrees (Deg, ${ }^{\circ}$ ) & $\begin{array}{l}\text { Modified sigma- } \\
\text { theta method }\end{array}$ & $\begin{array}{l}\text { Stability classes A- } \\
\text { F }\end{array}$ \\
\hline $\begin{array}{l}\text { Temperature } \\
\text { (Temp, T) }\end{array}$ & $\begin{array}{l}\text { Heat per unit } \\
\text { (mass } \infty \text { heat } \\
\text { capacity) of air }\end{array}$ & $\begin{array}{l}\text { Degrees } \\
\text { centigrade }\left({ }^{\circ} \mathrm{C}\right)\end{array}$ & $\times 9 / 5+32=$ & $\begin{array}{l}\text { Degrees } \\
\text { Fahrenheit }\left({ }^{\circ} \mathrm{F}\right) \\
-20^{\circ} \mathrm{C}=-4^{\circ} \mathrm{F} \\
-10^{\circ} \mathrm{C}=14^{\circ} \mathrm{F} \\
0^{\circ} \mathrm{C}=32^{\circ} \mathrm{F} \\
10^{\circ} \mathrm{C}=50^{\circ} \mathrm{F} \\
20^{\circ} \mathrm{C}=68^{\circ} \mathrm{F} \\
30^{\circ} \mathrm{C}=86^{\circ} \mathrm{F} \\
40^{\circ} \mathrm{C}=104^{\circ} \mathrm{F}\end{array}$ \\
\hline $\begin{array}{l}\text { Wind Direction } \\
\text { (WDir, WD) }\end{array}$ & $\begin{array}{l}\text { Direction from } \\
\text { which wind blows }\end{array}$ & Degrees (Deg, $\left.{ }^{\circ}\right)$ & $\begin{array}{l}90 / \text { per cardinal } \\
\text { wind direction }\end{array}$ & $\begin{aligned} 0^{\circ} & =\text { North } \\
90^{\circ} & =\text { East } \\
180^{\circ} & =\text { South } \\
270^{\circ} & =\text { West }\end{aligned}$ \\
\hline $\begin{array}{l}\text { Wind Speed } \\
\text { (Wspd, WS) }\end{array}$ & $\begin{array}{l}\text { Speed of air past } \\
\text { station }\end{array}$ & $\begin{array}{l}\text { meters per sec } \\
(\mathrm{m} / \mathrm{s})\end{array}$ & $\times 2.237=$ & $\begin{array}{l}\text { miles per } \mathrm{hr} \\
(\mathrm{mi} / \mathrm{hr}, \mathrm{mph})\end{array}$ \\
\hline
\end{tabular}


Appendix I-C

Julian Calendar

Version I (non-leap year)

\begin{tabular}{|c|c|c|c|c|c|c|c|c|c|c|c|c|c|}
\hline \multirow{2}{*}{$\begin{array}{c}\text { Day } \\
\text { of } \\
\text { Month } \\
\end{array}$} & \multicolumn{12}{|c|}{ Month } & \multirow{2}{*}{$\begin{array}{c}\text { Day } \\
\text { of } \\
\text { Month } \\
\end{array}$} \\
\hline & \multicolumn{11}{|c|}{ Julian Date } & Dec & \\
\hline 1 & 1 & 32 & 60 & 91 & 121 & 152 & 182 & 213 & 244 & 274 & 305 & 335 & 1 \\
\hline 2 & 2 & 33 & 61 & 92 & 122 & 153 & 183 & 214 & 245 & 275 & 306 & 336 & 2 \\
\hline 3 & 3 & 34 & 62 & 93 & 123 & 154 & 184 & 215 & 246 & 276 & 307 & 337 & 3 \\
\hline 4 & 4 & 35 & 63 & 94 & 124 & 155 & 185 & 216 & 247 & 277 & 308 & 338 & 4 \\
\hline 5 & 5 & 36 & 64 & 95 & 125 & 156 & 186 & 217 & 248 & 278 & 309 & 339 & 5 \\
\hline 6 & 6 & 37 & 65 & 96 & 126 & 157 & 187 & 218 & 249 & 279 & 310 & 340 & 6 \\
\hline 7 & $?$ & 38 & 66 & 97 & 127 & 158 & 188 & 219 & 250 & 280 & 311 & 341 & 7 \\
\hline 8 & 8 & 39 & 67 & 98 & 128 & 159 & 189 & 220 & 251 & 281 & 312 & 342 & 8 \\
\hline 9 & 9 & 40 & 68 & 99 & 129 & 160 & 1.90 & 221 & 252 & 282 & 313 & 343 & 9 \\
\hline 10 & 10 & 41 & 69 & 100 & 130 & 161 & 191 & 222 & 253 & 283 & 314 & 344 & 10 \\
\hline 11 & 11 & 42 & 70 & 101 & 131 & 162 & 192 & 223 & 254 & 284 & 315 & 345 & 11 \\
\hline 12 & 12 & 43 & 71 & 102 & 132 & 163 & 193 & 224 & 255 & 285 & 316 & 346 & 12 \\
\hline 13 & 13 & 44 & 72 & 103 & 133 & 164 & 194 & 225 & 256 & 286 & 317 & 347 & 13 \\
\hline 14 & 14 & 45 & 73 & 104 & 134 & 165 & 195 & 226 & 257 & 287 & 318 & 348 & 14 \\
\hline 15 & 15 & 46 & 74 & 105 & 135 & 166 & 196 & 227 & 258 & 2.8 & 319 & 349 & 15 \\
\hline 16 & 16 & 47 & 75 & 106 & 136 & 167 & 197 & 228 & 259 & 289 & 320 & 350 & 16 \\
\hline 17 & 17 & 48 & 76 & 107 & 137 & 168 & 198 & 229 & 260 & 290 & 321 & 351 & 17 \\
\hline 18 & 18 & 49 & 77 & 108 & 138 & 169 & 199 & 230 & 261 & 291 & 322 & 352 & 18 \\
\hline 19 & 19 & 50 & 78 & 109 & 139 & 170 & 200 & 231 & 262 & 292 & 323 & 353 & 19 \\
\hline 20 & 20 & 51 & 79 & 110 & 140 & 171 & 201 & 232 & 263 & 293 & 324 & 354 & 20 \\
\hline 21 & 21 & 52 & 80 & 111 & 141 & 172 & 202 & 233 & 264 & 294 & 325 & 355 & 21 \\
\hline 22 & 22 & 53 & 81 & 112 & 142 & 173 & 203 & 234 & 265 & 295 & 326 & 356 & 22 \\
\hline 23 & 23 & 54 & 82 & 113 & 143 & 174 & 204 & 235 & 266 & 296 & 327 & 357 & 23 \\
\hline 24 & 24 & 55 & 83 & 114 & 144 & 175 & 205 & 236 & 267 & 297 & 328 & 358 & 24 \\
\hline 25 & 25 & 56 & 84 & 115 & 145 & 176 & 206 & 237 & 268 & 298 & 329 & 359 & 25 \\
\hline 26 & 26 & 57 & 85 & 116 & 146 & 177 & 207 & 238 & 269 & 299 & 330 & 360 & 26 \\
\hline 27 & 27 & 58 & 86 & 117 & 147 & 178 & 208 & 239 & 270 & 300 & 331 & 361 & 27 \\
\hline 28 & 28 & 59 & 87 & 118 & 148 & 179 & 209 & 240 & 271 & 301 & 332 & 362 & 28 \\
\hline 29 & 29 & & 88 & 119 & 149 & 180 & 210 & 241 & 272 & 302 & 333 & 363 & 29 \\
\hline 30 & 30 & & 89 & 120 & 150 & 181 & 211 & 242 & 273 & 303 & 334 & 364 & 30 \\
\hline 31 & 31 & & 90 & & 151 & & 212 & 243 & & 304 & & 365 & 31 \\
\hline $\begin{array}{c}\text { Day } \\
\text { of } \\
\text { Month }\end{array}$ & Jan & Feb & Mar & Apr & May & Jun & Jul & Aug & Sep & oct & Nov & Dec & $\begin{array}{c}\text { Day } \\
\text { of } \\
\text { Month }\end{array}$ \\
\hline
\end{tabular}




\section{Julian Calendar \\ Version II (leap year)}

\begin{tabular}{|c|c|c|c|c|c|c|c|c|c|c|c|c|c|}
\hline \multirow{2}{*}{$\begin{array}{c}\text { Day } \\
\text { of } \\
\text { Month } \\
\end{array}$} & \multirow[b]{2}{*}{ Jan } & \multirow[b]{2}{*}{ Feb } & \multirow[b]{2}{*}{ Mar } & \multirow[b]{2}{*}{ Apr } & \multirow[b]{2}{*}{ May } & \multicolumn{3}{|c|}{ Month } & \multirow[b]{2}{*}{ Sep } & \multirow[b]{2}{*}{ oct } & \multirow[b]{2}{*}{ Nov } & \multirow[b]{2}{*}{ Dec } & \multirow{2}{*}{$\begin{array}{c}\text { Day } \\
\text { of } \\
\text { Month } \\
\end{array}$} \\
\hline & & & & & & $\begin{array}{l}\text { Jun } \\
\text { Julia }\end{array}$ & $\begin{array}{c}\text { Jul } \\
\text { n Date } \\
\end{array}$ & Aug & & & & & \\
\hline 1 & 1 & 32 & 61 & 92 & 122 & 153 & 183 & 214 & 245 & 275 & 306 & 336 & 1 \\
\hline 2 & 2 & 33 & 62 & 93 & 123 & 154 & 184 & 215 & 246 & 276 & 307 & 337 & 2 \\
\hline 3 & 3 & 34 & 53 & 94 & 124 & 155 & 185 & 216 & 247 & 277 & 308 & 338 & 3 \\
\hline 4 & 4 & 35 & 64 & 95 & 125 & 156 & 186 & 217 & 248 & 278 & 309 & 339 & 4 \\
\hline 5 & 5 & 36 & 65 & 96 & 126 & 157 & 187 & 218 & 249 & 279 & 310 & 340 & 5 \\
\hline 6 & 6 & 37 & 66 & 97 & 127 & 158 & 188 & 219 & 250 & 280 & 311 & 341 & 6 \\
\hline 7 & 7 & 38 & 67 & 98 & 128 & 159 & 189 & 220 & 251 & 281 & 312 & 342 & 7 \\
\hline 8 & 8 & 39 & 68 & 99 & 129 & 160 & 190 & 221 & 252 & 282 & 313 & 343 & 8 \\
\hline 9 & 9 & 40 & 69 & 100 & 130 & 161 & 191 & 222 & 253 & 283 & 314 & 344 & 9 \\
\hline 10 & 10 & 41 & 70 & 101 & 131 & 162 & 192 & 223 & 254 & 284 & 315 & 345 & 10 \\
\hline 11 & 11 & 42 & 71 & 102 & 132 & 163 & 193 & 224 & 255 & 285 & 316 & 346 & 11 \\
\hline 12 & 12 & 43 & 72 & 103 & 133 & 164 & 194 & 225 & 256 & 286 & 317 & 347 & 12 \\
\hline 13 & 13 & 44 & 73 & 104 & 134 & 165 & 195 & 226 & 257 & 287 & 318 & 348 & 13 \\
\hline 14 & 14 & 45 & 74 & 105 & 135 & 166 & 196 & 227 & 258 & 288 & 319 & 349 & 14 \\
\hline 15 & 15 & 46 & 75 & 106 & 136 & 167 & 197 & 228 & 259 & 289 & 320 & 350 & 15 \\
\hline 16 & 16 & 47 & 76 & 107 & 137 & 168 & 198 & 229 & 260 & 290 & 321 & 351 & 16 \\
\hline 17 & 17 & 48 & 77 & 108 & 138 & 169 & 199 & 230 & 261 & 291 & 322 & 352 & 17 \\
\hline 18 & 18 & 49 & 78 & 109 & 139 & 170 & 200 & 231 & 262 & 292 & 323 & 353 & 18 \\
\hline 19 & 19 & 50 & 79 & 110 & 140 & 171 & 201 & 232 & 263 & 293 & 324 & 354 & 19 \\
\hline 20 & 20 & 51 & 80 & 111 & 141 & 172 & 202 & 233 & 264 & 294 & 325 & 355 & 20 \\
\hline 21 & 21 & 52 & 81 & 112 & 142 & 173 & 203 & 234 & 265 & 295 & 326 & 356 & 21 \\
\hline 22 & 22 & 53 & 82 & 113 & 143 & 174 & 204 & 235 & 266 & 296 & 327 & 357 & 22 \\
\hline 23 & 23 & 54 & 83 & 114 & 144 & 175 & 205 & 236 & 267 & 297 & 328 & 358 & 23 \\
\hline 24 & 24 & 55 & 84 & 115 & 145 & 176 & 206 & 237 & 268 & 298 & 329 & 359 & 24 \\
\hline 25 & 25 & 56 & 85 & 116 & 146 & 177 & 207 & 238 & 269 & 299 & 330 & 360 & 25 \\
\hline 26 & 26 & 57 & 86 & 117 & 147 & 178 & 208 & 239 & 270 & 300 & 331 & 361 & 26 \\
\hline 27 & 27 & 58 & 87 & 118 & 148 & 179 & 209 & 240 & 271 & 301 & 332 & 362 & 27 \\
\hline 28 & 28 & 59 & 88 & 119 & 149 & 180 & 210 & 241 & 272 & 302 & 333 & 363 & 28 \\
\hline 29 & 29 & 60 & 89 & 120 & 150 & 181 & 211 & 242 & 273 & 303 & 334 & 364 & 29 \\
\hline 30 & 30 & & 90 & 121 & 151 & 182 & 212 & 243 & 274 & 304 & 335 & 365 & 30 \\
\hline 31 & 31 & & & & 152 & & 213 & 244 & & 305 & & 366 & 31 \\
\hline $\begin{array}{c}\text { Day } \\
\text { of } \\
\text { Month }\end{array}$ & Jan & Feb & Mar & Apr & May & Jun & Jul & Aug & sep & oct & Nov & Dec & $\begin{array}{c}\text { Day } \\
\text { of } \\
\text { Month }\end{array}$ \\
\hline
\end{tabular}




\title{
Chapter II \\ REWIRED HANDAR INSTRUMENTS AND TOWERS
}

\author{
Stan Martins \\ Kaiser Engineers, Livermore \\ Cleo Fry \\ Health and Ecological Assessment Division
}

\subsection{INTRODUCTION}

This chapter of the CHAWS manual is devoted to the electronic configuration of HANDAR instruments that were modified by Lawrence Livermore National Laboratory (LLNL) personnel. Because un rodified HANDAR instruments are described in detail in the HANDAR manuals, we do not provide detailed descriptions of these instruments in this chapter. Please consult the HANDAR manuals for descriptions of the hardware used for meteorological data collection. Copies of the appropriate manuals have been provided to each CHAWS site.

The HANDAR system consists of a variety of instruments for measuring the following meteorological parameters: temperature, wind direction, wind speed, and relative humidity. The sensors that detect these parameters are described in detail in their respective HANDAR manuals. However, at each CHAWS site, a few of the instruments have been rewired by LLNL personnel to configure the meteorological towers for their unique instrumentation. Wiring diagrams for these unique configurations are provided in Appendix II-A so that maintenance and troubleshooting can be performed. Some of the CHAWS systems also contain air-quality sensors; these are described in detail in their respective manuals.

The rewired instruments for Lexington-Blue Grass Army Depot are as follows:

- 60-m single-level towers.

- 30-m single-level towers.

- 26-pin connector wiring.

These systems have been rewired and are unique to the site. The wiring diagrams for these systems are presented in Figures II-1 through II-3, Appendix II-A. To avoid confusion, we use the same terminology (connection numbers and letters) as is used the HANDAR manuals. A glossary of abbreviations used in the diagrams is also found in Appendix II-B. 


\subsection{SITE CONFIGURATION}

To adequately characterize atmospheric dispersion throughout the Lexington site, it was necessary to construct a number of meteorological towers around the site. The purpose of this pattern is to depict local variations in wind and stability due to local effects.

The meteorological sensors are briefly described below. More detailed information and calibration procedures are given in the manuals for the respective instruments.

\subsection{Tower and Sensor Configuration}

Three of the four towers at Lexington-Blue Grass Army Depot are 30-m tall, and one tower is $60-\mathrm{m}$ tall. All towers have sensors at the top for one level each of wind direction and standard deviation of wind direction (sigma-theta), wind speed, and temperature.

\subsection{Meteorological Sensor Description}

Each tower configuration includes a 3-cup anemometer, a horizontal-winddirection vane, and a thermister (HANDAR Models 430A, 431 A, and 432A respectively). The HANDAR $540 \mathrm{~A}$ firmware (version 6.9) calculates sigma-theta from wind direction fluctuations.

All instrumentation sensor models have been approved by Environmental Protection Agency (EPA) and the U.S. Nuclear Regulatory Commission (NRC) for prevention of significant deterioration (PSD) monitoring and other environmental licensing purposes. Each temperature and humidity sensor is protected by an inverted triple conical naturally aspirated radiation shield, Model $442 \mathrm{~A}$.

\subsection{DATA ACQUISITION SYSTEM}

Each of the four monitoring stations contains a HANDAR 540A data-collection platform (DCP), which stores the data collected from the tower. Summaries of these data are transmitted via UHF radio data link to the base station at regular intervals.

Wind-direction data are sampled every 1 second to obtain an adequate number of values (300) for sigma-theta determination for each 5 -min sample period. Wind 
speed is sampled every 3-sec., and temperature are sampled every 20 seconds. The HANDAR $540 \mathrm{~A}$ firmware averages wind values and calculates sigma-theta every 5min and averages temperature and Battery voltage values every $15-\mathrm{min}$.

The data channels, station types, and station configurations are summarized by channel in Tables $11-1$ through $11-2$ below. There are two types of stations at LexingtonBlue Grass; they differ by tower height. This difference is reflected in the configuration of the channels. Wiring diagrams for the stations and for the 26-pin connector are presented in Figures II-1 through II-4.

Table II-1: HANDAR 540A DCP channel configuration list for Type Lexington-Blue Grass.

\begin{tabular}{llll}
\hline & $\begin{array}{l}\text { Channel } \\
\text { No. }\end{array}$ & Description & $\begin{array}{l}\text { Station } \\
\text { Number }\end{array}$ \\
\hline Type 1L & 01 & Battery voltage & $2,3,4$ \\
& 56 & Temp., level $1\left({ }^{\circ} \mathrm{C}\right)(30 \mathrm{~m})$ & \\
& 51 & Wind speed, level 1 (m/s) & \\
& 53 & Wind direction, level 1 (deg.) & \\
& 54 & Standard dev. of wind direction, level 1 & \\
Type 1P & 01 & Battery voltage & \\
& 66 & Temp., level 1 $\left({ }^{\circ} \mathrm{C}\right)(60 \mathrm{~m})$ & \\
& 61 & Wind speed, level 1 (m/s) & \\
63 & Wind direction, level 1 (deg.) & \\
& 64 & Standard dev. of wind direction, level 1 & \\
\hline
\end{tabular}




\section{Appendix II-A. Wiring Diagrams}

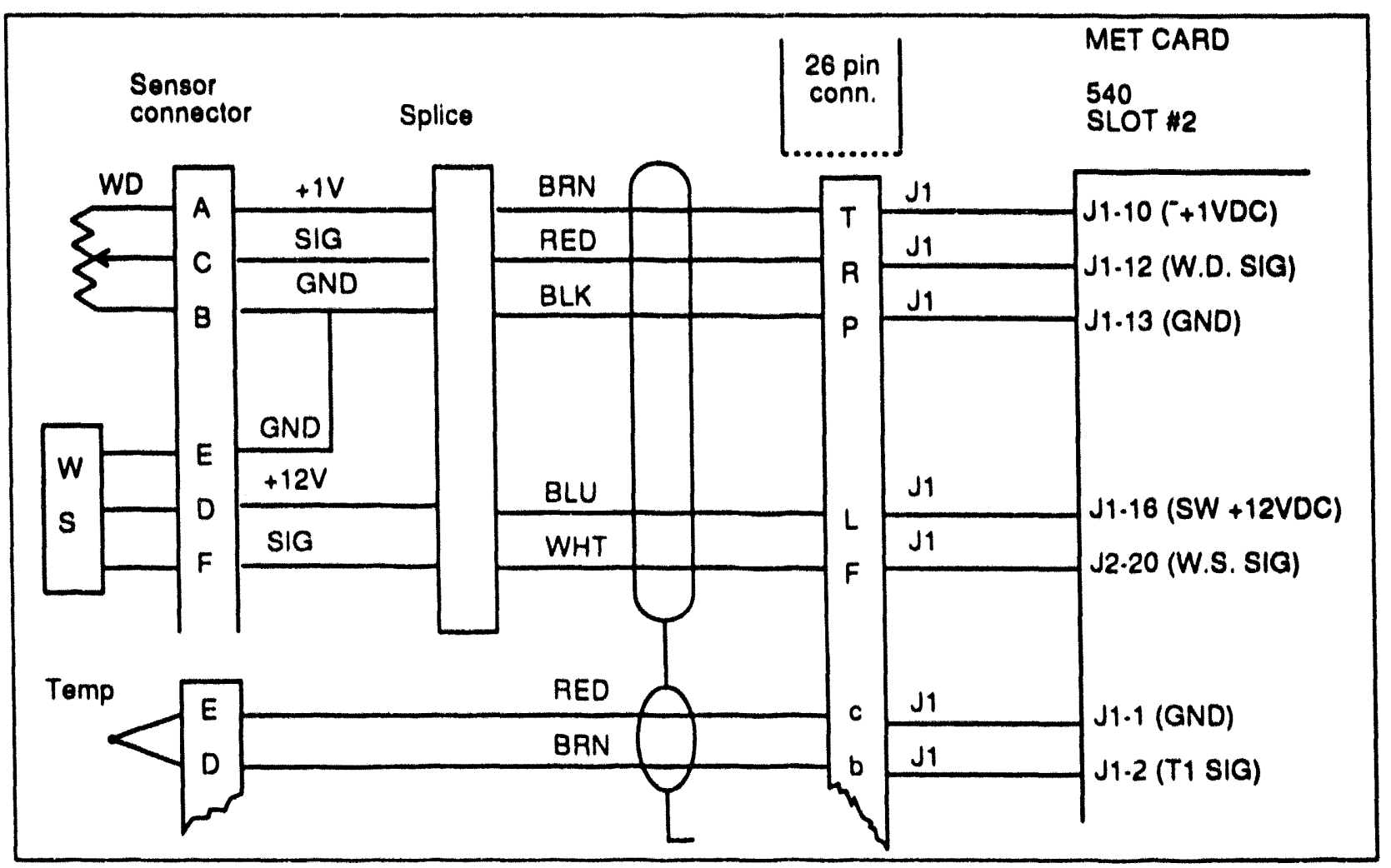

Figure II-1. Wiring diagram of $60-\mathrm{m}$ towers. 


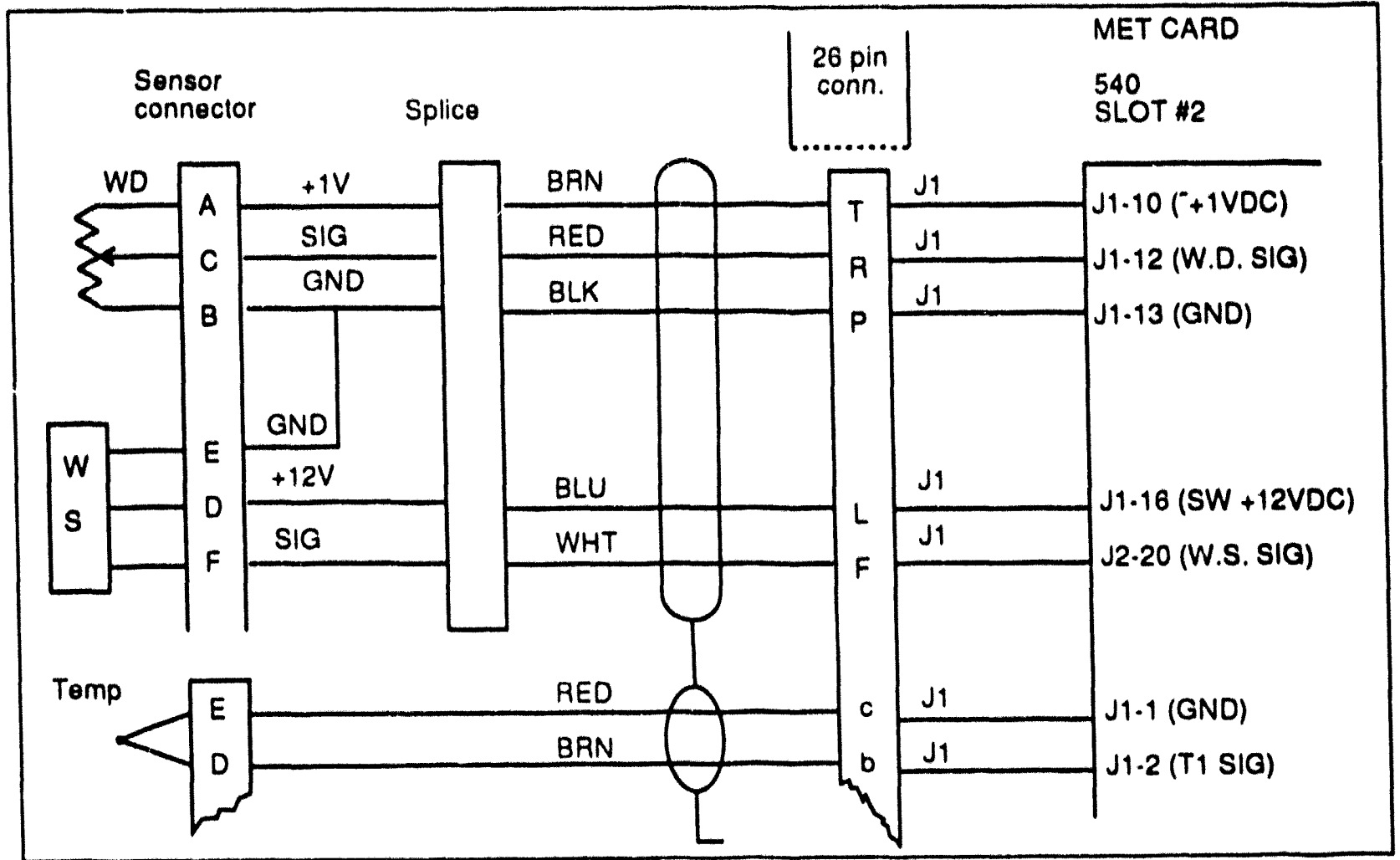

Figure II-2. Wiring diagram of $30-\mathrm{m}$ tower. 


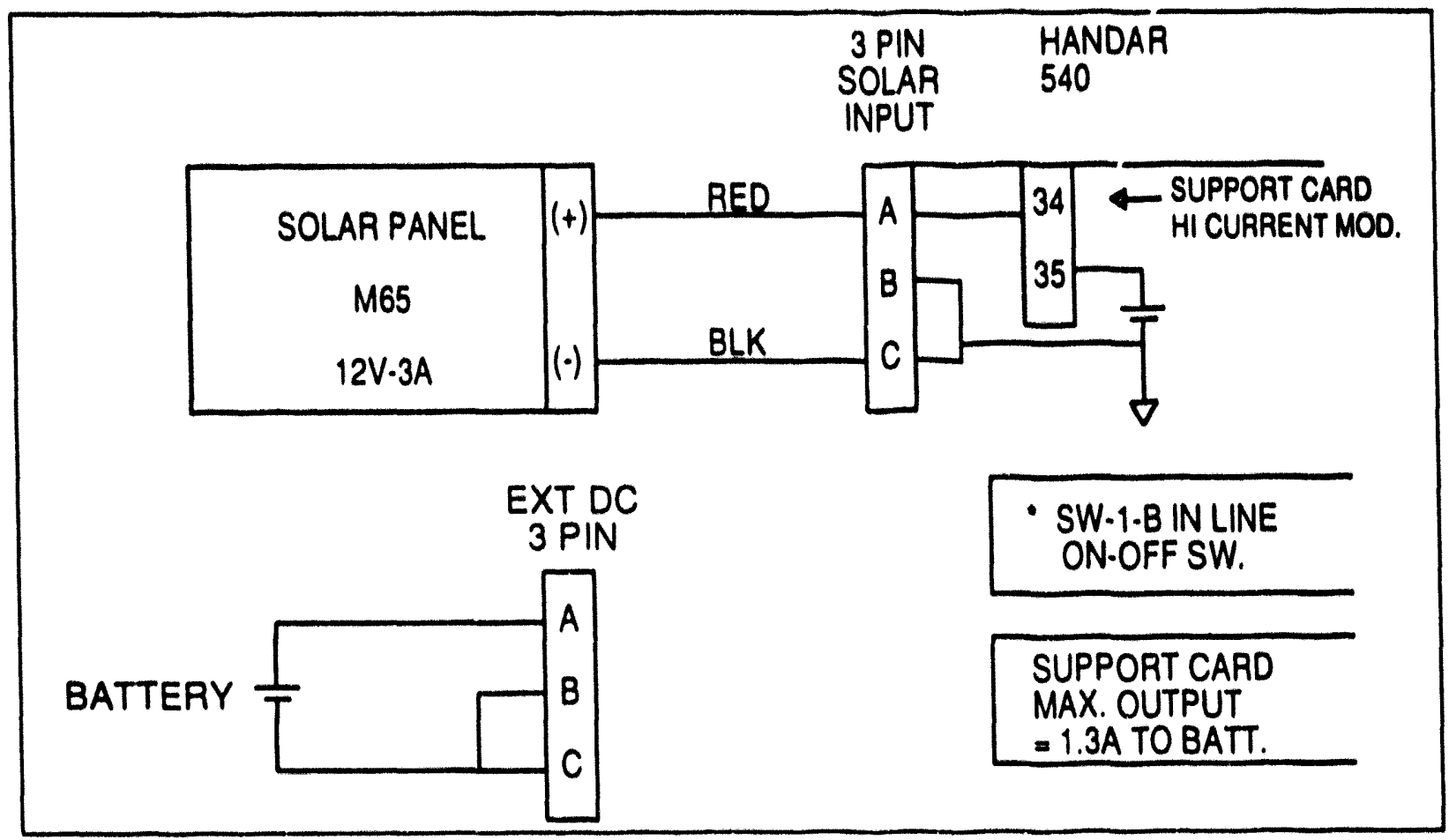

Figure II-3. Wiring diagram of solar panels. 
TERMINAL STRIPS (NOTE ALL WIRED THE SAME)

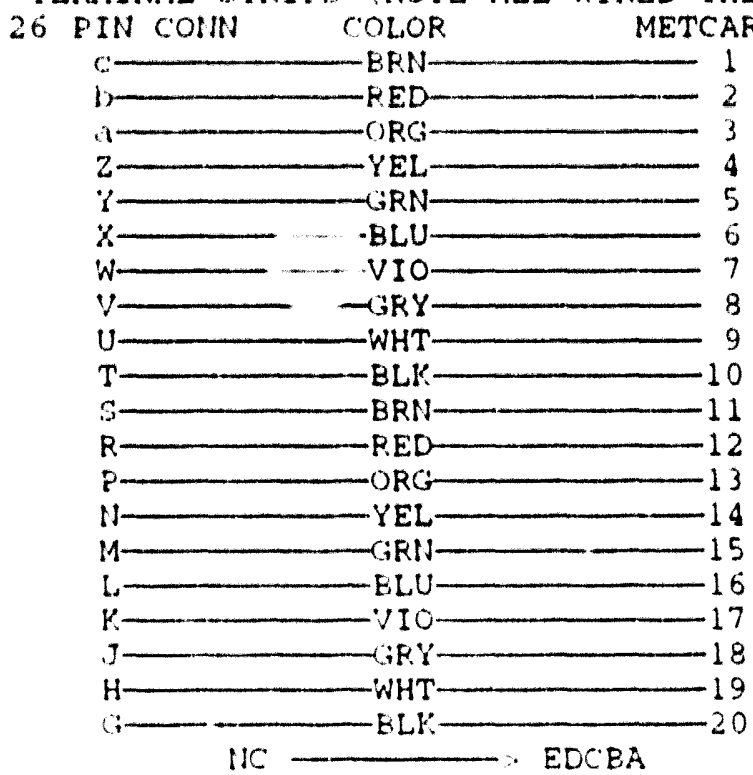

WS SIG J1-F TO J2-G

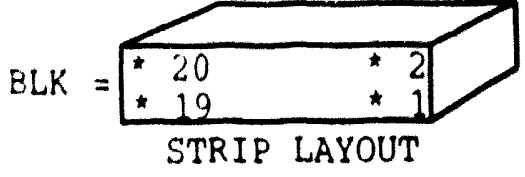

Figure II-4. Wiring diagram of 26-pin connector. 


\title{
Appendix II-B. Glossary of terms
}

\author{
Batt - Battery \\ BP - Barometric pressure \\ CALSIG - Calibration signal \\ $\mathrm{CH}$ - Channel \\ DCP - Data collection platform \\ GND - Ground \\ MET - Meteorology \\ NC - No correction \\ NO - Nitric oxide \\ $\mathrm{NO}_{x}$ - Oxides of nitrogen \\ $\mathrm{O}_{3}$ - Ozone \\ RH - Relative humidity \\ Sig - Signal \\ $\mathrm{SO}_{2}$ - Sulfur dioxide \\ ST - Station \\ SW - Switch \\ T1 - Temperature 1 \\ T2 - Temperature 2 \\ T3 - Temperature 3 \\ TB1 - Terminal box 1 \\ TB3 - Terminal box 3 \\ TB5 - Terminal box 5 \\ TB7 - Terminal box 7 \\ Temp - Temperature \\ TS - Terminal strip \\ WD - Wind direction \\ WDSIG - Wind direction signal \\ WDSW - Wind direction, wind speed \\ WS - Wind speed \\ WT - Weight
}




\title{
Chapter III SOUND DETECTION AND RANGING (SODAR) SYSTEMS
}

\author{
Ken Lamson \\ Stan Martins \\ Michael Novo \\ Environmental Sciences Division
}

(This chapter applies only to the Pine Bluff and Edgewood CHAWS sites.) 


\title{
Chapter IV \\ HANDAR INTERROGATED RADIO SYSTEM
}

\author{
Stan Martins \\ Kaiser Engineers, Livermore
}

\subsection{SYSTEM DESCRIPTION}

The HANDAR interrogated radio system is used to acquire meteorological data from remote weather stations and to log it into the CHAWS computer system. This system is composed of two parts: the weather stations and the radio base station.

Each weather station has a tower with at least one level of instrumentation and a HANDAR 540A Data-Collection Platform (DCP). Some stations may also have ancillary equipment such as air-quality-monitoring sensors. For a detailed description of these products or other sensors, consult the manual for each device.

\subsection{HANDAR 540A DATA-COLLECTION PLATFORM (DCP)}

One HANDAR 540A Data-Collection Platform (DCP) unit is connected to each station's sensors through a wiring harness. Analog signals are converted to digital information and stored in the 540A's memory where the data will reside for up to one week, depending upon the type of program used (see Table IV-1 for expected holding times). At regular intervals, the radio base station will poll each weather station via a UHF radio link. At this time, the 540A will send data from the most recent 15 -min period. Each $540 \mathrm{~A}$ is given a unique identification number and is programmed with a set of instructions specific for the type and number of sensors at its location.

Table IV-1. Data-holding capacity of the 540A DCP at the Lexington-Blue Grass site.

\begin{tabular}{cc}
\hline Program Type & Amount of data stored (hours) \\
\hline $1 \mathrm{~L}$ & 150 hours \\
$1 \mathrm{P}$ & 150 hours \\
\hline
\end{tabular}




\subsection{Hardware Architecture}

The 540A consists of a variety of electronic printed circuit cards in a weatherproof, lockable stainless steel box. A rechargeable gel-cell battery is used for power. An external charging circuit is also provided; this charging circuit is either a solar panel or an AC power supply. The circuit cards of the $540 \mathrm{~A}$, listed from right to left, when the unit is mounted on its side with the hinge down, or flat with the hinge toward you, are as follows:

- Support Card: This card contains most power-conversion functions.

- CPU Card: This card is in a shielded slot.

- Radio Card: This is a double card and occupies 2 slots.

- MET Cards: There are 1 to 3 MET cards (or meteorological cards) installed in each $540 \mathrm{~A}$. They are connected to the weather sensors and perform the analog to digital conversion. The MET cards are numbered from left to right so MET card \#1 will be closest to the battery on the left side.

The power switch for the unit is inside the unit, near the hinge, slightly left of center. For more information, consult the 540A-1 Multiple Access Data Acquisition System Operating and Service Manual. ${ }^{1}$

\subsection{Programming the $540 \mathrm{~A}$}

Before the 540A may be used, it must be programmed and given an identity number. This must be done every time it is turned on, loses power, or fails when the operator attempts to communicate with it.

The operator may communicate with the $540 \mathrm{~A}$ through the radio base station or through the $540 \mathrm{~A}^{\prime} \mathrm{s}$ local programming port and remote terminal, such as a Radio Shack Tandy 102 hand-held computer.

A quick programming reference is presented as Appendix VI-A. It will probably be most useful after working through this manual to learn the system. After that, the quick programming reference may be all that is necessary.

\subsubsection{Using the Radio Base Station}

The radio base station program is usually run on Slave \#2 of the CHAWS computer (See Chapter V). Most of the time, this program is in the Poll/Monitor mode. Press the $<$ F10 $>$ key on Slave \#2's Alloy terminal until the main menu 
Table IV-2. Station type placement.

\begin{tabular}{ccrr}
\hline Type & Station numbers & 540 ID numbers & \multicolumn{2}{c}{ 540A program name } \\
\hline $1 P$ & 1 & 00000001 & TYPE1P. 540 \\
$1 \mathrm{~L}$ & $2,3,4$ & $00000002,00000003,00000004$ & TYPE1L.540 \\
\hline
\end{tabular}

appears. Select $\langle F 3\rangle$, INTERACTIVE COMMUNICATIONS, from the Main Menu. Enter the station ID of the 540A DCP that is desired and press <Enter>. The station ID's are listed in Table IV-2.

2.2.1.1 540A Log-On. After entering the station ID, a message at the top of the screen should read "TRANSMITTING", then "RECEIVING", or "AWAITING RESPONSE". When contact has been made, you will receive a log-on message that says "P HANDAR 540A DCP - REV X.X" where " $X . X$ " is the firmware version number. The first letter may be an " $R$ " or a "P".

Once the station is logged on, any command in the HANDAR 540A Operating \& Service Manual may be given to the 540A.

2.2.1.2 Changing the 540A's ID. If more than one of the 540A DCP's have lost power or have never been programmed, use the following procedures:

- Turn off all but one of the 540A Data-Collection Platforms that require a new ID.

- In response to "Enter the platform ID:", type "0" (zero), <Enter> (for the temporary station ID). When the 540A is logged on, type "I", followed by the correct eight-digit (e.g., 00000001 ) station ID of the 540A to be programmed, then press $\langle$ Enter $\rangle$ (see station ID list). Now hit $\langle$ F5 $\rangle$ (log off) until "no DCP logged on" message appears at top of the screen, then hit $\angle F 1>(\log$ on) and type the correct (new) station ID (leading 0's may be omitted this time) followed by <Enter $>$.

2.2.1.3. Programming a $540 \mathrm{~A}$ from the Base Station. If a $540 \mathrm{~A}$ is to be reprogrammed, be sure that it is in the program mode. If not, follow the procedures in 2.2.4 to terminate a $540 \mathrm{~A}$ program. 
$540 \mathrm{~A}$ programs that may be used for programming are "TYPE1L 540 " or "TYPE1P. 540". These programs may be found in the ISLAVE directory of the CHAWS computer. A list of the programs to be used with each station is presented in Table IV-2.

Hit $<$ F2 $>$ (Load Prog) key. When the screen says "LOAD PS PROG -> DCP: PRESS ENTER", hit $<$ Enter $>$ and type the name of the 540A program. Press the $<$ Enter $>$ key and this program will be loaded into the $540 \mathrm{~A}$. If the program was loaded successfully, the word "DONE" will appear on the screen. If not, try loading the program again.

Next, type the letter " $\mathrm{J}$ " to set the time. Note: all 540A letter commands must be capitals and most single letter commands should not be followed by <Enter>. Type in the time as it will be displayed in the upper right-hand corner of the screen one minute into the future and press <Enter $>$ to set the time. Hit the " $\mathrm{V}$ " key and check the year. If the year is incorrect, type in the correct date, followed by <Enter>. If the year is correct, go on to the next step (do not hit $<$ Enter $>$. Now hit " $\mathrm{V}$ " again and do the same for the Julian date. Again, do not hit <Enter $>$ unless changing the date.

When programming has been completed for this DCP, put the system in run mode by following the instructions in 2.2.3.

\subsubsection{Saving a 540A Program. From the Interactive Menu of the Base Station} Program, log onto the 540A that contains the program to be saved. Hit the $\angle F 3>$ key on the base station slave computer. Observe the "TRANSMITTING", "RECEIVING" message at the top of the screen. This will be followed by the message,

$$
\text { "SAVE DCP PROG->PS: PRESS ENTER". }
$$

Press <Enter>. Type in the name of the file in which the 540A program is to be saved and press <Enter>. Now observe again the "TRANSMITTING", "RECEIVING" messages at the top of the screen again. When finished, a "DONE" prompt will appear.

Now put the $540 \mathrm{~A}$ back into the run or data-acquisition mode as described in section 2.2.3. 


\subsubsection{Using a Portable Computer}

A Tandy model 100 or Tandy model 102 portable computer has been provided for programming the HANDAR 540A. Consult the owners manual for the proper use of this computer. If the unit is not already in the terminal mode, perform the following steps:

1. Select "TELCOM" from the main menu by moving the cursor to that item with the space bar and press <Enter $>$.

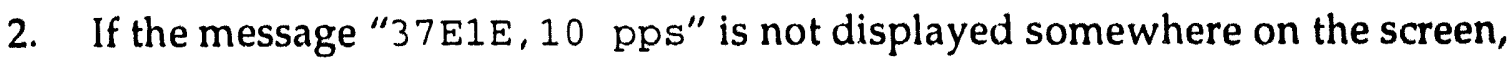
press $\langle$ F $3>$ (or type "STAT" <Enter $>$ ) and type "37E1E" <Enter $>$.

3. Press $\angle F 4>$ (TERM).

4. Connect the special cable between the 540A PROG/IO port and the 25-pin " $D$ " connector on the back of the computer.

2.2.2.1. 540A Log-On. Within 30 seconds after the connection has been made between the $540 \mathrm{~A}$ and the Tandy computer, a log-on message will be received that says:

"P HANDAR 540A DCP - REV X. $X "$

where " $\mathrm{X} . \mathrm{X}$ " is the firmware version number. The first letter may be either an "R" or a " $P$ ".

Once the station is logged on, any command in the HANDAR 540A Operating \& Service Manual may be given to the 540A.

2.2.2.2. Changing the $540 \mathrm{~A}^{\prime} \mathrm{s} I D$. The ID number of a $540 \mathrm{~A}$ may be changed at any time as long as the unit is in the program mode. This is usually done after the unit has been turned on because the ID will always come up as zero after the unit is turned on.

Be sure the $540 \mathrm{~A}$ is in the program mode. If not, type "?", "2", $<$ Enter $>$ to terminate the program.

Type the capital letter " $I$ ". The $540 \mathrm{~A}$ will respond with an 8 - digit number. If the ID is to be changed, enter the new 8-digit number. For example, if this is station 1, type "00000001" <Enter>.

2.2.2.3. Programming a 540A with the Tandy Hand-Held Computer. To program the $540 \mathrm{~A}$, be sure that it is in the program mode ( $\mathrm{a}$ " $\mathrm{P}$ " will be displayed on the left side of the screen). If not, terminate the program by following the procedure in 2.2.4. 
Now type " $\&$ ". The 540A will respond with

"LOAD PS PROG->DCP: PRESS ENTER".

Press the $\angle F 3>$ key on the Tandy and enter the 540A program name. Enter " 120 " when the Tandy asks for width and press <Enter $>$ twice. When finished, the $540 \mathrm{~A}$ will respond with "DONE". Now enter a " $\mathrm{J}$ " and enter a time 1 minute ahead of local standard time followed by <Enter>. Now hit the " $\mathrm{V}$ " key and enter two digits for the year. Hit " $\mathrm{V}$ " again and enter the Julian date followed by <Enter>.

After completing the programming, put the system in run mode or dataacquisition mode as described in 2.2.3.

2.2.2.4. Saving a $540 \mathrm{~A}$ Program. To save a program from a $540 \mathrm{~A}$, put it in the program mode as listed below. Enter a " 8 ". The $540 \mathrm{~A}$ will respond with:

"SAVE PS PROG->DCP: PRESS ENTER".

Press the $\langle F 2>$ key. Then, type the name of the program you wish to save, and press <Enter>. Press <Enter> again. When the program has been saved, the 540A will respond with "DONE". Hit the $\angle F 2>$ key again. Follow the editing instructions in the Tandy manual to remove the word "DONE" from the bottom of the program file and any extraneous text from the beginning.

2.2.3 540A data acquisition. After the $540 \mathrm{~A}$ has been programmed the data acquisition program must be started. The system must be in run mode.

Enter the following key sequence: " $\mathrm{H}$ ", " $\mathrm{N}$ ", "O", " $" r$. " The last line on the screen should say:

$$
\text { "P1 START OF MEAS. } \quad x x: x x: x x^{\prime \prime}
$$

where " $x x: x x: x x^{\prime}$ is a time in 24 -hour format. If you overshoot, press " $U$ " to step back up through the menu.

Enter a time, at least two minutes in the future, that falls on an even 15-min time period, but do not include seconds. Hit <Enter $>$. If the message

"CHANGE ALL CHAN? ( $1=\mathrm{Y}, 2=\mathrm{N} \cap)$ "

does not appear, go back to the beginning of this sequence. If the message does appear, type "1" <Enter>. Lists of channels are found in Tables IV-3 and IV-4. 
Table IV-3: HANDAR 540A DCP channel configuration list for Lexington-Blue Grass site.

\begin{tabular}{cl}
\hline $\begin{array}{c}\text { Channel } \\
\text { No. }\end{array}$ & Description \\
\hline 01 & Battery voltage \\
56 & Temp., level $5\left({ }^{\circ} \mathrm{C}\right)$ \\
66 & Temp., level $6\left({ }^{\circ} \mathrm{C}\right)$ \\
51 & Wind speed, level $5(\mathrm{~m} / \mathrm{s})$ \\
61 & Wind speed, level $6(\mathrm{~m} / \mathrm{s})$ \\
53 & Wind direction, level $5($ deg.) \\
63 & Wind direction, level 6 (deg.) \\
54 & Standard dev. of wind direction, level 5 \\
64 & Standard dev. of wind direction, level 6 \\
\hline
\end{tabular}

Now type the letter " $\mathrm{Y}$ " again to start the program. Next, type the letter " $\mathrm{S}$ ". The message

$$
\text { "R01 NEXT SCAN } x x \cdot x x \cdot x x^{\prime \prime}
$$

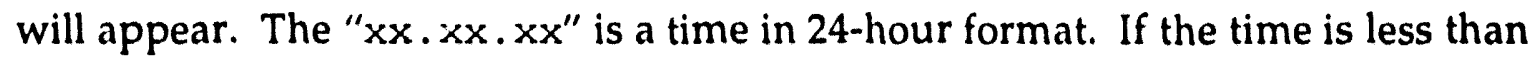
15 minutes, type "MVS". Another "NEXT SCAN" time will appear. If either time is greater 15 minutes (e.g., 23:14:00) then follow the procedure in section 2.2.4 
Table IV-4. Configuration of channels by station type.

\section{Channel}

No.

Description

TYPE 1L

$01 \quad$ Battery voltage

56 Temp., level $5\left({ }^{\circ} \mathrm{C}\right)$

51 Wind speed, level $5(\mathrm{~m} / \mathrm{s})$

$53 \quad$ Wind direction, level 5 (deg.)

54 Standard dev. of wind direction, level 5

TYPE 1P

$01 \quad$ Battery voltage

66 Temp., level $6\left({ }^{\circ} \mathrm{C}\right)$

61 Wind speed, level $6(\mathrm{~m} / \mathrm{s})$

63 Wind direction, level 6 (deg.)

64 Standard dev. of wind direction, level 6

(terminate $540 \mathrm{~A}$ program) and go back to the beginning of this sequence. If the time is less than 15 minutes, then proceed.

If more $540 \mathrm{~A}$ 's are to be programmed, repeat the log-on and 540A programming procedures and resume at step 2.2.3.

If the radio base station is being used to perform these procedures, press $\langle F 10\rangle$ to return to the main menu. Be sure to return to the polling menu when finished.

\subsubsection{A DCP Program Termination}

Do not use the following procedure if the $540 \mathrm{~A}$ is already in the program mode. To do so may "hang up" the $540 \mathrm{~A}$ to the point that it must be shut off and 
reprogrammed. If messages from the DCP are preceded by the letter " $P$ ", then it is already in the program mode.

If this procedure is being conducted from the radio base station, make sure the program is in interactive mode. From the polling screen, hit $\langle F 10\rangle\langle F 3\rangle$. Log onto the platform desired by responding to the prompt "Enter the plat form ID:" followed by <Enter>.

If a $540 \mathrm{~A}$ program is stopped, all data stored in it will be lost. To stop the program, type "?". The 540A will respond with

$$
\text { "R } \operatorname{ENTER}(1)=\text { SERVICE }(2)=A L L " .
$$

Press " 2 ", $<$ Enter $>$. The $540 \mathrm{~A}$ is nuw in the program mode and will not collect any data until placed in the run mode.

\subsection{RADIO BASE STATION}

The base-station hardware consists of an omni-directional antenna, a HANDAR 542 radio transceiver, and an IBM PC/XT compatible computer (Slave 2). The software used is a modified version of HANDAR's base station program called BASE.EXE. This program should always be called from Slave 2's AUTOEXC file (C: $\backslash$ NX\$ $\backslash A U T O$. U02 on the SPEAR computer or AUTOEXEC. U02 on the IBM) by re-booting slave 2 . Newer versions of BASE.EXE obtained directly from Handar will not work with CHAWS.

\subsection{Software Start-Up}

At Lexington-Blue Grass, both the EOC (Emergency Operations Center) and the AOC (Alternate Operations Center) may receive and process weather data when their CHAWS computers are connected to a radio base station. Only one of these facilities may use its radio base siation to acquire these data at any given time. If these data are required by other sites, a secondary method of dissemination must be employed.

Normally, the base-station software will start in the Poll/Monitor mode when the computer system is turned on. If the program has been terminated, it may be restarted by rebooting Slave 2 or typing "BASE -A900<Enter>". It will begin to poll at the next quarter hour. If desired, you may type "BASE - A1" $<$ Enter $>$ to have it begin to poll within 10 seconds. This should not be done as a general rule and after one poll in this mode, Slave 2 should be rebooted. 


\subsection{Termination of BASE. EXE Execution}

Do not terminate BASE. EXE unless there is a specific need to do so. Routine data from the weather stations will be lost if the program is not running at the quarter hour.

From most menus, hit $<F 10>$ until the message

$$
\text { "Terminate base station program? (Yes/No):" }
$$

appears. Enter " $Y$ ". From other menus you may have to respond to a specific prompt before you can hit $<$ F10 $>$.

Remember to restart the program as soon as possible after completing the special procedures that required BASE. EXE to be stopped.

\subsection{Interactive Communications}

As mentioned above, this mode can be used to initialize and program a $540 \mathrm{~A}$ DCP. See Appendix VI-A for more information. In addition, certain other procedures may be performed.

If the base-station program is in the Poll/Monitor mode, select $\angle F 10\rangle$ to return to the main menu. Select $\langle F 3\rangle$, INTERACTIVE COMMUNICATIONS, from the Main Menu. Enter the station ID of the new station and hit <Enter>.

\subsubsection{Polling Data on Demand}

From the interactive mode screen, after the platform is logged on, hit $\langle F 4\rangle$ and the polling menu should appear. Answer the questions in this menu regarding start time, stop time, date, logging and printing. Now hit $<F 9>$ to poll and wait until polling is completed. If you wish to poll another station, press $\langle\mathrm{F} 5\rangle$ (log off), then $<F 1>(\log$ on) and enter the new station number. Repeat this section to poll the new station.

\subsubsection{Time Check}

Wait until a routine poll has ended. Reboot the host PC/AT computer. After the base-station program has started again on Slave 2, enter the interactive mode as described above in section $3.3(\langle F 10\rangle\langle F 3\rangle)$ and $\log$ on to the $540 \mathrm{~A}$ in question. 
The 540A DCP's time must be about one minute ahead of the radio-base-station's clock to allow for any time slippage. Hit the " $\mathrm{J}$ " key and look at the clock in the upper right-hand corner of the computer screen. If the time reported by the $540 \mathrm{~A}$ is behind that of the computer, the time must be rhanged.

To change the 540A time, the orogram must be stopped. This will result in the loss of at least 15 minutes of data. Terininate the 540A program by following the procedures in 2.2.4. Now hit " $\mathrm{J}$ ". When the time appears, type in a time about one minute in the future of the clock in the upper right-hand corner of the screen. Now restart the program as described above in 2.2.3. 


\subsection{External Mode}

This mode allows the user to perform simple DOS commands between polls. From the Main Menu, select <F4> (EXTERNAL SOFTWARE EXECUTION). This suspends all radio-base-station functions except for the polling timer. Do not run other software programs in this mode because it may interfere with subsequent polling. Simple DOS commands such as DIR, COPY, and DEL may now be executed as long as they do not take more than about 25 seconds. To return to the polling mode, terminate the execution of external functions and type the word "EXIT", <Enter>. The main menu should appear. Now return to the Poll/Monitor mode, described below.

\subsection{The Poll/Monitor Mode}

If the MAIN MENU is not on the screen, hit $\langle F 10\rangle$ until it appears. Now select $<F 2>$ (Po11/Monitor). Any data that should have been logged prior to this point will now be taken. The radio-base-station software should be left in this mode whenever possible so that the host computer will always have the most current data.

\subsection{TROUBLESHOOTING GUIDE}

The following is a list of potential problems and probable solutions.

\subsection{None of the 540A's Respond to the Radio Base Station}

1. Check the 542 transceiver set up. Ensure that the HANDAR 542 transceiver is turned on and that it is connected to both the computer and to the antenna. Also make certain that the base-station antenna is still in its proper orientation. If these conditions are correct and none of the 540A's respond, try the following steps.

2. Test the 54 '? base station. Replace the radio-base-station transceiver with a spare 542. If the system works, have the old transceiver repaired.

3. Check the computer's communication configuration. Ensure that the communication port specified in the base-station configuration table is the 
same as the one that the transceiver is connected to. If not, make the necessary changes. The correct port is usually $\subset \cap \mathrm{M} 2$.

3. Test the base station's Slave card. Connect the transceiver to a different slave card or to the host computer. Run the radio-base-station software on that computer and try to communicate with the 540A's again. Please note that if the host's COM1 serial port is used for this test, it will be necessary to change the communications parameters in the base-station-software configuration table to COM1. At the conclusion of the test make sure to change them back to COM2. If communications are established with the $540 \mathrm{~A}$ 's, replace the slave card and have the old one repaired.

4. Test all base-station cables. Replace the cables between the computer and the 542 transceiver. If this works, discard the old cable.

5. Check the base-station antenna. If none of the stations will respond to the radio base station after the above solutions are tried, replace the antenna and/or antenna cable at the base station.

6. Check all of the 540A DCPs. In the unlikely event that all of the 540A's have some problem, the base-station communication problems may be cured by fixing each of the 540's. Go to each station and follow the diagnostic procedures for individual 540 's listed in 4.2 below.

\subsection{Individual 540A's Do Not Respond to the Base Station}

If individual 540A DCP's do not communicate with the base station, take the portable computer to the $540 \mathrm{~A}$ in question and establish contact as described in section 2.2.2.

\subsubsection{A Does Not Respond to Portable Computer}

If the $540 \mathrm{~A}$ will not $\log$ on to the portable computer, turn the $540 \mathrm{~A}$ off, wait 10 seconds and turn it on. If it still will not $\log$ on, try the following procedures: 
1. Check the 540A's battery voltage and power system. Is the battery voltage above 12 volts? This may be checked with a volt meter and/or by typing a " $\mathrm{W}$ " on the portable computer after the 540A has logged on. If the battery voltage is not above 12 volts, try the following:

a. Check the voltage on the charging circuit. If the charging circuit is bad, make necessary repairs.

b. Turn off the 540A and replace the support card. If the battery is then able to charge when the $540 \mathrm{~A}$ is turned back on, have the support card repaired. Be sure to reprogram the $540 \mathrm{~A}$ and start its program.

c. Turn off the $540 \mathrm{~A}$ and remove the battery leads from the battery and connect an external battery charger. If the battery does not charge in a reasonable period of time (overnight), replace it.

2. Check the $540 \mathrm{~A}$ 's printed circuit card. If the power system is OK, turn off the $540 \mathrm{~A}$ and replace the support card. Turn on the $540 \mathrm{~A}$. If it logs on to the portable computer, have the old support card repaired.

If the support card was not the problem, repeat this procedure with the CPU card and MET cards.

If the 540A DCP logs on to the portable computer after any one of these substitutiuns, have that card repaired. Be sure to identify and reprogram the DCP.

3. Check the 540A's identity number. Is the ID correct for that station? If not, correct the ID as described above in section 2.2.2.2

4. Check the 540A's radio card. If the 540A still does not communicate with the base station, turn off the $540 \mathrm{~A}$ and replace the radio card. Turn it back on. If it communicates with the base station, have the old radio card repaired.

5. Check the $540 \mathrm{~A}$ 's antenna system. Inspect the antenna and antenna cable at each station. Use a field-strength meter to determine if radio transmissions 
are occurring during a normal polling time. Correct any discrepancies. Be sure that the antenna's alignment is still correct.

\subsection{After Reestablishment of Communications}

Once communications with the $540 \mathrm{~A}$ are established and the unit is working properly, reprogram it and re-enter the correct base station ID, as described in sections 2.2.2.3 and 2.2.2.2. Once the 540A DCP has been given its proper ID, it may be reprogrammed from the radio base station by using the procedures outlined in Appendix IV-A.

\subsection{List of Manuals Needed for Chapter IV}

1. 540A-1 Multiple Access Data Acquisition System Operating E Service Manual. HANDAR, Inc., Sunnyvale, CA 94089

2. Operating and Service Manual for Interrogated Radio Systems. HANDAR, Inc., Sunnyvale, CA 94089

3. Model PCST/G Installation E User's Guide. Alloy Computer Products, Inc., Framingham, MA 01701.

4. Tandy Model 102 Operators Manual. Tandy Corporation, Fort Worth, TX, 76102. 


\section{Appendix IV-A}

\section{A Quick Programming Reference}

The radio-base-station program is usually run on Slave 2 of the CHAWS computer. Most of the time, this program is in the Poll/Monitor mode (Fig. IV-A1). Press the $\langle$ F10 $>$ key on the Slave 2 Alloy terminal until the main menu (Fig. IV-A2) appears. Select $\langle F 3\rangle$, INTERACTIVE COMMUNICATIONS, from the Main Menu. This will call the menu displayed in Figure IV-A3.

Poll/Monitor mode

Polling enabled

$09913: 39: 06$

-.- Next poll time: 278 13:45:00 DCP 00000001 -.-

$13: 39$ C: $\backslash$ SLAVE $>$ ECHO OFF

1 Enable polling 2 Display status

3 Reset poll 4 Disable polling

10 Return

Figure IV-A1. Poll/Monitor menu. 
$\begin{array}{ll}\text { Startup mode } & 09913: 40: 14\end{array}$

HANDAR REMOTE DATA COLLECTION SYSTEM CONTROLLER

VHF RADIO VERSION

VERSION RI.1 $\quad$ (c) HANDAR 1984

MAIN MENU

1. CONFIGURATION

2. POLL/MONITOR

3. INTERACTIVE COMMUNICATION

4. EXTERNAL PROGRAM EXECUTION

10. EXIT TO OPERATING SYSTEM

ENTER SELECTION :

Figure IV-A2. Main menu.

Interactive mode

No DCP logged on

$099 \quad 13: 40: 17$

Enter the platform ID:

Figure IV-A3. Interactive menu. 


\section{A-1.0 540A LOG-ON}

While in the interactive mode (Fig. IV-4), enter the station ID of the 540A DCP that is desired and press <Enter>. A message at the top of the screen will read

$$
\begin{aligned}
& \text { "TRANSMITTING...", then } \\
& \text { "AWAITING RESPONSE...", then } \\
& \text { "RECEIVING...". }
\end{aligned}
$$

When contact has been made, you will receive a log-on message that says:

$$
\text { "P HANDAR 540A DCP - REV X. } X \text { " }
$$

\begin{tabular}{|c|c|c|c|c|}
\hline \multirow[t]{2}{*}{ Procedure } & \multirow[t]{2}{*}{ Key Strokes } & \multicolumn{2}{|c|}{ Screen Display } & \multirow[b]{2}{*}{$099 \quad 15: 42: 35$} \\
\hline & & Interactive mode & DCP 00000006 & \\
\hline \multirow[t]{5}{*}{ END RUN } & & R HANDAR 540A DCP - REV 6.7 & & \\
\hline & I & 00000006 & & \\
\hline & ? & $\mathrm{R} \quad \operatorname{ENTER}(1)=\operatorname{SERVICE} \quad(2)=\operatorname{ALL} 2$ & & \\
\hline & $2<$ Enter $>$ & P HANDAR 5 40 A DCP - REV 6.7 & & \\
\hline & $\langle F 2><$ Enter: & LOAD PS PROG-:DCP: PRESS ENTER & & \\
\hline \multirow[t]{2}{*}{ PROGRAM } & TYPE1.540 Enter: & P DONE & & \\
\hline & J & P STATION TIME & $15: 43: 35$ & \\
\hline \multirow[t]{3}{*}{ SET TIME } & $15: 43: 35$ Enter: & P GTATION TIME & & \\
\hline & v & $P \quad$ YEAR $(X X)$ & & \\
\hline & $v$ & P DCP JULIAN DATE $\quad 099$ & & \\
\hline \multirow[t]{6}{*}{ START TIME } & HNOV & P HANDAR 540A DCP - REV 6.7 & & \\
\hline & & PO1 SENSOR TYPE 12 & & \\
\hline & & PO1 MEAS INTERVAL & & \\
\hline & $15: 45$ & PO1 START OF MEAS & $15: 45:$ & \\
\hline & $1<$ Enter $>$ & CHANGE ALL CHANS ? $(1=Y, 2=N) 1$ & & \\
\hline & & P01 START OF MEAS $\quad 15: 45: 00$ & & \\
\hline STAR RUN & Y & R RUN/MONITOR MODE & & \\
\hline \multirow[t]{4}{*}{ CHECK TIME } & $s$ & R01 NEXT GCAN & & \\
\hline & M & $\mathrm{R}$ CHANNEL NO. & & \\
\hline & $\mathrm{v}$ & $\mathrm{R}$ CHANNEL NO. & & \\
\hline & $\$$ & R31 NEXT GCAN & & \\
\hline POLL/MON. & $\because F 10>\angle F 2>$ & & & \\
\hline
\end{tabular}

where " $\mathrm{X} . \mathrm{X}$ " is the firmware version number (see Fig. IV-A4). The first letter may be an " $R$ " or a " $P$ ". Once the station is logged on, any command in the HANDAR $540 A$ Operating \& Service Manual may be given to the 540A.

Figure IV-A4. Interactive menu, sample session using TYPE1.540. 


\section{A-2.0 PROGRAMMING THE 540A.}

If the $540 \mathrm{~A}$ is to be reprogrammed, be sure that it is in the program mode. It is in this mode if each line begins with the letter " $P$ ". If not, perform the procedures in the 540A DCP PROGRAM TERMINATION section below. Figure IV-A4 may be used as a reference for these procedures. Key Stroke lines 1 through 3 in this figure must be omitted if the $540 \mathrm{~A}$ is in the program mode.

Hit $\angle A\rangle$ (A) key. When the screen says

"LOAD PS FROG -> DCP: PRESS ENTER",

press the $<$ Enter $>$ key. The bottom of the screen should now state

"Enter DCP program filename:".

Obtain the name of the 540A program to be used with this 540 from Table V-3. Now type the name of the 540A program to be used (e.g., TYPE1.540). Press the <Enter> key, and this program will be loaded into the 540 . If the program was loaded successfully, the word

\section{"DONE"}

will appear on the screen. If not, try loading the program again.

Next, type the letter " $\mathrm{J}$ " to set the time. All 540 A letter commands must be capitals and most single letter commands should not be followed by <Enter>.

Type in the time as it will be displayed in the upper right hand corner of the screen one minute into the future and press $<$ Enter $>$ to set the time. Hit the " $\mathrm{V}$ " key and check the Julian date. Type in the correct date, followed by <Enter>. Now hit " $\mathrm{V}$ " again, and do the same for the year.

\section{A-3.0 540 DATA ACQUISITION}

After the 540 has been programmed, the data- acquisition program must be started. Enter the following key sequence: " $\mathrm{H}$, " " $\mathrm{N}$, " " $\mathrm{O}$, " " $\mathrm{V}$ ". The last message line on the screen should say:

$$
\text { "P1 START OF MEAS. } x x: x x: x x^{\prime} \text {, }
$$

where " $x x: x x: x x^{\prime}$ is a time in 24-hour format. If the time is less than 15 minutes, type "MVS". Another NEXT SCAN time will appear. If either time is greater than 15 minutes (e.g., 23:14:00), follow the procedure in the TERMINATE 540A PROGRAM section below and go back to the beginning of this section and start over. If the time is less than 15 minutes, then proceed. The programming of this $540 \mathrm{~A}$ is complete. 
If more 540's are to be programmed, hit the $\angle F 5>$ key, log of $f$, then hit the $<F 1>$ key, $\log$ on. Now repeat the log-on and $540 \mathrm{~A}$ programming procedures above. If this is the last $540 \mathrm{~A}$, then hit the $\angle F 10\rangle$ key, then hit the $\angle F 2>$ key from the MAIN MENU and data logging should resume on the HANDAR Slave Computer.

\section{A-4.0 CHANGING THE 540A's IDENTIFICATION NUMBER}

If more than one of the 540 DCP's have lost power or have never been programmed, use the following procedures. Turn off all but one of the 540A DataCollection Platforms that require a new ID.

Type " 0 " (zero), <Enter> (for the temporary station ID) in response to "Enter the plat form ID:". When the $540 \mathrm{~A}$ is logged on, type " $I$ ", followed by the correct, eight-digit (e.g., 00000001) station ID of the 540A to be programmed (see station ID list). Now hit $\angle F 5>(\log$ of $f), \angle F 1>(\log \circ$ on) and type the correct (new) station ID (leading 0 's may be omitted this time) followed by $<$ Enter $>$.

\section{A-5.0 540A DCP PROGRAM TERMINATION}

Do not use the following procedure if the $540 \mathrm{~A}$ is already in the program mode. To do so may "hang up" the $540 \mathrm{~A}$ to the point it must be shut off and reprogrammed. If messages from the DCP are proceeded by the letter " $P$ ", then it is already in the program mode.

If a $540 \mathrm{~A}$ program is stopped, all data stored in it will be lost. To stop the program, type "?". The 540A will respond with:

$$
\text { "R } \operatorname{ENTER}(1)=\operatorname{SERVICE}(2)=A L L " .
$$

Press " 2 ", $<$ Enter $>$. The $540 \mathrm{~A}$ is now in the program mode and will not collect any data until placed in the run mode. 


\section{Appendix IV-B}

540A Program Lists

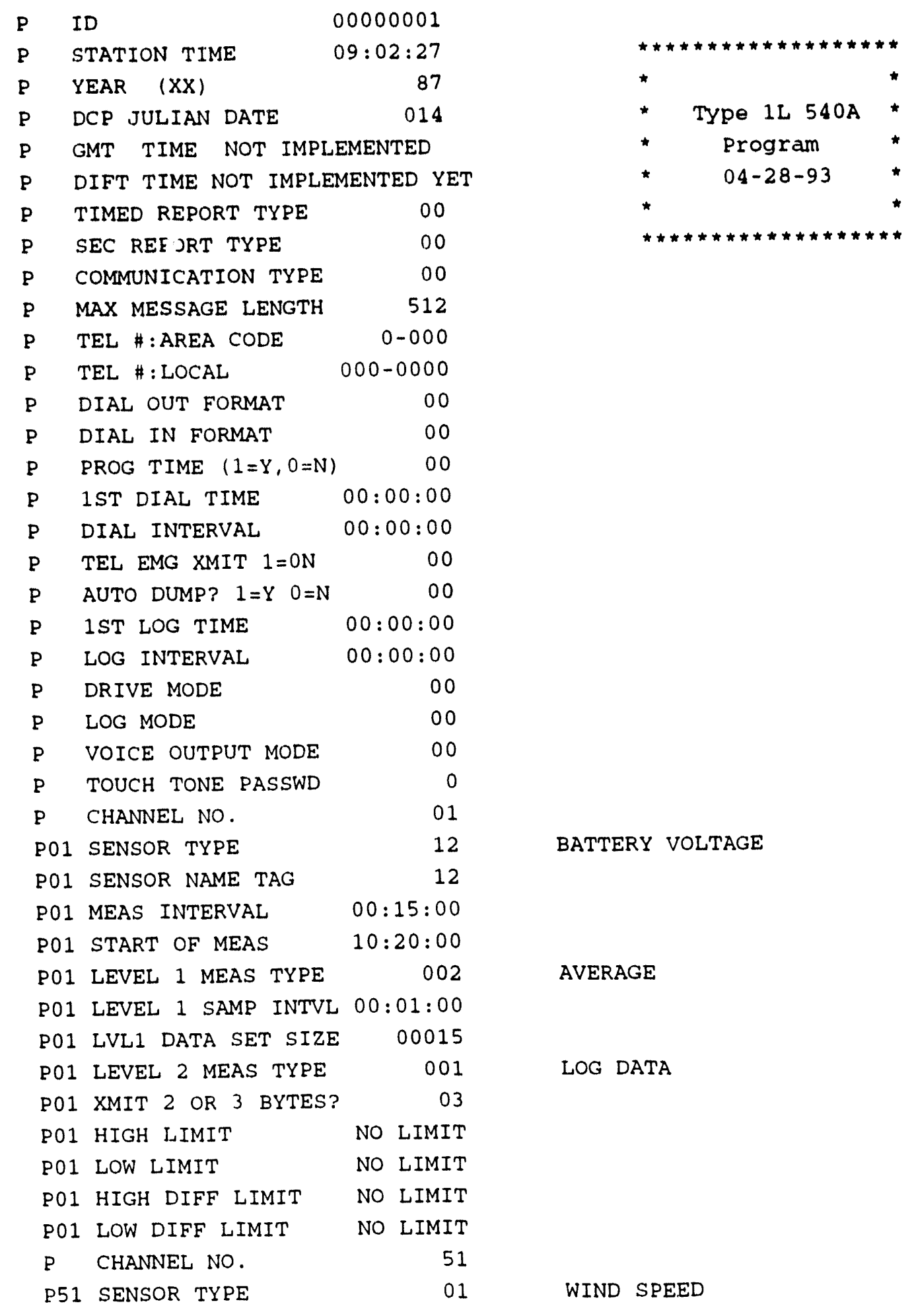




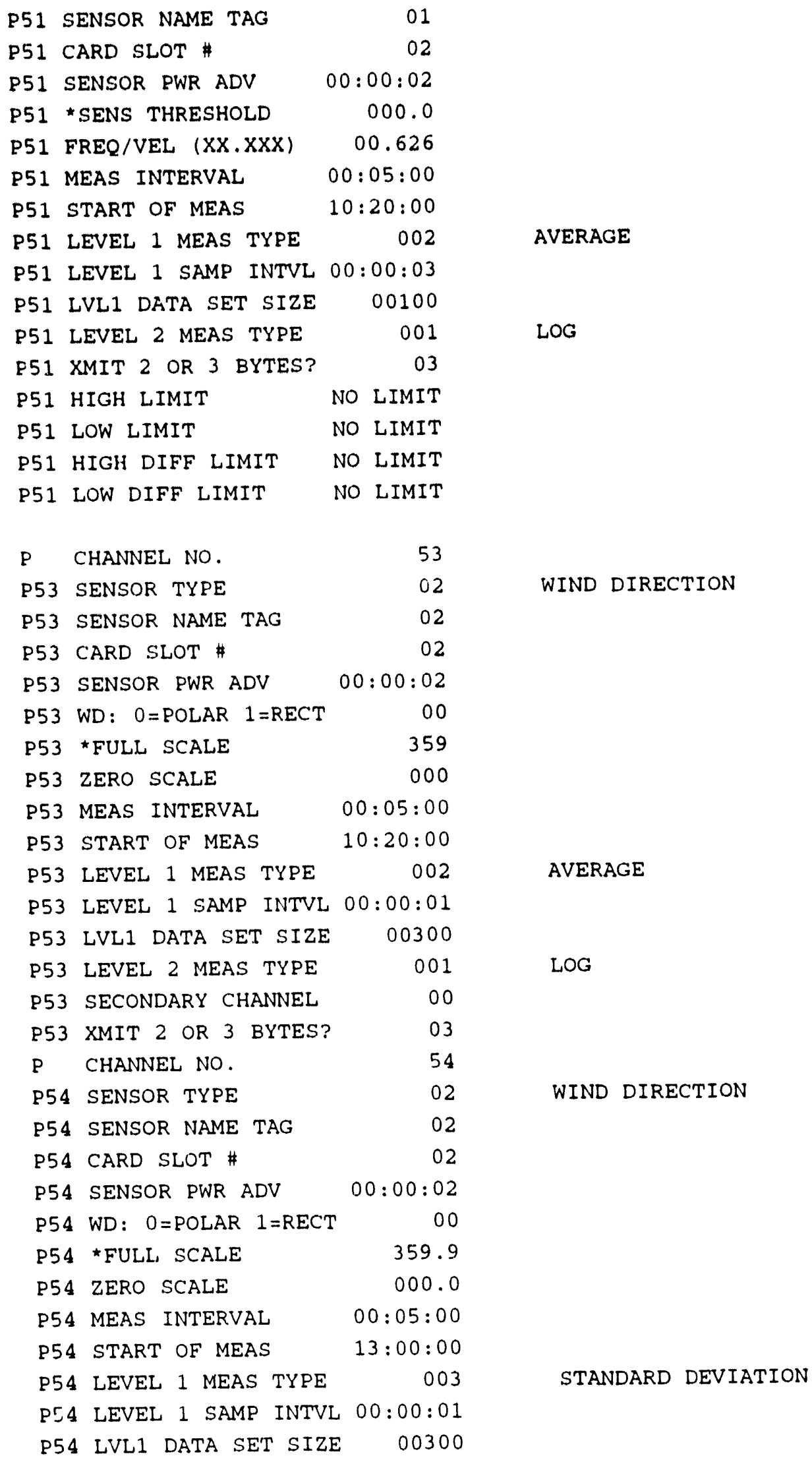




$\begin{array}{llrl}\text { P54 LEVEL 2 MEAS TYPE } & 001 & \text { LOG } \\ \text { P54 SECONDARY CHANNEL } & 00 & \\ \text { P54 XMIT 2 OR 3 BYTES? } & 03 & \\ \text { P CHANNEL NO. } & 56 & \\ \text { P56 SENSOR TYPE } & 03 & \text { TEMPERATURE } \\ \text { P56 SENSOR NAME TAG } & 03 & \\ \text { P56 CARD SLOT \# } & 02 & \\ \text { P56 SENSOR PWR ADV } & 00: 00: 02 & \\ \text { P56 TEMP INPUT }(1-8) & 01 & \\ \text { P56 TEMP SCALE 0=C 1=F } & 00 & \\ \text { P56 } \text { *TEMP FORMAT } & 000.0 \\ \text { P56 MEAS INTERVAL } & 00: 15: 00 & \\ \text { P56 START OF MEAS } & 10: 20: 00 & \\ \text { P56 LEVEL 1 MEAS TYPE } & 002 & \text { AVERAGE } \\ \text { P56 LEVEL 1 SAMP INTVL 00:00:20 } & \\ \text { P56 LVL1 DATA SET SIZE } & 00045 & \\ \text { P56 LEVEL 2 MEAS TYPE } & 001 & \text { LOG } \\ \text { P56 XMIT 2 OR 3 BYTES? } & 03 & \\ \text { P56 HIGH LIMIT } & \text { NO LIMIT } \\ \text { P56 LOW LIMIT } & \text { NO LIMIT } \\ \text { P56 HIGH DIFF LIMIT } & \text { NO LIMIT } \\ \text { P56 LOW DIFF LIMIT } & \text { NO LIMIT }\end{array}$




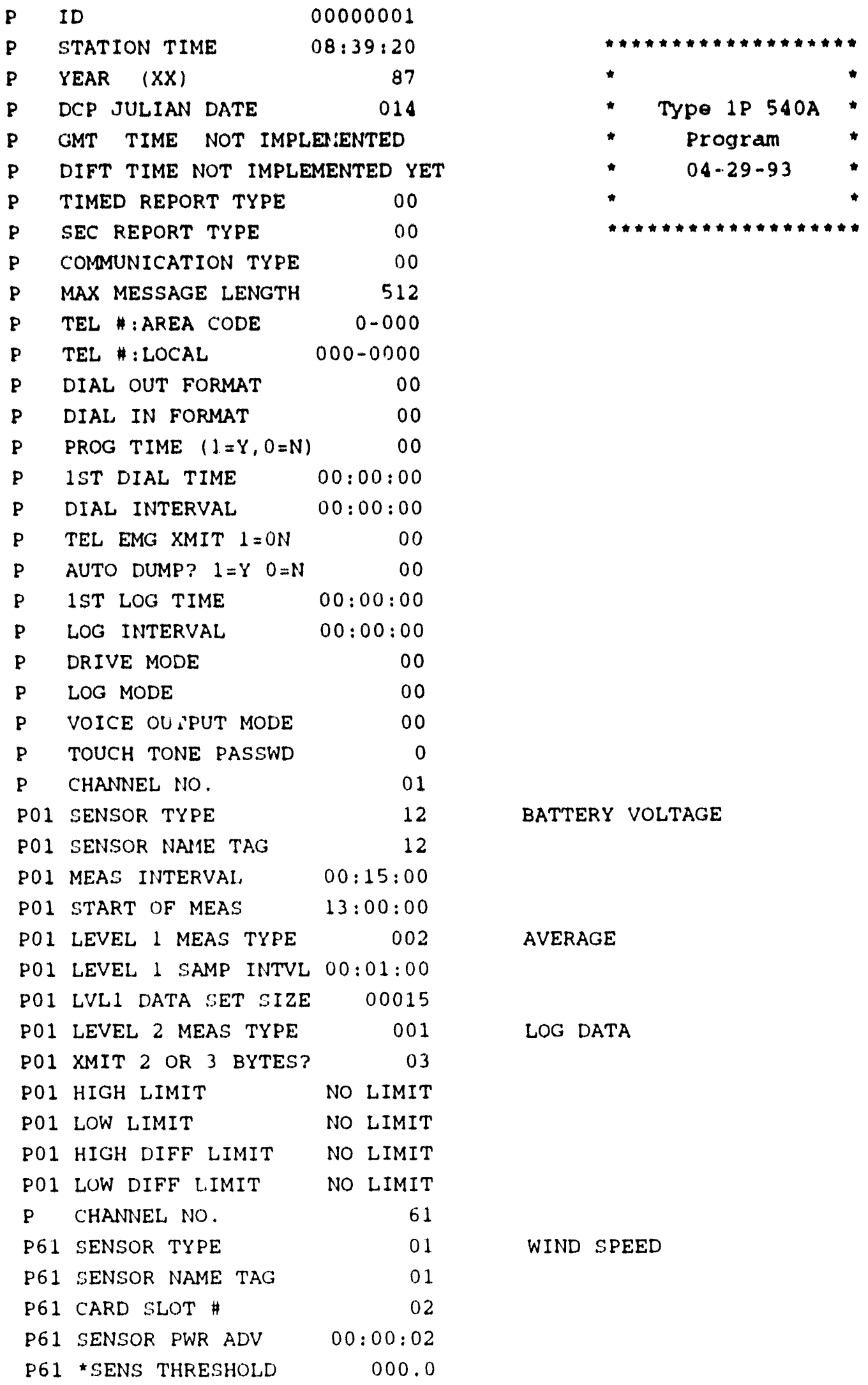




\begin{tabular}{|c|c|c|c|}
\hline P61 & FREQ/VEL $(X X, X X X)$ & 00.626 & \\
\hline P61 & MEAS INTERVAL & $00: 05: 00$ & \\
\hline P61 & START OF MEAS & $13: 00: 00$ & \\
\hline P61 & LEVEL 1 MEAS TYPE & 002 & AVERAGE \\
\hline P61 & LEVEL 1 SAMP INTVL 0 & $00: 00: 03$ & \\
\hline P61 & LVL1 DATA SET STZE & 00100 & \\
\hline P61 & LEVEL 2 MEAS TYPE & 001 & LOG \\
\hline P61 & XMIT 2 OR 3 BYTES? & 03 & \\
\hline P61 & HIGH LIMIT & NO LIMIT & \\
\hline P61 & LOW LIMIT & NO LIMIT & \\
\hline P61 & HIGH DIFF LIMIT & NO LIMIT & \\
\hline P61 & LOW DIFF LIMIT & NO LIMIT & \\
\hline $\mathbf{P}$ & CHANNEL NO. & 63 & \\
\hline P63 & SENSOR TYPE & 02 & WIND DIRECTION \\
\hline P63 & SENSOR NAME TAG & 02 & \\
\hline P63 & CARD SLOT \# & 02 & \\
\hline P63 & SENSOR PWR ADV & $00: 00: 02$ & \\
\hline P63 & WD: $\quad 0=$ POLAR $1=$ RECT & 00 & \\
\hline P63 & ^FULL SCALE & 359 & \\
\hline P63 & ZERO SCALE & 000 & \\
\hline P63 & MEAS INTERVAL & $00: 05: 00$ & \\
\hline P63 & START OF MEAS & $13: 00: 00$ & \\
\hline P63 & LEVEL 1 MEAS TYPE & 002 & AVERAGE \\
\hline P63 & LEVEL 1 SAMP INTVL & $00: 00: 01$ & \\
\hline P63 & LVL1 DATA SET SIZE & 00300 & \\
\hline P63 & LEVEL 2 MEAS TYPE & 001 & LOG \\
\hline P63 & SECONDARY CHANNEL & 00 & \\
\hline P63 & XMIT 2 OR 3 BYTES? & 03 & \\
\hline $\mathbf{P}$ & CHANNEL NO. & 64 & \\
\hline P64 & SENSOR TYPE & 02 & WIND DIRECTION \\
\hline P64 & SENSOR NAME TAG & 02 & \\
\hline P64 & CARD SLOT \# & 02 & \\
\hline P64 & SENSOR PWR ADV & $00: 00: 02$ & \\
\hline P64 & 1 WD: $0=$ POLAR $1=$ RECT & 00 & \\
\hline P64 & *FULL SCALE & 359.9 & \\
\hline P64 & 4 ZERO SCALE & 000.0 & \\
\hline P64 & 4 MEAS INTERVAL & $00: 05: 00$ & \\
\hline P64 & 4 START OF MEAS & $13: 00: 00$ & \\
\hline P64 & 4 LEVEL 1 MEAS TYPE & 003 & STANDARD DEVIATION \\
\hline P64 & 4 LEVEL 1 SAMP INTVL & $00: 00: 01$ & \\
\hline P64 & 4 LVL1 DATA SET SIZE & 00300 & \\
\hline P64 & 4 LEVEL 2 MEAS TYPE & 001 & LOG \\
\hline P64 & 4 SECONDARY CHANNEL & 00 & \\
\hline P64 & 4 XMIT 2 OR 3 BYTES? & 03 & \\
\hline & CHANNEL NO. & 66 & \\
\hline
\end{tabular}




$\begin{array}{lrr}\text { P66 SENSOR TYPE } & 03 & \text { TEMPERATURE } \\ \text { P66 SENSOR NAME TAG } & 03 & \\ \text { P66 CARD SLOT } & 02 & \\ \text { P66 SENSOR PWR ADV } & 00: 00: 02 & \\ \text { P66 TEMP INPUT }(1-8) & 01 & \\ \text { P66 TEMP SCALE O=C 1=F } & 00 & \\ \text { P66 *TEMP FORMAT } & 000.0 & \\ \text { P66 MEAS INTERVAL } & 00: 15: 00 & \\ \text { P66 START OF MEAS } & 13: 00: 00 & \\ \text { P66 LEVEL 1 MEAS TYPE } & 002 & \text { AVERAGE } \\ \text { P66 LEVEL 1 SAMP INTVL } 00: 00: 20 & \\ \text { P66 LVL1 DATA SET SIZE } & 00045 \\ \text { P66 LEVEL 2 MEAS TYPE } & 001 & \\ \text { P66 XMIT 2 OR 3 BYTES? } & 03 & \\ \text { P66 HIGH LIMIT } & \text { NO LIMIT } \\ \text { P66 LOW LIMIT } & \text { NO LIMIT } \\ \text { P66 HIGH DIFF LIMIT } & \text { NO LIMIT } \\ \text { P66 LOW DIFF LIMIT } & \text { NO LIMIT }\end{array}$




\section{Chapter V \\ CHAWS COMPUTER SYSTEM}

Stan Martins

Kaiser Engineers, Livermore

\subsection{INTRODUCTION}

The CHAWS computer system has many functions and is comprised of a number of separate but interrelated computers, software programs, and peripheral devices (see Fig.-V-1). These are grouped by function and discussed below.

\subsection{Hardware Architecture}

A SPEAR PC/AT compatible 386SX computer is used as the heart of the system. It contains Alloy Slave cards, which are semi-autonomous computers themselves. The $\mathrm{PC} / \mathrm{AT}$ is called the host, and each slave is called a user. Normally each user has its own specific function.

\subsection{System Software}

The operating system used for the CHAW computer is MS DOS Version 3.3 or higher (Ver. 5.0 has been provided with the SPEAR computer). In addition, NTNX from Alloy Computer Products is used to communicate with the PC Slave cards and to administer system resources such as the hard disk, floppy drives, and printers.

Please note that two different version of the slave operating system have been installed at the Lexington-Blue Grass Army Depot. ATNX, Ver. 1.40, is used with the slaves in the older IBM PC/AT computer and NTNX, Ver. 3.0, is used with the slaves in the newer SPEAR computer. These two operating systems MUST NOT be interchanged. Slave cards from the old computer must not be installed in the new computer nor may slaves from the new computer be used with the older one. The firmware on each of the two groups of slaves is different, and specific for either ATNX or NTNX. This revision of the CHAWS manual is directed at the newer system. To deal with the older IBM system, refer to the first revision of this manual. 


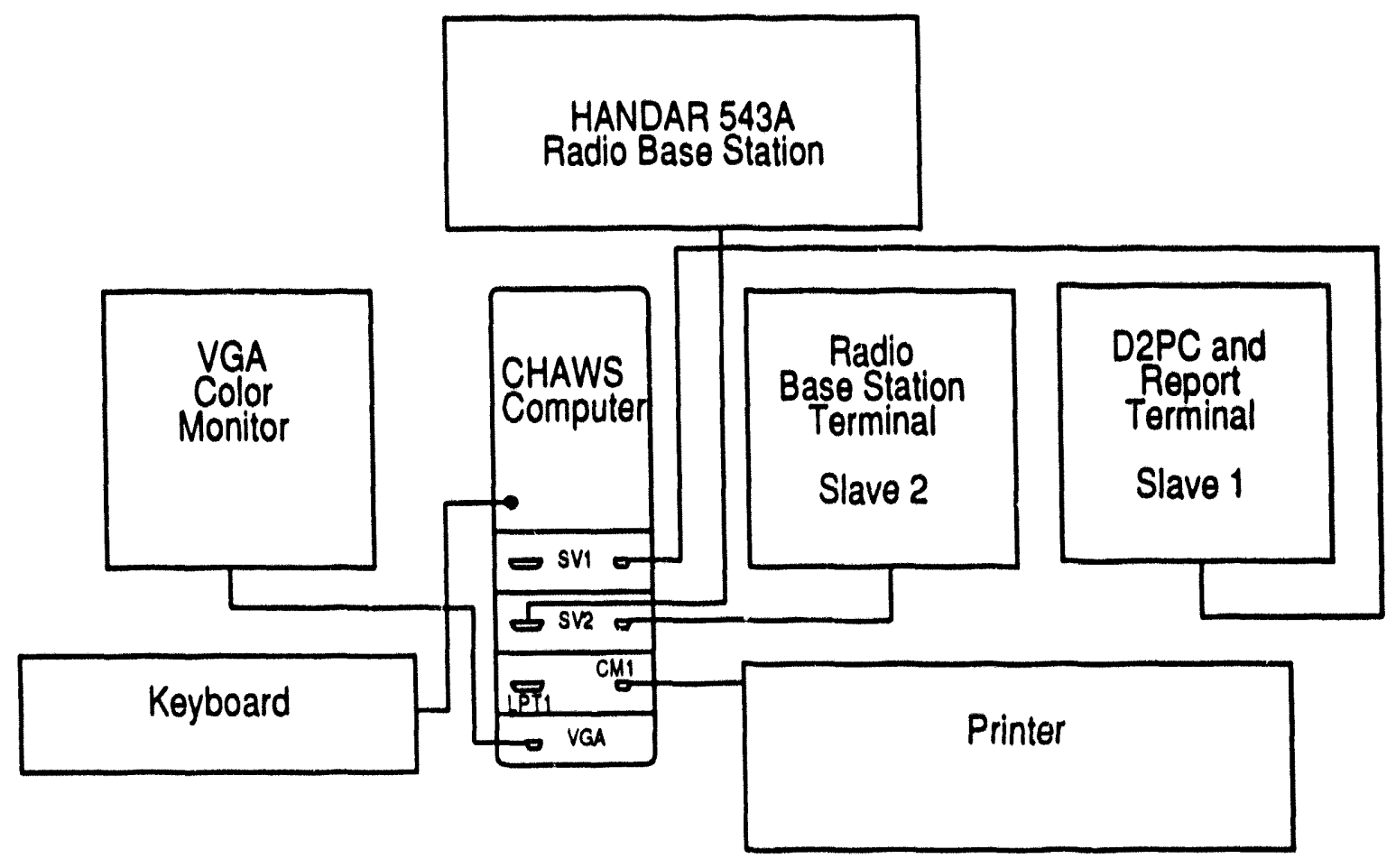

Figure V-1. Lexington-Blue Grass Army Depot CHAWS computer system.

\subsection{System Functions}

The following functions are accomplished by the use of a combination of hardware and software.

\subsubsection{Weather Data Acquisition}

Meteorological information is collected from remote weather stations, displayed on a computer screen, and stored on the host computer hard disk for future use.

\subsubsection{Modeling, Hazard Prediction, and Graphics}

The acquired weather data are used by a number of programs to predict hazardous-substance dispersion and to give a visual presentation of wind speed, wind direction, and temperature.

\subsubsection{Report Writing}


The CHAWS computer system may be used to generate reports based on the acquired weather data. Such reports could include air-quality summaries and local weather reports.

\subsection{OPERATIONS}

The following procedures may be used in the day-to-day operations of the CHAWS computer system. (Refer to Chapter I for additional considerations in daily operations.)

\subsection{Cold Start}

To start the entire system from a power-down condition:

1. Apply power to all computers and peripherals in the CHAWS Computer System.

2. Be sure that all components are on and working properly. (The power lights for each component should be on, and all software modules should be running and performing their jobs properly.)

3. If the software that is supposed to run on any user is not running, or if any piece of equipment fails to operate, consult section 3.0 of this chapter, Troubleshooting Guide.

\subsection{The SPEAR PC/AT Host Computer}

All other users (slaves) are dependent upon the host computer. A momentary loss of power or rebooting of the host will reset all other users. The host may be used to run almost any software (consult the "PC-Plus User's Guide" and the "NTNX Installation Guide" for the exceptions). It has, however, two primary functions:

1. It provides hard disk, printer, and communications for all other users. This is accomplished through the use of the NTNX operating system, which is installed automatically when the system is reset if the standard CHAWS AUTOEXEC. BAT is in place on the computer's hard disk. 
2. It performs calculations for downwind hazard prediction and to provide a graphics presentation of the results. Consult Chapter VI for details of these functions.

\subsection{Routine Weather-Data Logging}

\subsubsection{Normal Base-Station Program Execution}

The weather data-acquisition computer, Slave 2, will start running BASE. EXE, which is the HANDAR radio-base-station software, when the computer is powered up or rebooted when the standard CHAWS autoexec files are in their proper place on the computer's hard disk. For Slave 2, this file is AUTO. U02 in the C: $\backslash$ NX\$ directory. This program will start BASE. EXE running in the data-polling mode. If this is not the case, consult section 3.0 of this chapter, Troubleshooting.

\subsubsection{Starting the Buse-Station Program}

If the radio-base-station program has been stopped for any reason, it may be restarted by rebooting the data-acquisition computer (Slave 2). This is done by hitting the $\langle C t r l\rangle,\langle A l t\rangle$, and $\langle$ Del $>$ keys on its keyboard simultaneously. The same result may be obtained by terminating any applications software that may be running on the data-acquisition computer. When the DOS prompt appears, type "CD $\triangle S L A V E$ " $<$ Enter>, followed by "BASE -A900" <Enter>. This will cause BASE. EXE to be run with data acquisition scheduled to begin at the next quarter hour. If data logging does not commence at the next even 15-min interval, consult the Troubleshooting Guide, section 3.0. BASE. EXE should not be run alone, because this will cause data acquisition to be terminated at midnight. 
2.3.3 Returning the Base-Station Program to the "Poll/Monitor" mode.

If the radio-base-station software is in a menu other than "Pol1/Monitor" mode, press $\langle F 10\rangle$ until the main menu appears. Now hit $\angle F 2>$ from the Main Menu. The polling menu should now be on the screen. The message "Polling enabled" should be in the upper center screen. If not, and if no polls are pending, the procedures described in section 2.3.2 may be used to start polling. Should it be undesirable to do this, consult the HANDAR manual.

\subsection{Telephone Communications}

Depending upon the configuration of your system, telephone communications may be used to share data with other computers and/or to obtain data from other devices. Currently, this feature has not been installed at Lexington-Blue Grass Army Depot.

\subsubsection{Initiating Telephone Communications with a Dedicated System}

If telephone communications are handled by a dedicated slave card, it is only necessary to turn the system on for this program to begin. The easiest way to reset this program is to reboot its slave. If no terminal is connected to this slave, it may be reset from any other user by typing "SLVRESET $N$ " $<$ Enter $>$ where " $\mathrm{N}$ " is the number of that slave card.

\subsubsection{Initiating Telephone Communications on a Shared System}

If telephone communications are performed by the host or a slave card that has more than one function, it may be necessary to invoke the communication software. See Appendix V-A for an example of this procedure.

\subsection{SODAR Data Logging}

Lexington-Blue Grass Army Depot has no SODAR unit. 


\subsection{Using the Printer}

When Alloy's NTNX operating system is installed, the printer(s) connected to the system are placed under the control of a program called SPOOL.COM. To use this tool effectively, one should read Section 4, Print Management, in the "PC-Plus User's Guide."

Briefly, any document that is printed by applications software may be sent to the printer by pressing the $\langle A 1 t>$ and the $\langle F 10\rangle$ keys simultaneously. Then, after the print menu appears at the bottom of the screen, press <Enter $>$; this must be done on the terminal that printed the document.

A file may be printed directly from the hard disk by typing " $\backslash S P O O L$ " and the name of the file to be printed, followed by <Enter $>$.

A user can acquire the exclusive use of the printer for direct printing by typing “SPOOL $/ D D^{\prime}<$ Enter $>$. This is helpful when running programs like $D 2 P C$, where it is necessary to have current information sent to the printer at all times. The printer may be released from the direct mode of operation, type "\SPOOL /DS" <Enter>.

In the D2PC example, above, where the printer has been placed in the direct print mode, the output to the screen from D2 PC may be sent to the printer. After typing "D2 $P C$ " $<$ Enter $>$, press the $<C t r 1>$ and "P" keys at the same time. When finished with $D 2 P C$, be sure to press $\langle C \operatorname{tr} 1\rangle$ " $P$ " again and return the printer to the spool mode by typing “ $\backslash$ SPOOL /DS" <Enter>.

\subsection{TROUBLESHOOTING GUIDE.}

The following is a list of potential problems and possible solutions.

\subsection{System-Power Problems}

All or part of the system has no power. Power indicator lights are out.

1. Be sure that equipment has not been accidentally unplugged or turned off.

2. Check the integrity of all circuit breakers and fuses for that part of the system. Reset or replace the effected breaker or fuse.

3. Some power-conditioning equipment will power down during a "brown out" or power loss. If your system is so equipped, reset this device. 
4. If an Uninterruptible Power Supply (UPS) has been installed, try bypassing it by plugging the effected equipment directly into a 120 -volt receptacle. If this corrects the problem, read the UPS manual to be sure it is being used correctly. If it is being used correctly, have it serviced.

\subsection{Default Software Does Not Start When System Is Powered-Up or Rebooted}

Be sure that the computer has booted from the hard disk. The door on drive $\mathrm{A}$ should be open, and the host should be running "LOGIT" or "GRAPHIT". To verify this, type $\langle C \operatorname{Cr} 1>$ " $C$ ". A message should appear which asks "Terminate batch job $(\mathrm{Y} / \mathrm{N})$ ?". Type " $\mathrm{N}$ " to continue or " $\mathrm{Y}$ " to quit, followed by <Enter>.

If the door on drive $A$ is closed, open it and reboot.

If the computer does not boot, refer to section 3.3. If the computer boots but the expected software is not running, restore the CHAWS system as described in section 3.3.3, below.

\subsection{Hard-Disk Problems}

If the computer will not boot from the hard disk or fails to run standard software packages or displays disk errors, perform the following procedures.

\subsubsection{Use of the American Megatrends ROM Monitor Diagnostics to Identify Problems}

Follow the SPEAR manuals for the use of this utility.

\subsubsection{Find Lost Clusters and Corrupted Files}

1. From the root directory of C drive type "COPY AUTOEXEC. BAT *.SLV" and press <Enter>. Now type "DEL AUTOEXEC. BAT" and press $<$ Enter>. Reboot the system.

2. Press <Enter $>$ twice and type "CD $\backslash$ BIN" $<$ Enter $>$, "CHKDSK / F" $<$ Enter $>$, "N" $<$ Enter $>$. A list of files with cross-linked clusters may be displayed. If so, delete these files by typing "DEL $\backslash$ directory name $\backslash f i l$ lename. extension" for each file listed. For example, such a file 
may be listed as " $\mathrm{C}: \backslash$ HANDAR $\backslash$ RAWDAT. DAT". To delete this file, the operator would type "DEL C: \HANDAR \RAWDAT. DAT" <Enter>. If the operator is unsure whether these files should be deleted, they may be copied to a new filename prior to deleting them.

3. From the root directory of C drive type "COPY AUTOEXEC. SLV * BAT" and press <Enter $>$. Now reboot the system.

\subsubsection{Restoring the CHAWS System to the SPEAR Computer}

If important files are inadvertently erased from the computer's hard disk, it may be necessary to re-install certain systems.

1. Hard-disk formatting. If this becomes necessary, be sure to back up all data files and other unique files before proceeding with this process. ALL FILES WILL BE LOST FROM THE COMPUTER. Consult the SPEAR manuals for details on this procedure.

2. Restoring the DOS system to the machine. This may be done at the end of process 1., above, or it may be done by booting from the DOS disk in drive $A$ and then typing "SYS C:" <Enter>. Now COpy COMMAND. COM to the root directory of drive $C:$. Be sure that all other DOS files are located in the $C: \backslash$ BIN directory.

3. Installing NTNX. Boot the computer and make $C: \backslash$ the default directory (type "C:" <Enter>, the "CD $\mathrm{C}: \backslash$ " <Enter $>$ ). Place the first NTNX installation disk in drive $A$ and follow the instructions in the NTNX installation guide.

4. Installing the CHAWS files. Place the first CHAWS installation disk in Drive $B$ and type "B:CHAWINST" < Enter>. Follow the on screen instructions.

\subsection{Telephone Communications}


If telephone-communication problems exist between the CHAWS system and other computers, be sure that all equipment is connected properly and that power is applied to the modem. If these are all correct, install a PCST/G terminal on the modem slave and try the following:

1. Be sure that WAITDATA. EXE or whatever communications software that is used is configured for the same serial port to which your modem is connected. For a slave card, this will always be COM2. For the Host computer, it will usually be CoM1. If a slave is being used, be sure that line 22, ring indicator, is not connected between the modem and the slave. If this line is allowed to go high, the slave will reboot and no communications will occur.

2. Unplug and replug the modem's power cord from/to the UPS. Turning it off and on may not reset it. To test the modem, connect a terminal to Slave 3 (it is connected to the modem) and run the modem communications software. Now type "AT" < Enter>. If an "OK" is returned, then communications exist between the modem and the computer. Try the procedure that previously failed one more time.

3. If the "OK" prompt was not received above, then connect a new modem to the system in exactly the same manner that the old on was connected. Repeat the procedure stated in 2., above.

a. If the new modem does not work, connect the serial line from the modem to a different user and run the modem software on that user.

1) If this works, then the serial port on the first user is defective and must be replaced.

2) If the second user does not communicate with the new modem, replace the serial cable and/or adapters.

b. If the new modem works, then have the old modem repaired.

4. If the modem and serial port are functioning properly, connect a telephone handset to the telephone line used for the modem.

a. If there is no dial tone or the telephone will not support two-way communications with another phone, have the telephone line repaired. 
b. If the telephone line, modem and computer seem to be working, replace the RJ-11 line between the modem and the wall connector. Be sure to install it in the port marked "Tel Line".

\subsection{SYSTEM INSTALLATION AND SPECIFICATIONS.}

This section is supplied primarily as a reference. The CHAWS system should have already been installed.

All hardware should be installed in a clean environment, with a temperature range between 60 and $80^{\circ} \mathrm{F}$ and a non-condensing relative humidity of 20 to $80 \%$.

Power supplies for all computers must be surge protected.

\subsection{Uninterruptible Power Supply (UPS)}

Connect the power cable of each UPS to a 120 -volt, 20 -amp, $60-\mathrm{Hz}$ circuit. If needed, connect a power-distribution strip to one of its output sockets. Do not use any type of surge suppression between the UPS and the computer or peripheral device. Do not overload the UPS. If it has a rating of $1.0 \mathrm{KVA}$, then a load of no more than 8.3 amps may be placed on it. The lower the load, the longer the UPS will function when line power is lost. 


\subsection{Computers}

Place all computers and peripherals in a cool, well-ventilated area. Follow the manufacturer's recommendations for installation. Be sure that all power connections are made to either a surge protector or to a UPS.

\subsection{Base Station}

Follow the instructions in the HANDAR "Operating and Service Manual for Interrogated Radio Systems" for the installation of all HANDAR base-station equipment.

\subsubsection{Radio Base Station}

Install the HANDAR 542 radio base station near the data-acquisition computer. Connect its power co:d to the UPS. Attach the antenna coaxial cable to the DIN connector in back. Now connect the serial cable to the 25-pin " $D$ " connector in back of the radio base station.

\subsubsection{Direct Telephone System}

If a HANDAR direct telephone connection is used, install the Central Station IF card in an empty slot in the data-acquisition (host or slave) computer. Attach the modular telephone connector to the plug provided. Attach a serial cable between the 25-pin " $D$ " connector on the Central Station IF card and a serial port on the dataacquisition computer (either COM1 or COM2).

\subsubsection{Connecting the Radio Base Station to the Computer}

A special 25-pin cable adapter should be installed on COM2 of the PC/Slave before connecting the serial cable from the base station to the slave card. The adapter is needed to prevent line 22, ring indicator, from being connected to the slave. COM2 on the PC/Slave card is the 25-pin " $\mathrm{D}$ " connector. 


\subsection{PC/Slave Card Installation}

Use the "NTNX Installation Guide" and "PC-PLUS User's Guide" to perform the following procedures.

\subsubsection{PC/Slave Card Set Up}

1. Enter the same base address for all users in this system with the dip switches located on each slave card. The locations for the correct bank of dip switches and the corresponding settings are found in the NTNX guide. The default value is 220 .

2. Set the user number for each card with the dip switches located on each slave.

3. Set the amount of memory on each card with the first set of dip switches.

4. Install the math co-processor (PC Math 16) on the slave card that is to be used for data processing.

\subsubsection{PC/Slave Card Installation}

Install the slave card(s) in empty slot(s) in the host PC/AT computer or on its expansion chassis (if used) in any empty slot.

Attach a monitor cable to each of the slaves' 9-pin connectors and to an appropriate terminal. This will usually be a Alloy PCST/G or a Link M3 terminal.

\subsubsection{PC/Slave Card System Software Installation}

Place the CHAWS installation disk in drive $A$ of the host PC/AT and reboot the system. Type "INSTALL" <Enter>. This will place the slave NTNX operating system on the hard disk along with the rest of the CHAWS system.

If a new slave card has been added to the system, it may be necessary to tell the system it is there. This can be done by running a program called "NXCNFG". Consult the "NTNX Installation Guide" for this procedure. 


\subsection{Telephone Modem}

The telephone modem must be connected to COM2 of the slave card that will be used for this purpose or to COM1 of the host computer if a slave is not used. Use a 25pin serial cable and a special 25-pin adapter to make this connection to a slave, or a 9pin/25-pin cable if the host is used. The adapter is needed to prevent line 22, ring indicator, from being connected to the slave. Follow the modem manufacturer's instructions for installing and programming the modem.

\subsection{List of Manuals Needed for Chapter V}

1. Microsoft MS-DOS Version 5.0 Manual. The Microsoft Corporation 1991.

2. PC PLUS User's Guide. Alloy Computer Products, Inc., Framingham, MA 01701.

3. NTNX Installation Guide. Alloy Computer Products, Inc., Framingham, MA 01701.

4. Model PCST/G Installation E User's Guide. Alloy Computer Products, Inc., Framingham, MA 01701.

5. INMAC Modem Operations Manual. INMAC Corporation, Santa Clara, CA 95952-8031.

6. Operating and Service Manual for Interrogated Radio Systems. HANDAR, Inc., Sunnyvale, CA 94089

7. 540A-1 Multiple Access Data Acquisition System Operating and Service Manual. HANDAR, Inc., Sunnyvale, CA 94089 


\section{APPENDIX V-A \\ EOC/AOC Telephone Link}

This feature has not been istalled at the Lexington-Blue Grass Army Depot . This description is provided in the event that such a system may be installed in the future.

Telephone modems may be installed on COM2 of Slave 3 on both the EOC and the $\mathrm{AOC}$ computers to facilitate data transfer between these two locations. A program called WAITDATA. EXE may be installed on each computer. For a detailed explanation of the use of this program, see Appendix IV-C.

No terminal has been provided for this function, because this function has been designed to be transparent to the user. Should a terminal be desired for use with the modem, a spare terminal should be connected to Slave 3's 9-pin terminal port. Under no circumstances should the modem be removed from Slave 3 .

If a modem is desired on Slave 1 or on the Host computer, purchase a second modem. DO NOT use the one provided for Slave 3. As mentioned above, pin 22, ring indicator, must not be connected to a slave card. If this happens, the slave will re-boot itself when this line goes high.

MEX-PC stands for Modem Executive PC and has been supplied with several CHAWS systems. If you wish to use this software with your modem, consult the MEXPC manual for details. It may be provided as either MEX. COM or MEX-PC. COM on your system. 


\section{APPENDIX V-B \\ Computer System Time-Keeping}

When ATNX or NTNX is installed on a computer, it administers all system resources. Since it is a multi-tasking operating system, the DOS software clock is affected and generally slows down with respect to the hardware clock. To compensate for this problem, the Alloy utility call UPTIMEAT. EXE is used. When installed by the AUTOEXEC.BAT, this utility will periodically adjust the software time to the hardware time, usually every 10 seconds. This works well when the hardware time is reliable. Unfortunately, some hardware clocks gain or loose more time than is acceptable for CHAWS computers.

The SPEAR PC/AT hardware clock will always gain about 22 seconds per day. The program CORCTIME. EXE was written to adjust for this problem. It is executed by either GRAPHIT. BAT or LOGIT. BAT when the file CORCTIME. NOW is present. CORCTIME. NOW is generated when BASE. EXE is running on Slave 2 at midnight. Therefore, if BASE. EXE is not running at midnight, the system time will not be corrected, and eventually, the computers time will be in the future of the 540 DCPs and no data will be collected.

If the hardware clock on the SPEAR PC/AT must be adjusted, use the following protocol on the Host computer:

- From the DOS prompt, type UPTIMEAT $900<$ Enter $>$. This will change the rate at which the software clock is updated from the hardware to every 900 seconds.

- Now use the DOS TIME utility to reset the software clock to a time that is 2 minutes behind the Handar 540 DCP clock (e.g. TIME 09:30<Enter $>$ ).

- Now type UPTIMEAT $10<$ Enter $>$. This will change the update rate of the software clock back to once every 10 seconds. 


\title{
Chapter VI \\ GRAPHIC DISPLAY AND DATA-PROCESSING SOFTWARE
}

\author{
Michael H. Merry \\ Certified Consulting Meteorologist \\ Frank J. Gouveia \\ Health and Ecological Assessment Division \\ Edited by Stan Martins \\ Kaiser Engineers, Livermore
}

\subsection{PURPOSE}

This chapter describes the necessary programs to convert HANDAR meteorological data to valid hourly averages. It also explains how to operate the nearreal-time high-resolution graphics that display recent meteorology on the host computer's screen. It then describes methods of tabulating and archiving the data and of reporting air-quality data to government agencies, if requested. Currently, Lexington-Blue Grass Army Depot does not acquire air-quality data. The sections dealing with air-quality in this section are provided for reference only.

\subsection{Overview}

Data from the raw signals output by the meteorological sensors and air-quality analyzers are converted by the computer to valid hourly averages of measured parameters. The method for this conversion is displayed in the flowchart in Figure VI1 and discussed below.

A number of programs are used in the conversion of the data, and Section 2 of this chapter provides a detailed description of each program's function. Section 3 describes the operation of the programs. Section 4 discusses the interpretation and use of the results and provides procedures for archiving the data. (The regular daily operation of the CHAWS system continuous software is discussed in Chapter I of this manual.)

Abbreviations in this chapter are explained when they are first used, and are also listed in the first two tables as well as in Appendix I-A. Brackets "[]" appearing in filenames are not used in the actual files. They designate non-generic data that depend on the particular date for the file in question. 
Part A: Sensor and Hardware Configuration

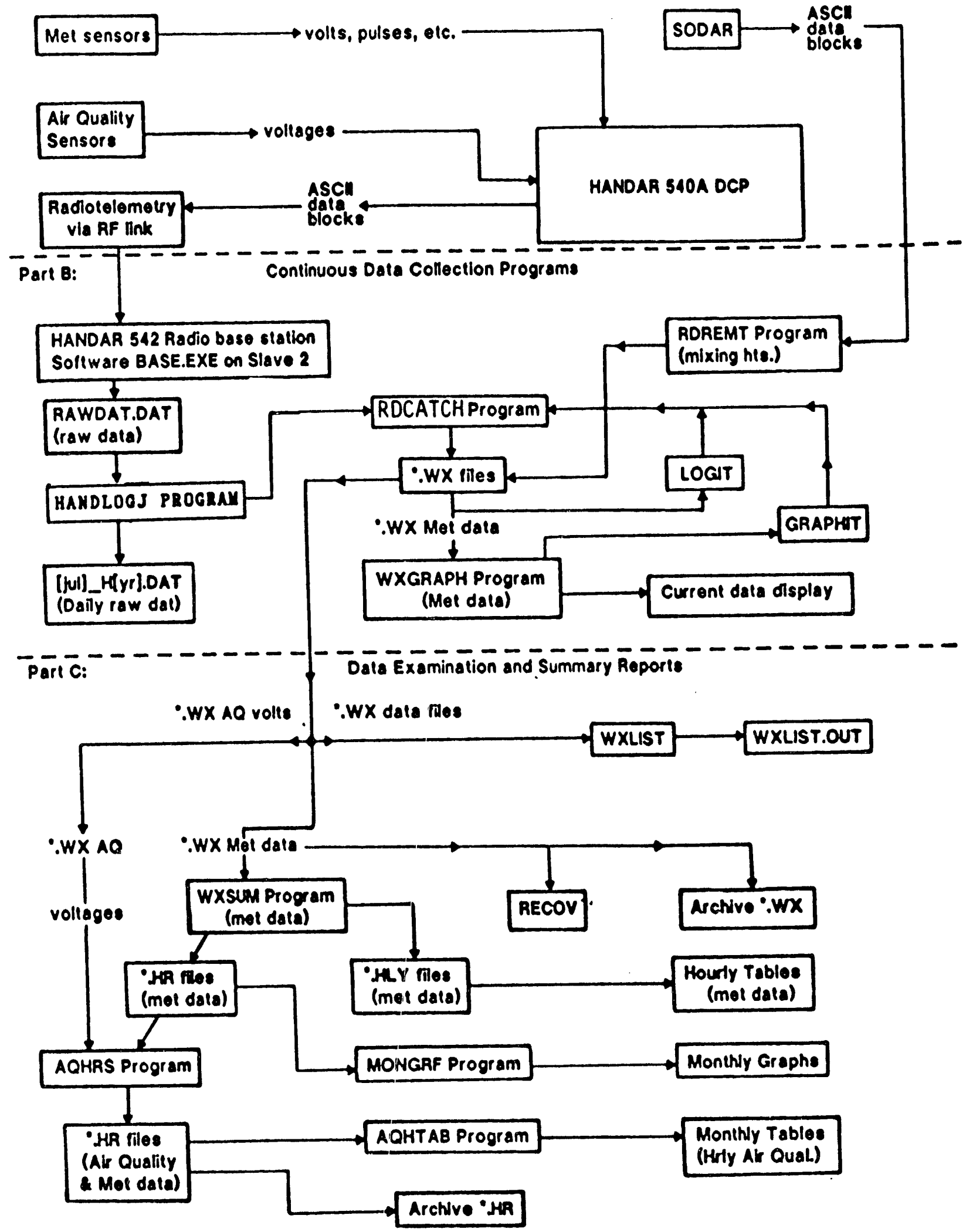

Figure VI-1. CHAWS data train and software flow chart. 


\subsection{Summary}

Each CHAWS sensor generates a voltage, series of pulses, or other signal related to the value of the parameter it is monitoring. This "raw" value is converted to digital data, and transmitted via radiotelemetry to a central location. (Details of this acquisition and transmission are discussed in Chapters II through V and in "Tooele Army Depot Air Quality Monitoring Systems User's Guide: Description, Standard Operating Procedures, and Installation Report," UCID-20988.) Then the data are quality-checked, displayed if requested, and averaged by a series of programs discussed in this chapter.

The data-processing software flowchart is illustrated in Figure VI-1, and the major programs are listed in Table VI-1. The first series of programs runs continuously in a real-time mode and handles the gathering of immediate (short-term) data. These programs are run by using either the LOGIT or the GRAPHIT batch files (depending on whether or not a graphic display is desired). The second series of programs averages and handles long-term data (hourly and longer averages) and is run when needed. These programs are started manually, but most are of the "turnkey" variety and require little input. The programs average the short-term data into hourly averages and determine the primary and secondary maxima and means for longer periods. Other manually operated programs that appear to branch off in the figure are for quality assurance $(\mathrm{QA})$ and data-recovery analysis. They are not required for data reduction, but are recommended for $\mathrm{QA}$.

\subsection{DATA FILE AND PROGRAM DESCRIPTIONS}

This section describes the role of each data file and each program in the dataprocessing "train." It also describes what each program does in the order of their operation. A summary of the programs, functions, files used, and their locations is presented in Table VI-1.

\subsection{Data Files}

A number of different storage files are used to store raw, short-term edited, and hourly average values for use in the data-processing and presentation software. These files are listed in Table VI-2. Each file in the table appears in its place in the data train shown in Figure VI-1. Data stored in RAWDAT. DAT and the *. WX files 
Table VI-1. Software summary.

\begin{tabular}{|c|c|c|c|c|}
\hline $\begin{array}{l}\backslash \text { Directory } \backslash \\
\text { Program.ext }\end{array}$ & Purpose & Limitations & $\begin{array}{l}\text { Input } \\
\backslash \text { directory } \backslash \text { files }\end{array}$ & $\begin{array}{l}\text { Output } \\
\text { \directory\files }\end{array}$ \\
\hline $\begin{array}{r}\text { HANDAR } 540 \mathrm{~A} \\
\text { internal }\end{array}$ & $\begin{array}{l}\text { Single station data } \\
\text { processing }\end{array}$ & $\begin{array}{l}\text { MET volts translated } \\
\text { and avg; } A Q \text { in volts }\end{array}$ & $\begin{array}{l}\text { Raw MET } \backslash A Q \text { signals for } \\
\text { data }\end{array}$ & ASCII data blocks \\
\hline $\begin{array}{l}\backslash S L A V E \backslash \\
\text { BASE.EXE }\end{array}$ & $\begin{array}{l}\text { Base station data } \\
\text { gathering }\end{array}$ & $\begin{array}{l}\text { No quality assurance } \\
\text { (QA) }\end{array}$ & $\begin{array}{l}\backslash S L A V E \backslash D E L T C N F . C F G \\
\text { (ASCII data blocks) }\end{array}$ & $\begin{array}{ll}\backslash S L A V E \backslash & (n=1-4 \\
\text { RAWn.DAT } & \text { or DAT })\end{array}$ \\
\hline $\begin{array}{l}\backslash \text { HANDAR } \\
\text { HANDLOGJ . EXE }\end{array}$ & $\begin{array}{l}\text { Daily raw data file } \\
\text { storage }\end{array}$ & $\begin{array}{l}\text { Use for year end (1st } 5 \\
\text { days new year) }\end{array}$ & $\begin{array}{l}\text { \SLAVE\RAWn. DAT } \\
\text { (ASCII data blocks) }\end{array}$ & $\begin{array}{l}\text { \RAWDAT } \backslash \\
\{j u I] \_H\{y r] . D A T\end{array}$ \\
\hline $\begin{array}{l}\backslash B I N \backslash \\
\text { LOGIT.BAT }\end{array}$ & $\begin{array}{l}\text { Controls data transfer } \\
\text { to *WX; some QA }\end{array}$ & $\begin{array}{l}\text { Quality Assurance for } \\
\text { MET data but not for } \\
\text { Air Quality }\end{array}$ & $\begin{array}{l}\text { ISLAVE } \backslash \text { RAWn. DAT where } \\
n=1.4 \text { or DAT }\end{array}$ & $\mid W X O B S \backslash *$.WX \\
\hline $\begin{array}{l}\backslash B I N \backslash \\
\text { GRAPHIT.BAT }\end{array}$ & $\begin{array}{l}\text { LOGIT function. } \\
\text { Graphic display of } \\
\text { MET values. }\end{array}$ & $\begin{array}{l}\text { No Air Quality data } \\
\text { MET data only; need } \\
\text { AQHTAB }\end{array}$ & $\begin{array}{l}\backslash W X O B S \backslash * \cdot W X \\
\backslash \text { HANDAR } \backslash W X C D . F I L \\
\text { \HANDAR \WXGRAPH. INI }\end{array}$ & $\begin{array}{l}\backslash \text { WXOBS } \backslash * . \mathrm{HR}, \\
\mid \text { WXOBS } \backslash * \text { *WX }\end{array}$ \\
\hline $\begin{array}{l}\text { \HANDAR } \\
\text { WXLIST. EXE }\end{array}$ & $\begin{array}{l}\text { Create listing of } 5-\mathrm{min} \\
\text { avg. } A Q \text { \& wind values } \\
\text { \& } 15-\mathrm{min} \text { avg. temp } \\
\text { and RH vals }\end{array}$ & $\begin{array}{l}\mathrm{AQ} \text { voltages NOT yet } \\
\text { translated. For } \mathrm{ppb} \text {, } \\
\text { multiply voltages by } \\
100 .\end{array}$ & $\begin{array}{l}\backslash W X O B S \backslash * \cdot W X \\
\backslash H A N D A R \backslash W X C D . F I L \\
\backslash H A N D A R \backslash W X L I G T . I N I \\
\backslash H A N D A R \backslash W X L I S T . P R E \\
\backslash H A N D A R \backslash W X C O N F . C N F\end{array}$ & $\begin{array}{l}\text { \HANDAR \WXLIST. OUT, } \\
\text { \HANDAR \WXLIST . XXX }\end{array}$ \\
\hline \begin{tabular}{l}
$\backslash$ HANDAR \} $\\
{\text { WXSUM.EXE }}$ & $\begin{array}{l}\text { Create files and tables } \\
\text { of hourly averaged } \\
\text { MET data and AQ } \\
\text { voltages }\end{array}$ & $\begin{array}{l}\text { AQ voltages NOT yet } \\
\text { translated. For Ppb } \\
\text { multiply voltages by } \\
100 .\end{array}$ & $\begin{array}{l}\backslash W X O B S \backslash * \cdot W X \\
\backslash H A N D A R \backslash W X C D . F I L \\
\backslash H A N D A R \backslash W X S U M . I N I \\
\backslash H A N D A R \backslash W X C O N F . C N F \\
\backslash H A N D A R \backslash H R C O N F . C N F\end{array}$ & $\begin{array}{l}\backslash \text { WXOBS } \backslash \text { *.HR, } \\
\backslash W X O B S \backslash \text { *.HLY, } \\
\text { MESSAGES.XXX }\end{array}$ \\
\hline \begin{tabular}{l} 
AQHRS. BAT Or \\
\AQCAL\} $\\
{\text { AQHRS. EXE }}$ & $\begin{array}{l}\text { Translate } A Q \text { voltages } \\
\text { to ppb \& elim. CALs }\end{array}$ & $\begin{array}{l}\text { Does not do CAL, } \\
\text { ZERO or SPAN }\end{array}$ & $\begin{array}{l}\backslash W X O B S \backslash * \text {.WX, *. HR } \\
\backslash \text { HANDAR \WXCONF.CNF } \\
\backslash \text { HANDAR \HRCONF.CNF }\end{array}$ & $\begin{array}{l}\backslash A Q C A L \backslash \\
A Q\{\text { mony } r\} . T A B\end{array}$ \\
\hline $\begin{array}{l}\backslash A Q C A L \backslash \\
A Q H T A B \cdot E X E\end{array}$ & $\begin{array}{l}\text { Create monthly } A Q \\
\text { table(s) }\end{array}$ & $\begin{array}{l}\text { From } 1 \text { to } 16 \text { tables } \\
\text { generated per month }\end{array}$ & $\begin{array}{l}\backslash W X O B S \backslash * \cdot H R \\
\backslash \text { HANDAR } \backslash H R C O N F . C N F\end{array}$ & $\begin{array}{l}\backslash A Q C A L \backslash \\
A Q[\text { mony } r] \cdot T A B\end{array}$ \\
\hline $\begin{array}{l}\backslash A Q C A L \backslash \\
\text { AQCAL.EXE }\end{array}$ & $\begin{array}{l}\text { Find ZERO and SPAN } \\
\text { values for daily CALs }\end{array}$ & $\begin{array}{l}\text { Stations must be } \\
\text { synchronized; no drift } \\
\text { checks done }\end{array}$ & $\begin{array}{l}\backslash W X O B S \backslash \star \\
\text { \HANDAR } \backslash W X C O N F . C N F\end{array}$ & $\begin{array}{l}\backslash A Q C A L \backslash \\
\text { AQCAL (YY).TXT } \\
\text { MESSAGES. XXX }\end{array}$ \\
\hline
\end{tabular}
\end{tabular}
\end{tabular}

ABBREVIATIONS -- DEFINITIONS

$A Q$ - Air quality

$O / P$.- Output of data

Avg - Average (mean) value(s)

QA - Quality assurance

CAL -- Calibration (may refer to a ZERO or SPAN value)

Temp -- Temperature

Ed - Edit or editing to eliminate bad data

$\mathrm{RH}$ - Relative humidity

I/P - Input of data

Val - Value

MET -- Meteorological data or systems

Vrbl -. Variable

(For actual definition of unfamiliar terms, see Clossary -- Appendix I-A) 
contain 5- and 15-minute average values of meteorological parameters and untranslated voltages that represent air-quality $(\mathrm{AQ})$ values. Data stored in the *. HR files consist of hourly average values. $A Q$ voltages on these *. $\mathrm{HR}$ files are not translated to parts per billion (ppb) until $A Q H R S$ is run.

For easy identification, the names of all edited data files include the letter " $T$ " followed by five numbers for the Julian date and year, two characters for the configuration type, and an extension describing the file type. For example, the data for Lexington-Blue Grass Army Depot for April 9, 1993, are stored in the raw file "T09992L3.WX", where 099 is the Julian date, 93 is for 1993, and L3 is the configuration type. Julian dates are given by month in Appendix I-C. Hourly data would have the same filename but a different extension name (* . HR, see Table VI-2).

\subsection{Configuration and Initialization Files}

To run certain software programs, specific configuration, initialization, and preset files must be present in the default directory (see Table VI-3). These provide the program with input specific to the particular site. The WXCONF. CNF file, for instance, provides information on the various channels of data and their respective locations and averaging periods. It also provides RDCATCH with a range of reasonable values for the meteorological parameters. Important: *. CNF files are not to be altered without prior consultation with personnel at LLNL.

The initialization files ( ${ }^{*}$. INI) provide the program with site-specific information or tell it the parameters to use to determine the output display type and layout, number of tables or graphs, etc. They can be edited with PE2 (Section 3.4). You may alter these files to fit the needs of a particular run.

The WXGRAPH. INI file contains information regarding the colors, scale, and parameters to be displayed on the WXGRAPH screen (see Section 3.1.7).

The WXLIST. INI and WXSUM. INI files contain information regarding screen colors and other options for running their respective programs-WXLIST and WXSUM (see Sections 3.2.1 and 3.2.2).

The $A Q H T A B$ initialization file, $A Q H T A B$. INI, tells the AQHTAB program to create tables for certain stations and pollutants. It provides site-specific information to the $A Q H T A B$ program and identifies the $A Q$ station numbers by providing a unique name for each station at a given site. 
Table VI-2. Data files used and created for Lexinton-Blue Grass Army Depot.

\begin{tabular}{|c|c|c|c|c|c|c|}
\hline Filename & $\begin{array}{l}\text { Exten. } \\
\text { name }\end{array}$ & $\begin{array}{l}\text { Program } \\
\text { creating }\end{array}$ & $\begin{array}{l}\text { Description } \\
\text { of contents }\end{array}$ & $\begin{array}{l}\text { Format } \\
\text { (note) }\end{array}$ & $\begin{array}{l}\text { Files } \\
\text { per yr }\end{array}$ & $\begin{array}{l}\text { Bytes } \\
\text { per file }\end{array}$ \\
\hline $\begin{array}{l}\text { RAWn. }(n=1-4) \\
\text { RAWDAT. }\end{array}$ & DAT & $\begin{array}{l}\text { BASE } \\
\text { WAITDATA }\end{array}$ & $\begin{array}{l}\text { Raw, uned. } \\
\text { data file }\end{array}$ & ASCII & $\begin{array}{l}\text { Temp } \\
(\mathrm{N} / \mathrm{A})\end{array}$ & variable \\
\hline [jul]_H[yr]. & DAT & HANDLOGJ & $\begin{array}{l}\text { Daily raw } \\
\text { data files }\end{array}$ & ASCII & 365 & 276,000 \\
\hline T[julyr]L3. & wx & RDCATCH & $\begin{array}{l}\text { 5- \& 15-min } \\
\text { MET,AQ Avg }\end{array}$ & $\begin{array}{l}\text { Dir Ac } \\
\text { binary }\end{array}$ & 365 & 16,896 \\
\hline WXLIST. & OUT & WXLIST & $\begin{array}{l}\text { 5- \& 15-min } \\
\text { MET,AQ avg }\end{array}$ & ASCII & 12 & variable \\
\hline T[julyr $] L 3$. & $H R$ & WXSUM & $\begin{array}{l}\text { Hourly } \\
\text { MET,AQ avg }\end{array}$ & $\begin{array}{l}\text { Dir Ac } \\
\text { binary }\end{array}$ & 365 & 7,584 \\
\hline $\mathrm{T}[$ julyr $] \mathrm{L} 3$. & HLY & WXSUM & $\begin{array}{l}\text { Hourly avg } \\
\text { MET tables }\end{array}$ & ASCII & 365 & 32,704 \\
\hline$A Q H R$. & $T A B$ & $\begin{array}{c}A Q H T A B \\
(1 \mathrm{Ch})\end{array}$ & $\begin{array}{l}\text { Monthly } A Q \\
\text { data by } h r\end{array}$ & $A S C I I$ & 12 & variable \\
\hline$A Q[$ monyr] & $T A B$ & $\begin{array}{l}A Q H T A B \\
(2-16 \quad \mathrm{ch})\end{array}$ & $\begin{array}{l}\text { Monthly } A Q \\
\text { data by hr }\end{array}$ & ASCII & 12 & variable \\
\hline$A Q C A L[Y Y]$ & $T X T$ & $A Q C A L$ & $\begin{array}{l}\text { Daily CAL } \\
\text { ZERO, SPAN }\end{array}$ & $A S C I I$ & 1 & 85,405 \\
\hline
\end{tabular}

NOTE: ASCII files can be edited on the screen, printed, or typed with the DOS "type" command. This cannot be done with binary files, but they are the most efficient means of storage.

ABBREVIATIONS -- DEFINITIONS (in addition to those included with Table VI-1)

$\mathrm{Ch}$ - Data channel for CHAWS system. Dir Ac -- Direct access

jul -3-digit Julian date (starting with Jan. 1) yr -- Last two digits of year
Uned -- Data not been edited for QA Temp -- Temporary file

Table VI-3. Configuration, initialization, preset and help files used.

\begin{tabular}{|c|c|c|c|c|}
\hline$\backslash$ Directory $\backslash$ filename & Exten. name & Program using & Description of Contents & Format \\
\hline$\backslash S L A V E \backslash D E L T C N F$. & $\mathrm{CFG}$ & BASE. EXE & Contains poll parameters & Binary \\
\hline$\backslash$ HANDAR \WAITCOM. & CFG & WAITDATA modem & Answers phone or calls out. & ASCII \\
\hline$\backslash$ HANDAR \PASSWORD. & $C F G$ & WAITDATA * * files & Answers phone or calls out. & ASCII \\
\hline$\backslash$ HANDAR $\backslash W X C O N F$. & $\mathrm{CNF}$ & Any using ${ }^{*}$ WX file & MET, AQ Sta. \& Ch. QA param. & ASCII \\
\hline$\backslash H A N D A R \backslash H R C O N F$. & $C N F$ & Any using * ${ }^{*}$ HR file & MET AQ Sta. \&. Ch. Config. & ASCII \\
\hline$\backslash$ HANDAR $\backslash W X G R A P H$. & INI & WXGRAFH, RDWXGINI & Graphics Settings & ASCII \\
\hline$\backslash$ HANDAR $\backslash$ WXLIST. & INI & WXLIST & Screen Settings & ASCII \\
\hline$\backslash$ HANDAR $\backslash$ WXLIST. & PRE & WXLIST & Station and Channel presets & ASCII \\
\hline$\backslash$ HANDAR $\backslash$ WXLIST. & HLP & WXLIST & Hit F1 key for this help menu & ASCII \\
\hline$\backslash$ HANDAR \WXSUM. & INI & WXSUM & Screen Settings & ASCII \\
\hline$\backslash$ HANDAR \WXSUM. & HLF & WXSUM & Hit F1 key for this help menu & ASCII \\
\hline$\backslash(A L L$ DIR.) $\backslash$ & E'RO & PE2 & Screen, Margin Settings & ASCII \\
\hline$\backslash B I N \backslash P E 2$. & HLF & PE2 & Hit F1 key for this help menu & ASCII \\
\hline$\backslash A Q C A L \backslash A Q H T A B$ & INI & AOHTAB & Output Table Specifications & ASCII \\
\hline
\end{tabular}


There are two preset files containing default settings for tasks that are commonly performed. The preset file WXLIST. PRE provides the WXLIST program with preset station and channel combinations that are commonly requested by the user. The preset file PE2 . PRO defines the function keys (F1, F2 etc.), sets the margins, and presets various other tasks to make it easier to use PE2.

The help files (*.HLP) provide the user with simple instructions to help run the programs. They usually explain the function of certain keystrokes. While it is not necessarily recommended without discussion with personnel at LLNL, the user may edit these files using PE2. They can be read by striking the $\angle F 1>$ key from their respective programs. The WXSUM. HLP file explains the keystroke commands to assist a user with running WXSUM. The PE2. HLP file displays the keystroke commands used for running PE2. It need not be modified by the user.

\subsection{Continuous Data-Collection Programs}

This section describes the software designed to operate continuously on the CHAWS data-acquisition system. The essential software will run automatically once the system is booted. Software for high-resolution graphics of recent meteorology requires a simple command to start (GRAPHIT).

\subsubsection{Single-Station Signal-Processing and Averaging Software}

As is illustrated in Figure VI-1, there is a HANDAR 540A Data-Collection Platform (DCP) at each station. This platform collects voltages, pulses, or other signals from each sensor. It includes an instruction set that translates the meteorological sensor voltages to meteorological units. It then sends these ASCII values to the HANDAR Base Station via the radiotelemetry system discussed in Chapter IV.

\subsubsection{Base-Station Software (BASE.EXE)}

Note from Figure VI-1 that ASCII data blocks are fed directly from each station's signal-processing software to the HANDAR 542 Radio Base Station via RF link. The purpose of BASE. EXE is to collect these ASCII data blocks and store them as daily files (RAWDAT.DAT) containing unedited 5- and 15-minute average parameter values. Meanwhile, it also displays them on the Alloy terminal screen as they are collected. The BASE. EXE program can also be used to reprogram the HANDAR 540A DCPs. 


\subsubsection{Batch File for Logging Without Display (LOGIT. BAT)}

This batch file runs RDCATCH. EXE (see 2.3.6) every 15 minutes for data transfer tr um the RAWDAT. DAT file to the *.WX files without graphic display.

\subsubsection{Batch File for Logging With Display (GRAPHIT. BAT)}

This batch file runs WXGRAPH. EXE (see 2.3.7). If the WXGRAPH. INI file is set for real-time operation (see 3.1.6), it calls routinely every 15 minutes for data transfer from the RAWDAT.DAT file to the *.WX files as well as the other WXGRAPH routines for graphic display.

\subsubsection{Logging of the Raw Data Files (HANDLOGJ. EXE)}

This program creates daily files of the RAWDAT data for storage in case a user is unsure about the data base. These ASCII files "[jul]H[yr]. DAT" are huge (see Table VI-2), so retaining them is not recommended unless absolutely necessary. Because permanent storage consumes a lot of time and space, only temporary storage is recommended. For permanent storage, use the * . WX files, because they are much more efficiently stored (see 4.4.1).

\subsubsection{Program for Logging Without Display (RDCATCH. EXE)}

This program copies all the data from the RAWDAT. DAT files to the direct-access binary *. WX files on hard disk. It is run by the batch file LOGIT. BAT (see above) for continuous transfer of data without graphic display or by GRAPHIT.BAT when graphic display is included.

In addition to data transfer, RDCATCH does some preliminary QA editing by screening out values of meteorological parameters above or below certain limits. These limits are specified for each instrument in the configuration file WXCONF. CNF, which is read by RDCATCH. No preliminary QA is performed on the AQ data, however, nor is it transformed from volts to concentrations.

\subsubsection{Program for Graphic Display (WXGRAPH. EXE)}


This program uses high-resolution color graphics to continuously update and display the latest weather data on the host computer's screen. It is designed for singlecycle operation but may be called by GRAPHIT for continuous operation if the review mode is specified as FALSE (see 3.1.6). When in the review mode, it can display data from any data period that has been stored in the * WX files.

The WXGRAPH program draws the site map using the available information from WXCONF.CNF and WXGRAPH. INI. Depending on the review-mode status, it then will either run continuously with data from the latest 15 -minute period or display historic data for the specified time period.

The date and time of the display being drawn are typed across the bottom of the screen and the latest wind direction arrows placed at each station. Then trajectories are drawn starting at selected locations with different colors for the different start times. A sample screen-dump printout appears as Figure VI-2.

The trajectories consist of a series of arrows (triangles) or circles for each 5-minute period and are calculated by analyzing 5-minute average wind data. They may be thought of as the plotting of successive positions of a particle released at a specified location. The release time is calculated by subtracting the time length of the trajectory from the time appearing at the bottom of the screen and adding 15 minutes. WXGRAPH uses all available wind data in a "one over distance squared" method to approximate wind between stations. The trajectory arrow is pointed downwind with the calculated wind except where the wind speed is less than 1 meter per second, when the symbol is an open circle.

Next, WXGRAPH draws several time series graphs on the right side of the screen. The data traces have time on the horizontal axis from left to right and feature the last few hours of data for wind direction, wind speed, and temperature from any set of stations. A site-wide average of all the stations may also be drawn.

\section{CAUTIONS:}

- The WXGRAPH wind trajectories may appear misleading to the untrained eye. When viewing them, please remember that they represent the path of a prior puff released at the start of the period and do not represent an instantaneous snapshot plume from a continuous release or the future path or a current release. 

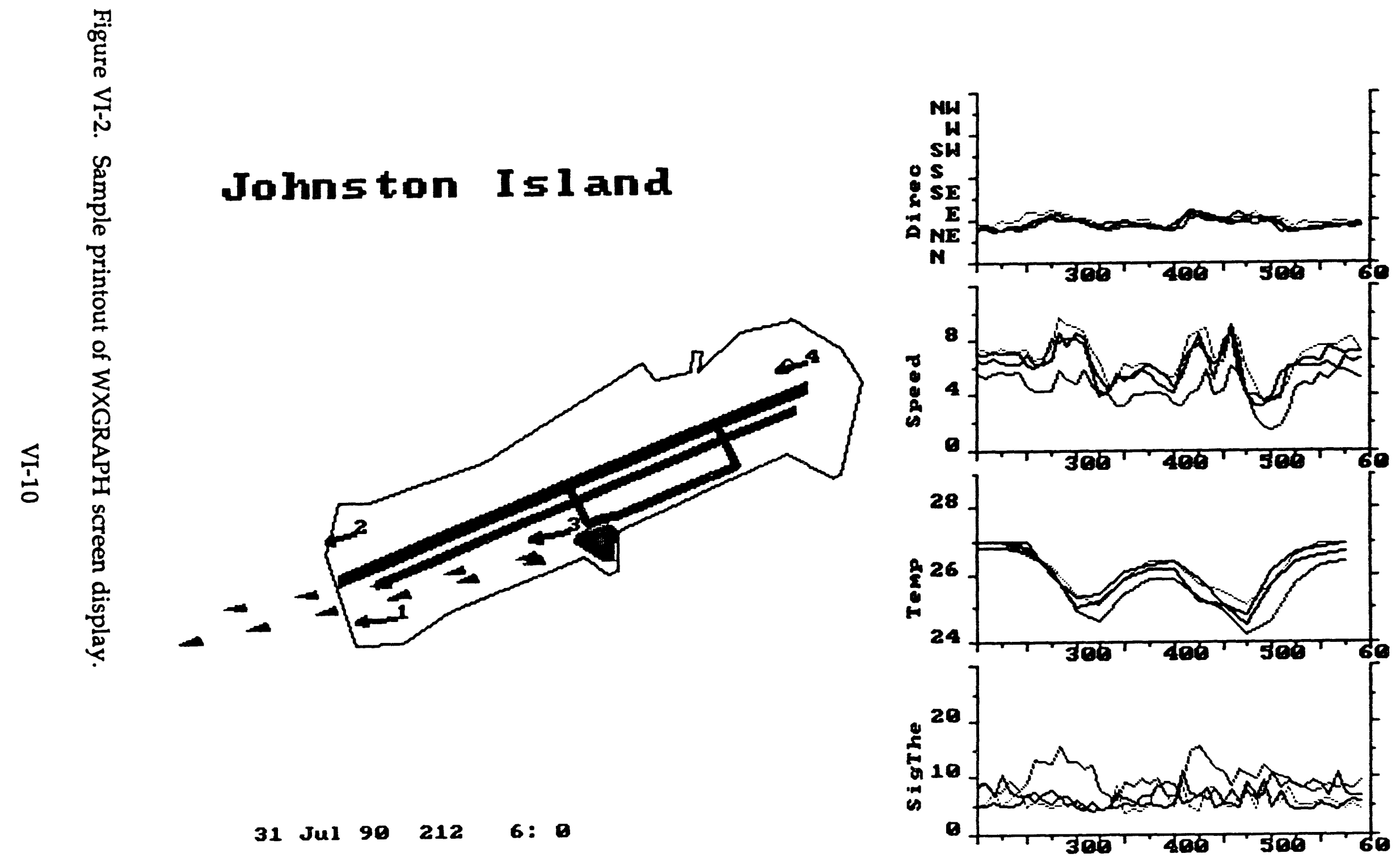
- When no station reports no wind speed and direction, the trajectory algorithm does not advance and the trajectory symbol stalls on the screen.

\subsection{Data-Examination and Summary Programs}

The software programs described in this section are used to study, reduce, and archive the data base. Data are processed and tables are created. Detailed examination of these tables and their use are described in section 4.2.

\subsubsection{WXLIST}

This is the data-listing program for the CHAWS system. It enables the operator to view the 5- and 15-minute weather data (or air-quality voltages) stored in the * wX files. Data can be output to three devices: the screen, a file, and the printer. This will be the handiest program for examination of the short-term data base within the last few hours.

\subsubsection{The Hourly Averaging Program (WXSUM)}

The WXSUM program reads meteorological parameters and AQ voltages from the *. WX files and averages them. It can create two types of files-* . HR and *. HLY-for storage and/or for printing the averages out as tables. The files created have similar names to the *.WX files except for the extensions (see Table VI-2). While the ${ }^{*}$. WX and * . HR files are in direct-access binary format, the * . HLY files are in ASCII format.

For each hour, from the selected start date to the selected end date, four 15-minute average values of temperature and humidity and twelve 5-minute average values of each wind and air-quality parameter are averaged. This reduces the number of values needing storage (the file lengths of the * WX and the *. HR files appear in Table VI-2) and prepares data files for other programs.

WXSUM first checks to see that the start date is before the end date. Then the program finds the start date and computes hourly averages. Tables are made and sent to their selected destinations. After the last hour of the last day, the program closes all open files and stops. The *. HLY and *. HR files should appear in the WXOBS subdirectory.

\subsubsection{The AQ Hourly Translation Program (AQHRS)}




\subsubsection{The AQ Hourly Translation Program (AQHRS)}

Because the WXSUM program described above does not change AQ voltage outputs to direct readings of concentration, it is necessary to run another program before the $A Q$ values on the *. HR files can be interpreted with any validity.

The AQHRS program creates hourly averages of $A Q$ concentrations by reading the raw ${ }^{*}$. WX AQ voltages data, multiplying them by 100 to obtain parts per billion (ppb), and eliminating ZERO and SPAN values gathered during the daily CAL checks. The data are processed minimally and are intended only for immediate use by on-site personnel.

The $A Q H R S$ program reads raw 5-minute-average $A Q$ and 15 -minute-a verage CAL voltage data from the *.WX file. The CAL channel (calibration channel 2 ) for each station is checked to see if it indicates a calibration. Data gathered during CAL periods are replaced with null data characters (-9999.), while all remaining data are averaged for each one-hour period through the ending time of the last *. WX or * . HR file (whichever comes first). The program also translates the hourly average voltages to ppb by multiplying the values by 100 .

Because data are read in binary form from the * wx file and written onto the *. HR file, the possibility of duplicate runs and double conversions is eliminated.

\subsubsection{The Hourly Data Tabulation Program (AQHTAB)}

This program displays hourly average $A Q$ values, including the daily and monthly maximum, second maximum, and mean (average) concentrations, for any or all monitored pollutants at any or all $\mathrm{AQ}$ stations for a given month. (The second maximum is simply the second highest hourly concentration for the 24-hour period (midnight to midnight) or for the hour of the day involved.)

Output consists of a table or a set of 16 tables, saved as files on hard disk under the filename $A Q H R$. TAB (for single tables) or $A Q$ [mony $r$ ] . TAB (for a set of up to 16 tables), where "mon" is the 3-letter abbreviation for the month and " $y r^{\prime}$ " is the last two numbers of the year. These tables can be printed directly with a PRINT program (Section 3.3.5) or by using PE2 (Section 3.4). Each table displays all the hourly concentrations in parts per billion by volume (ppbv) for a given pollutant at a given station for the month by time of day (across the page) and day of month (down the page). Table VI-4 is an example of such a table. 
voltages. Most of these will be about one one-hundredth of the observed ambient concentrations in ppbv (or of the CAL ZERO or SPAN values if in the CAL mode).

\subsubsection{The Data Recovery Analysis Program (RECOV)}

A *. Wx file can be thought of as a table with 96 rows (or lines) corresponding to the 9615 -minute periods in a day and one column for each instrument in the field. Because of data-logger failure, transmission problems, or instrument failure (usually a rare occurrence), $a *$. WX file may not be complete. By running RECOV, the operator may keep track of the data recovered by the CHAWS system and stored in *. WX files.

The RECOV program reads the *.WX files and generates daily tables showing the status of each 15-minute period for each instrument. Table VI-5 is a sample of such a table. The program interchanges the rows and columns, so the tables contain 96 columns (one for each 15-minute period) and a row for each instrument (including all the stations). It writes the letter " $\mathrm{M}$ " if data are missing and the ASCII 250 symbol "-" if they are present. It writes these tables to a file "RECOV. OUT".

The date, filename, and percentage of data recovered appear at the top of the page, with hour of the day listed across the page at several levels. The index, station number, and channel-type number appear in the left margin, while the station number and instrument-type name appear on the right.

\subsection{PROGRAM OPERATION}

This section describes the operational aspects of the data-processing software. One subsection is dedicated to eich program. Section 3.1 describes the programs that can be run in a real-time mode (including GRAPHIT and WXGRAPH). They are run daily to handle the incoming data. Section 3.2 describes the operation of programs that are run independently of the immediate data. Some of this software produces summary files with tables or graphs. These graphs are described in detail in Section 4.

Before running these programs, one should read and understand Section 2.0 (to see what the programs do) as well as this section. 


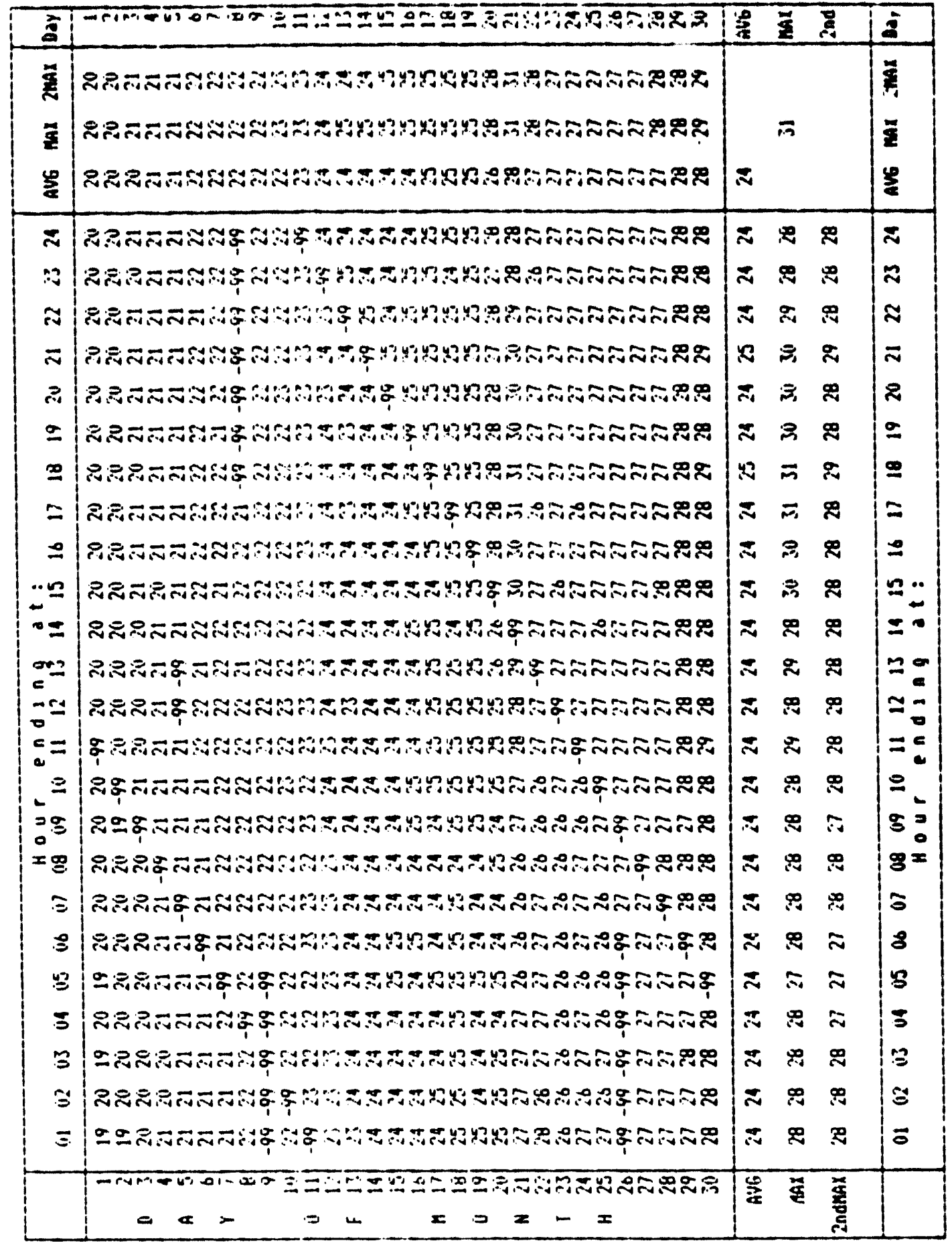




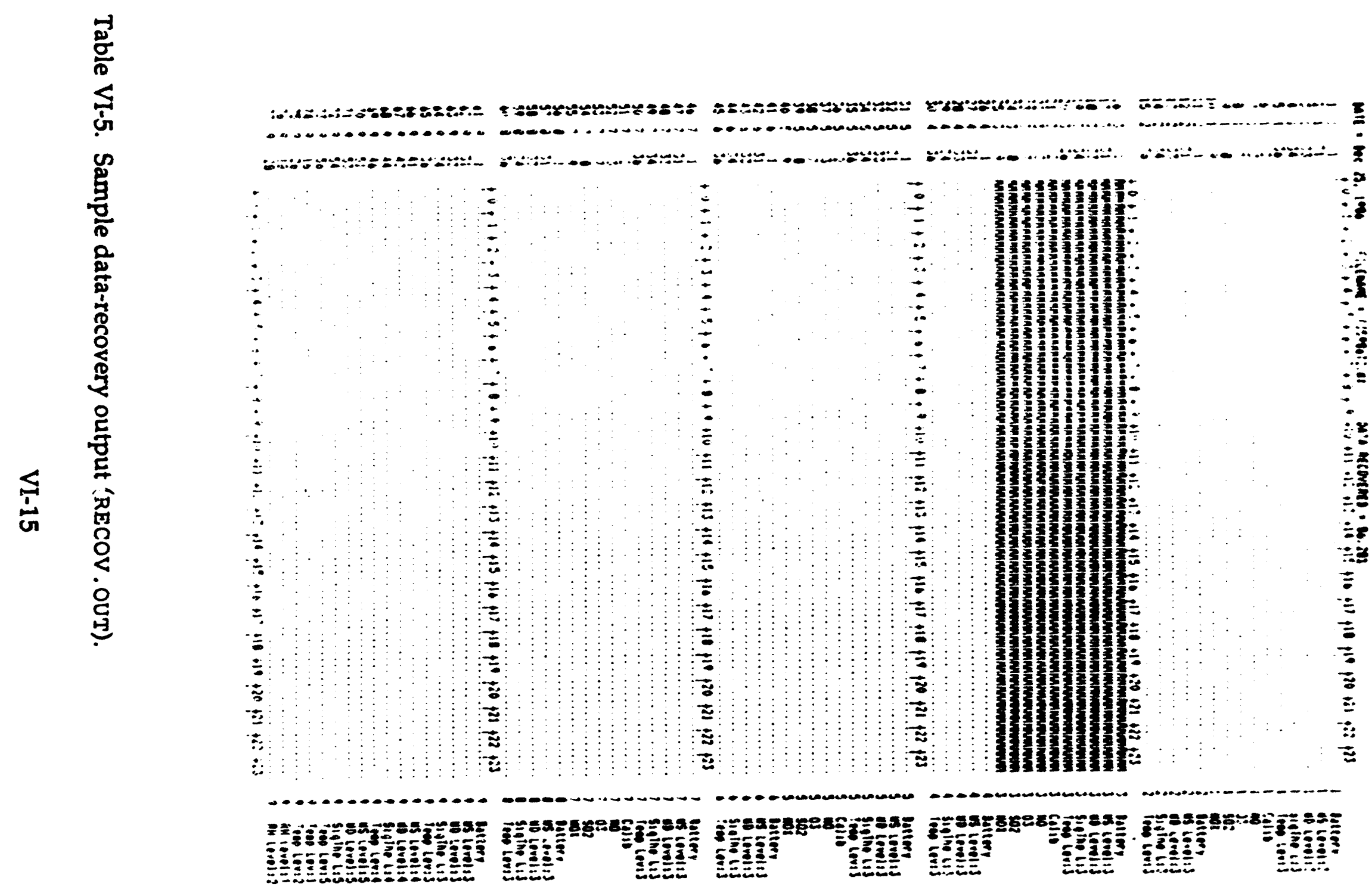




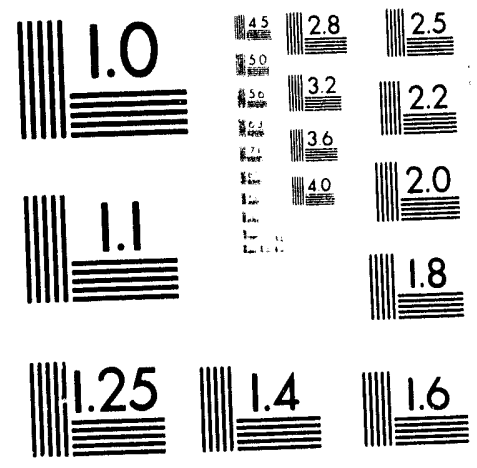



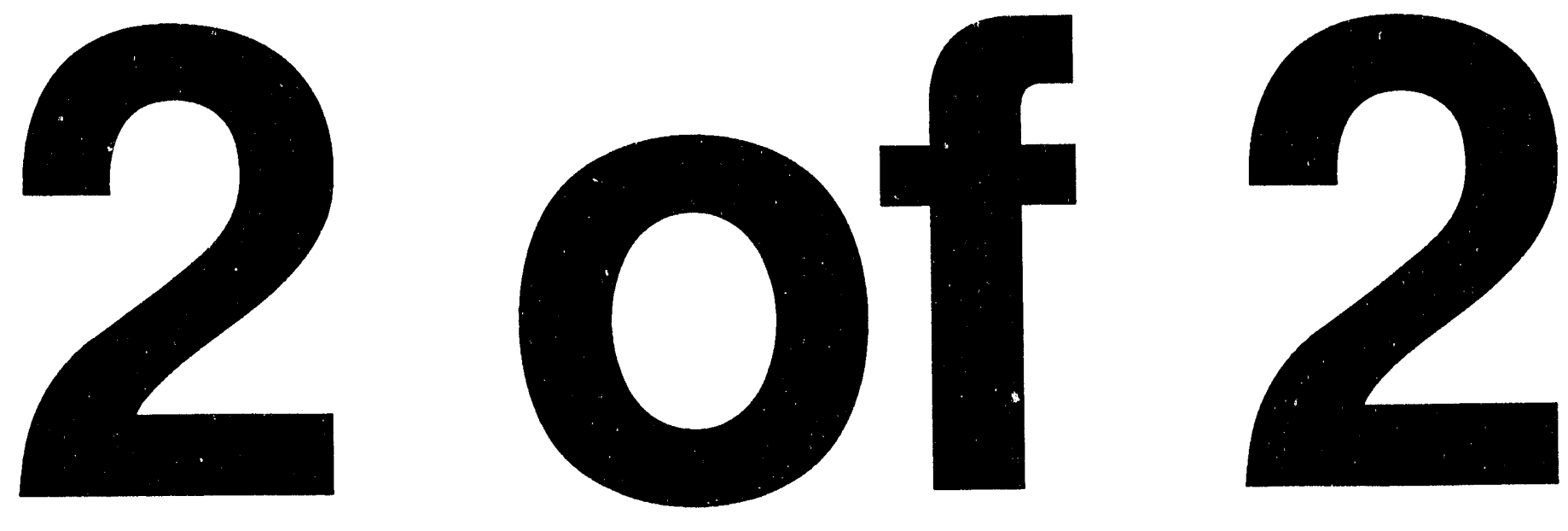


\subsection{Continuous Data-Collection Programs}

The programs described in this section provide continuous data display and collection for the CHAWS system. Careful and scrupulous examination of the data in the graphic display mode by a trained expert is highly recommended to obtain proper quality control of the data base.

The programs described in this section operate automatically and continuously once started. They are started either at boot-up or at execution of a single command.

\subsubsection{BASE.EXE}

Data collection at the HANDAR 542A Radio Base Station is started by the CHAWS data-acquisition computer when it is powered up or rebooted. When this happens, a program called BASE. EXE is run. It should enter the data-gathering mode and start scanning (polling) the stations for data. Examine the figures in Chapter I, Section 3.5 to make sure the screens each appear as they shruld.

If the computer operates, but polling does not start, it could be that the correct files have not been loaded. The procedures for file loading and troubleshooting appear in Chapter V.

If BASE. EXE has been stopped for any reason, it may be restarted by rebooting the data-acquisition computer. This is done by hitting the $\langle\operatorname{Ctr} l\rangle,\langle A l t\rangle$, and $\langle$ Del $\rangle$ keys on its keyboard simultaneously between data polls. (WARNING-This will erase all volatile memory; see Chapter I, Section 3.3 for details). If data logging does not commence at the next even 15-minute interval, consult the Troubleshooting guide in Chapter V, Section 3.

\subsubsection{LOGIT.BAT}

This batch file automatically performs all of the functions of GRAPHIT. BAT, below, with the exceptions of the graphics display on the host computer. It should be run in place of GRAPHIT when the graphics display is not required. When using this program, follow all of the instructions given for GRAPHIT. BAT. 
This program is run by the batch file LOGIT.BAT and GRAPHIT.BAT for continuous transfer of data to the *.WX files when the CHAWS system is left unattended. It may be started independent of this batch file by typing the DOS command "RDCATCH" from the HANDAR directory. No further input is required.

\subsubsection{HANDLOGJ.EXE}

This program is necessary to operation of the CHAWS system. It is run automatically by LOGIT. BAT and GRAPHIT. BAT to create temporary RAW. DAT and daily ASCII files from the RAWn. DAT and RAWDAT.DAT files. The daily files are named in as "[juI]_H[Yr].DAT" and are used for storage if a backup to the data base is needed. These files are created daily and should be erased five days later because the files are large and are a duplication of data that has been stored in binary format, which is more efficient. Prior to deletion, RECOV should be run to determine if all records have been stored in binary format. Section 3.4 describes PE2, which has procedures for editing and storing the daily ASCII files.

\subsubsection{GRAPHIT.BAT}

This batch file runs the WXGRAPH program to display current data as shown in Figure VI-2. Its operation will also replace the functions of LOGIT. Please run it when on site to keep track of data acquisition.

Before starting GRAPHIT, you must terminate LOGIT by hitting $<$ Ctrl $>$ and $<$ Break $>$ (Scroll Lock) simultaneously. (Before doing this, make sure the hard lisk does not access data for at least several seconds.) You should then get a DOS ompt character set that ends with " $>$ ". If rebooting has not been done for $12 \mathrm{~h}$. ux or more, you should insure that accumulated time and data errors are eliminater $b_{3}$ d d the $\langle\operatorname{Ctrl}\rangle,\langle A 1 t\rangle$, and $\langle$ Del $>$ at the same time between data polls se Corpterl,

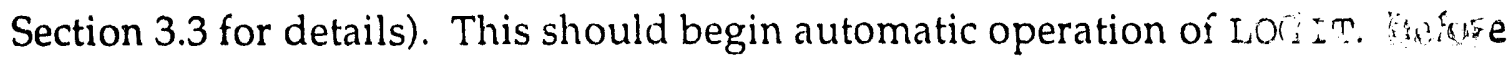
starting GRAPHIT, you must now terminate LOGIT as described abu ve

Now start GRAPHIT by typing its name after the promf w in' 'itin. $<$ Enter $>$. (If not in the root or HANDAR directory, type "CD $\backslash \operatorname{HANDAR}^{\prime \prime} \cdots i, \ldots$ before typing "GRAPHIT".) Verify its operation by the appearance of a map on tha screen (see the next subsection).

\subsubsection{WXGRAPH. EXE}


For near real-time operation, start this program by typing "GRAPHIT" from the root or HANDAR directory (see above). The default initialization file WXGRAPH. INI must have the review mode as FALSE (see 3.1.7 below).

For the review mode, type "WXGRAPH" from the a directory after making sure the initialization file shows the review mode as TRUE.

Verify its operation by the appearance of a map on the screen. After drawing the map, the program draws trajectories and time series (see Section 2.3.6 and Figure VI-2).

\subsubsection{WXGRAPH. INI}

The purpose of the WXGRAPH initialization file WXGRAPH. INI is to tell the WXGRAPH program what parameters, time scales, and colors to use in the graphic display.

To examine this file, get in to the HANDAR directory (if not already there) by typing "CD $\backslash$ HANDAR" <Enter> Now type "PE2 WXGRAPH. INI". The file should then appear on the screen. If not, see Section 3.4 (PE2). Edit it using PE2, and you must SAVE or FILE it by typing "SAVE WXGRAPH. INI NOTABS" on the PE2 command line (unless the second line of your PE2. PRO file says "S BLANKCOMPRESS OFF", per subsection 3.4.6). If you do not do this, strange things may happen to this file and the WXGRAPH program. It will not know what it is reading, and many errors will occur. $<F 2>$ or $\angle F 3>$ may be used to get "SAVE" or "FILE" on the command line, respectively.

According to current needs, you may change various numbers and labels in order to change trajectory locations, starting times, and colors, as well as many parameters associated with the time-series graphs. Table VI-6 shows an abbreviated version of the file with one-line descriptions in the right-hand columns.

It is important to remember that WXGRAPH is expecting these parameters in a certain order. If a line of WXGRAPH. INI is moved, deleted, or added, WXGRAPH may not be able to read the data properly. When more than one number is required on the same line, the numbers must be separated with commas. Labels must be delimited at both ends with single quotes ( 1 ), and the length of each label is limited to 8 characters for the map file and 6 for the title. Four groups of items can be 
Table VI-6. Sample initializing file for WXGRAPH (WXGRAPH. INI).

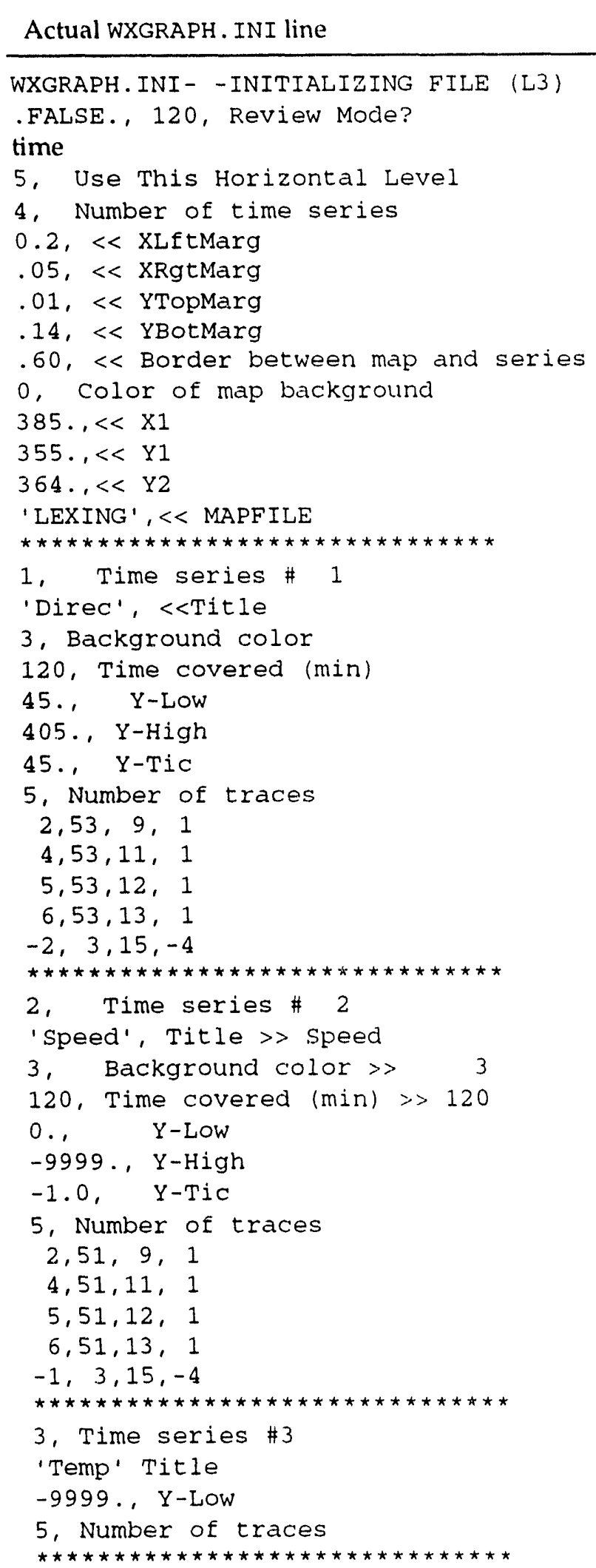

Short Description (see text for details)

Remark Line; no effect on WXGRAPH

FALSE=real-time;TRUE=review; $120=\mathrm{cycl}$

Level for wind trajectory data

Number of graphic param.plots (always 4)

Position of time-series axes

in boxes (no reason to change)

$0=$ far left; $1=$ far right; $60=$ right of $\mathrm{ctr}$.

$0=$ black, $1=$ blue, etc. (see Table VI-7)

Right edge of map UTM coord., kilometers

Bottom edge of map UTM coordinate, $\mathrm{km}$.

Top edge of map UTM coordinate, $\mathrm{km}$.

Map filename (see Table VI-8)

Top plot (highest on page)

Direc $=$ wind direction; $\operatorname{MAX} 6$ char.

3 = Cyan (see Table VI-7)

$120=2$ hours (recommended); $30-360$ OK

Bottom of WD scale, deg (leave $45=\mathrm{NE}$ )

Top of wind dir scale, degrees $(405=\mathrm{NE})$

Tic mark interval (must be 45 degrees)

$5=5$ parameter traces plotted (MAX of 5)

Sta.\#, Ch.\# (53=WD), Color (Tab.VI-7),

Data Point Mark (Table VI-10)

Sitewide Avg(Tb VI-9),\#Avgs, color, mark

Next plot (2nd highest on page)

Speed=wind speed; $\max$ of 6 char.

$3=$ Cyan (see Table VI-7)

$120 \mathrm{~min}(2 \mathrm{hr}$ ) recom.; $30-360 \mathrm{~min}$ OK

Bottom of wind speed scale; keep $0 \mathrm{mps}$

$-9999 .=$ Set top of WS scale abv max. value

Tic mark interval (-1 with any vrbl scl)

Must match no. of lines below (up to 5)

Sta.\#, Ch.\# (51=WS), Color (Tab.VI-7),

Data Point Mark (Table VI-10)

Sitewide Avg (Tb VI-9),\#Avgs, color, mark

Third plot on page

Temp = temperature ( $\mathrm{Ch} \# 56$ for level 5)

$-9999 .=$ Set top of Temp. to incl. min.

(For these 6 lines, see above) 
Table VI-6 (continued). Initializing file for WXGRAPH (WXGRAPH. INI).

\begin{tabular}{|c|c|}
\hline Actual WXGRAPH. INI line & Short Description (see text for details) \\
\hline \multicolumn{2}{|c|}{ 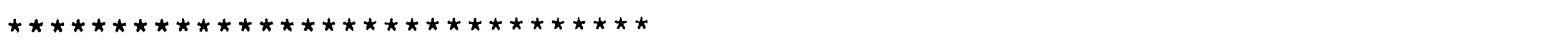 } \\
\hline 4, Time series \#4 & Fourth plot on page \\
\hline 'SigThe', Title & SigThe=sigma theta ( $\mathrm{Ch} \# 54$ for level 5 ) \\
\hline $80 ., \mathrm{Y}$-High & $801=$ maximum value; Do not change \\
\hline 10.. Y-Tic & $101=$ Tic interval; Do not change \\
\hline \multicolumn{2}{|c|}{ 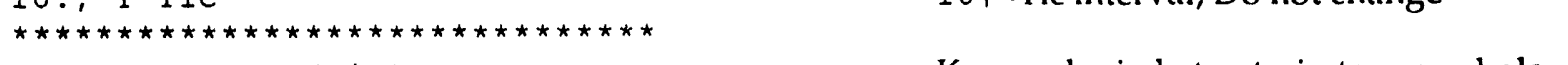 } \\
\hline 1, step every (min) & Keep as $1 \mathrm{~min}$ betw. trajectory symbols \\
\hline 1. Number of trajec & 1 traj drawn each loc. $(0-10 ; 2-3$ recom.) \\
\hline 60,11 & Traj. Time $(20,30,40,60 \mathrm{~min}$ OK), Color \\
\hline \multirow{2}{*}{\multicolumn{2}{|c|}{$\begin{array}{l}2, \text { Number of locations } \\
390.7,361.2\end{array}$}} \\
\hline & \\
\hline $388.0,359.0$ & Start Locations in UTM coord., $\mathrm{km}$. \\
\hline $388.0,362.0$ & (\#lines I No. of locations above) \\
\hline \multicolumn{2}{|c|}{ 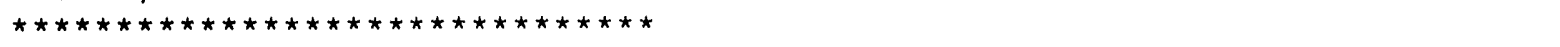 } \\
\hline
\end{tabular}

changed: miscellaneous, map, time series, and trajectories. Each of these groups is described below.

3.1.7.1 Miscellaneous. The first 9 lines of WXGRAPH. INI contain miscellaneous information. The first line is a remark line and is not read by the program; use it for any information you want to display in the file itself, such as site name or time the run was made. The next line determines the mode of display (review or real time). The question is posed "Review Mode?". The answer (which appears before the cycle-time value and the question itself) is ". TRUE." for review mode or ". FALSE." for real-time mode. (For operation of GRAPHIT, "FALSE" must be specified. If review mode is selected, the WXGRAPH program should be started directly.) The time per cycle (cycle time) must also be specified. The cycle time is the amount of time added to the reference time when drawing the next WXGRAPH screen, which is not automatic when in review mode.

The next line determines the horizontal instrument level used for data when a trajectory path is drawn.

The wind-direction break tells WXGRAPH when to add 360 to wind directions so the top and bottom edges of the graph are not exactly north. This greatly reduces the amount of jumping across the scale that would be often done with borders at north or east due to the frequent winds from these directions at most sites. At Lexington-Blue 
Grass, the wind-direction break is set to zero, so the top and bottom of the wind direction graph represents wind coming from true north.

The number of time-series graphs should always be four.

The next four lines determine the position of the times-series axis inside the graph windows. There should be no reason to change these numbers. The border between the time-series graphs and the map is specified next as a decimal number from 0 (far left) to 1 (far right).

The period end-time at the far right of any series graph is also displayed on the bottom left of the screen, below the map. The number 0.60 shown in Table VI- 6 will result in graphs being drawn just to the right of the center of the screen.

3.1.7.2 Map. The map background color (see Table VI-7) must be chosen to contrast with the map colors. The next three lines represent the map boundaries ( $\mathrm{x} 1$, $Y 1$, and $Y 2$ ), which can be changed using PE2. $X 1$ is the left edge, $Y 1$ is the bottom, and $Y 2$ is the top. $X 2$ is the right edge and is calculated by WXGRAPH to avoid distortion of the map.

The units used on the map are UTM coordinates, with units expressed in kilometers. The map filename is presented as a quoted string. See Table VI-8 for a list of the CHAWS sites and corresponding map file names. The map files should be in the MAPS subdirectory.

Table VI-7. List of color index numbers.

\begin{tabular}{clcl}
\hline Index & Color & Index & Color \\
\hline 0 & Black & 8 & Gray \\
1 & Blue & 9 & Light blue \\
2 & Green & 10 & Light green \\
3 & Cyan & 11 & Light cyan \\
4 & Red & 12 & Light red \\
5 & Magenta & 13 & Light magenta \\
6 & Brown & 14 & Yellow \\
7 & White & 15 & High-intensity white \\
\hline
\end{tabular}


Table VI-8. Map filenames.

\begin{tabular}{ll}
\hline \multicolumn{1}{c}{ Site } & Use map file \\
\hline Tooele & LRGRSCL \\
Edgewood & EL \\
Pine Bluff & PINEB \\
Lexington & LEXING \\
Johnston Island & JOHN \\
\hline
\end{tabular}

3.1.7.3 Time series. You can edit the WXGRA PH. INI file, line by line (see Table VI-6), using PE2 (Section 3.4) for the desired time-series graphs. The parameters for these plots are specified on lines between the asterisk lines $(\star \star \star \star \star \star \star \star \star \star \star \star \star)$. Each time-series graph corresponds to an information package in the initialization file, starting with the time-series number. The time-series title describes the parameter to be plotted. It appears on the second line inside quotes and must not be greater than six characters. The background color is next (see Table VI-7 for colors). The axes and title are drawn with black (except if black is the background color, in which case they appear green). The amount of past data drawn can be changed in the next line. Two hours $(120 \mathrm{~min})$ seems to be a good balance between amount of data shown and the time it takes to draw a graph.

For most parameters, the vertical axis limits Y-Low, Y-High, and Y-Tic should not be changed. However, certain parameters that vary (e.g., wind speed) can have the bottom fixed at zero and the top programmed to vary with the maximum wind speed. In such cases, enter a Y-High of -9999 for the top or a Y-LOw of ZERO for the bottom.

The tic-mark interval, Y-Tic (for the notches on the scale), can also be adjusted for wind speed but should stay the same for wind direction and most other parameters.

When one or both of the axis limits is allowed to vary with the data, the tic-mark interval ( $\mathrm{Y}-\mathrm{TiC}$ ) should be set to -1 . This tells the program that it can also change the tic interval but that the smallest it should be is 1 (the absolute value of $\mathrm{Y}-\mathrm{TiC}$ ). The tic interval should always be 45 on a wind-direction plot.

The "Number of traces" line in the WXGRAPH. INI file contains information the program uses to draw actual graphs of time series traces (usually on the right side of the screen). As can be seen in Table VI-6, there can be up to 5 traces per graph with one line below to describe each trace. 
Each of these lines should contain 4 numbers for each trace: 1 , station number; 2 , channel number; 3 , color; and 4, data-point style (appearance of data marks such as stars, crosses, etc.). A negative station number is used to depict a site-wide average. It is followed by the number of values averaged in each 15-minute data period, rather than by channel number. (Because data from the anemometers are in 5-minute averages, 3 is used in Time Series No. 1 (Table VI-6) because there are three 5-minute averages in 15 minutes.) Table VI-9 is a list of negative station numbers and the corresponding parameter being averaged.

The channel number referred to above is the standard CHAWS channel number (e.g., 31 is wind speed at level 3; 56 is temperature at level 5). The trace color should contrast with the time-series-graph background color. Traces from the same station should have the same color for each plot. See Table VI-7 for a list of colors. The datamarker types appear in Table VI-10.

3.1.7.4 Trajectories. Near the bottom of the initializing file are a few lines that give the operator the ability to change the way the trajectories are drawn. The first line contains the time-step number between data markers. This should always be 1 ( 1 minute).

The next line sets the number of trajectories to be drawn at all locations. This number must be between 0 and 10, although drawing more than four trajectories is both time consuming and covers too much of the map. Two or three trajectories at all start locations give the best results.

Table VI-9. Negative station num bers for site-wide averages.

\begin{tabular}{cl}
\hline Station No. & Parameter \\
\hline-1 & Wind speed \\
-2 & Wind direction \\
-3 & Sigma theta \\
-4 & Temperature \\
-5 & Relative humidity \\
\hline
\end{tabular}


Table VI-10. Data-line marker types.

\begin{aligned} & \hline Value Trace drawn with \\ & \hline-4 Crosses \\ &-3 Stars \\ &-2 Rectangles \\ &-1 Circles \\ & 1 Dotted line \\ & 2 Dashed line \\ & 3 Solid line \\ & \hline\end{aligned}

The next line(s) describes the color and length of time of the trajectory. The number of these lines of color information must be equal to the number of trajectories. Typical time lengths are 20,40, and 60 minutes for three trajectories and 30 and 60 minutes for two. Refer to Table VI-7 for the numeric values of the 16 colors.

The number of locations to start a trajectory and a list of those locations appear at the bottom of the initializing file. WXGRAPH uses UTM coordinates (E-W then N-S) with units of kilometers. The number of coordinate pairs should be equal to or greater than the number of locations. Although WXGRAPH can accept 0 to 10 locations, 3 locations that encircle the site give the best results.

\subsection{Data Examination and Summary Programs}

The purpose of the software described in this section is to study, reduce, and archive the data base. As with Section 3.1, careful examination by a trained expert of the tables discussed below is highly recommended for quality-control purposes.

This software operates independently of the CHAWS data-acquisition system. Because the host computer and Slave 2 terminals are presumed to be involved with data acquisition, these programs should be run from the Slave 1 keyboard (unlike those discussed above).

Before running any of the programs discussed below, check the input file list given in Table VI-1 to be sure all the input files are in the correct subdirectories. In most cases, the input files will be in the HANDAR subdirectory and the output files will be written to the WXOBS subdirectory. 
When answering interactive user-input questions on the screen, you may use " $\mathrm{Y}$ " or " $\mathrm{y}$ " for "yes" and " $\mathrm{N}$ " or " $\mathrm{n}$ " for "no".

Many of these programs produce tables showing data for 5-, 15-, or 60-minute periods over a day or month. Detailed use of these tables is discussed in Section 4.2.

\subsubsection{WXLIST.EXE}

WXLIST is to be run from the HANDAR subdirectory to provide readily available examination of the short-term *.WX file data. Before running it, make sure that the following files are in HANDAR: WXLIST.EXE, WXLIST. HLP, WXLIST. PRE, WXLIST. INI, WXCONF. CNF, and WXCD. FIL. Also be sure that WXCD. FIL has 20 lines by viewing in PE2 (see PE2 instructions in Section 3.4). If not, add lines until there is a total of 20. Line 20 should look like this: "20_WXLIST $C: \backslash$ HANDAR". All the *. WX files to be read must be in the WXOBS subdirectory. The same version of WXLIST will work at all the sites. The WXLIST preset file (WXLIST. PRE, subsection 3.2.1.4) is site specific and user defined.

To run WXLIST, type "wXl ist <Enter>". You should now see a user input screen display (Figure VI-3). Changeable parameters are highlighted in green, and the cursor parameter is highlighted in white. Changeable parameters consist of the following:

Start date and time

Amount of time (hrs and mins)

Station number

Output destination (screen, file, and/or printer)
Stop date and time

Number of channels

Channel number and name

3.2.1.1 Changing Input Parameters. To move the cursor from one parameter to another, use the $<t a b>$ and $<$ shift $><t a b>k e y$. Change parameters by using the Up and Down Arrow keys and the Page Up ("<PgUp>") and Page Down ("<PgDn>") keys on the right side of the keyboard. In general, the $<$ PgUp $>$ and $<$ PgDn $>$ keys increment the selected parameter by a larger amount. The increments by which the values are changed appear in Table VI-11. Correct, pre-defined keystrokes respond with a highpitched "beep"; undefined keystrokes respond with a low-pitched "blah". 


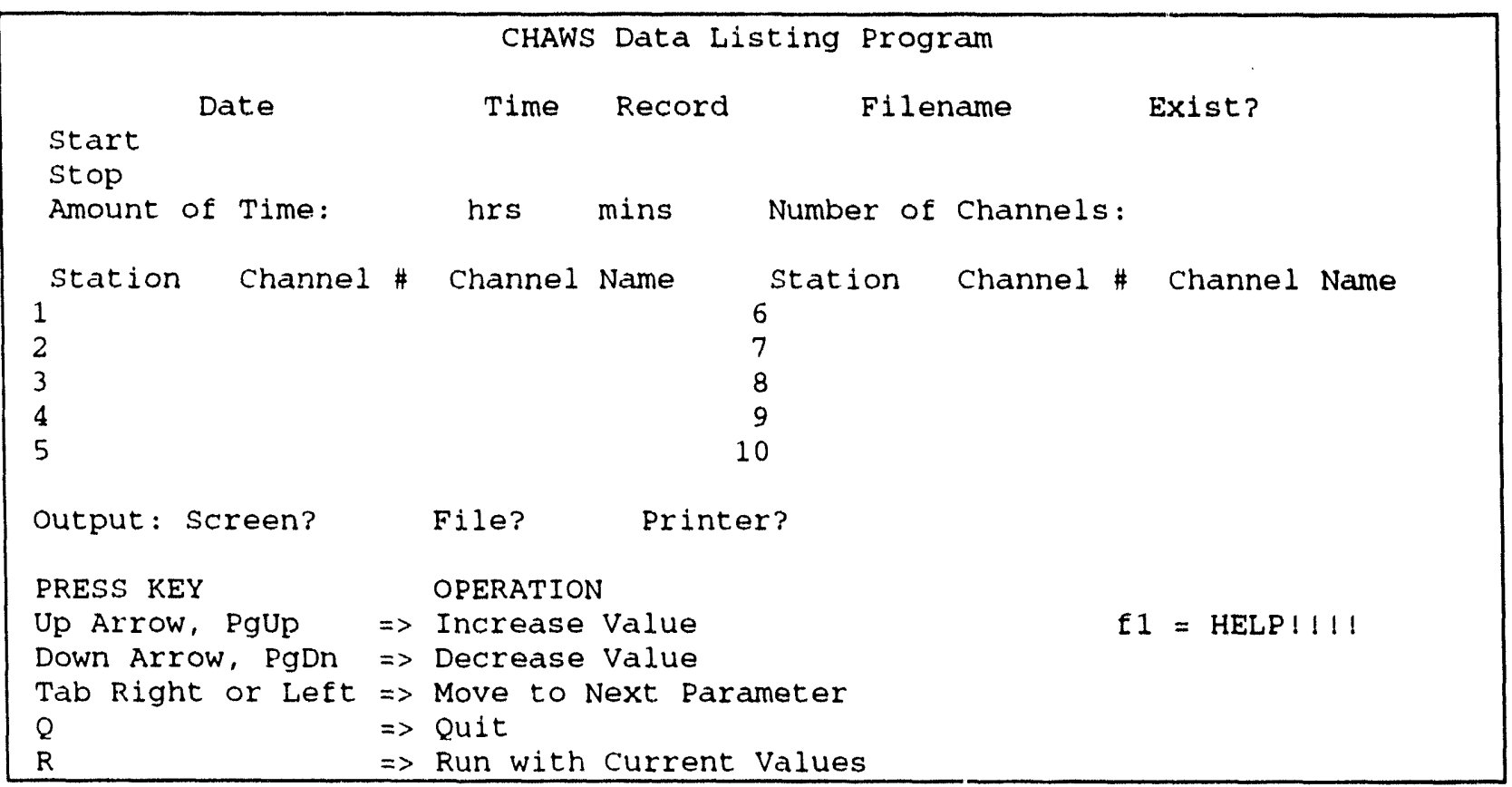

Figure VI-3. WXLIST user-input screen display.

Table VI-11: WXLIST input-screen display changes.

\begin{tabular}{llccc}
\hline & & & Channel & Station \\
& & $\begin{array}{c}\text { Date } \\
\text { (days) }\end{array}$ & $\begin{array}{c}\text { Time } \\
(\text { mins })\end{array}$ & $\begin{array}{c}\text { \#Channels } \\
(\mathrm{n})\end{array}$ \\
\hline Up Arrow & $(8)=$ Increase value by & +1 & +15 & +1 \\
Down Arrow & $(2)=$ Decrease value by & -1 & -15 & -1 \\
$<$ PgUp> & $(9)=$ Increase value by & +7 & +60 & +1 \\
$<$ PgDn> & $(3)=$ Decrease value by & -7 & -60 & -1 \\
\hline
\end{tabular}

The default settings for the WXLIST program are as follows:

- Start date/time - current date/time less one hour.

- Stop date/time - current date/time.

- Number of channels - one.

- Sta/chan combination - usually Station 1/Channel 1 (Battery).

- Output - to screen, to file "WXLIST.OUT", but not to printer. 
As start date/time and stop date/time are changed, the amount of time run (end time minus start time) changes accordingly. Although this amount can be negative while searching through the dates/times for the right combination, if you try to run it with a negative amount of time (start date and end dates reversed), WXLIST will create the error message "Check Start/End Dates" or "Check Start/End Times" in the upper left-hand corner of the screen (above the start date). This message will also prompt you as to where to look for the error. If you change the amount of time directly by using the arrow keys, the start date/time will remain fixed but the end date/time will change to reflect this change.

The number of channels can range from 1 to 10. Pressing the down arrow from 1 will give you 10; pressing the up arrow from 10 will give you 1 . As the number of channels changes, the station/channel number spaces below are filled or deleted with default values or with the most recent values. (For screen and printer output, it is recommended that you use only up to eight channels to keep the tables clear. Otherwise, the numbers will wrap-i.e., they will go to the next line without printing under the right headings.)

This is the time to use the arrow keys to select station and channel numbers. Move the cursor to highlight a station space. Select the desired station by using arrow keys. Now move to highlight the corresponding channel-number space $(\rightarrow)$. Select a channel number using the arrow keys. You will be able to toggle only through those channel numbers installed at the given station.

If you then move back to the station space $(\leftarrow)$ and change the station to one that does not have that channel, the station and channel number will blink until one of them is corrected to a valid station or channel number.

Data can be sent to any combination of up to three output devices: the screen, a file (WXLIST. OUT), or the printer. Move the highlight to each and toggle through $\mathrm{Y}(\mathrm{es}) / \mathrm{N}(\mathrm{o})$ with the Up or Down Arrow keys. WXLIST. OUT can be found in the HANDAR subdirectory after termination of the program. If output is requested to go to the printer, make sure that the printer is at the top of the page and on line before striking " $R$ " to run the listing portion of the program.

3.2.1.2 Other Keystrokes. Press $\langle F 1>$ to view the help screen. Press $\langle F 2>$ to view/edit the preset file (WXLIST. PRE) (discussed below). Press $\angle F 3>$ to see a directory of available *. WX files. Press " $D$ " to reset the program to default settings. Press " $Q$ " to quit. ( $R, D$ and $Q$ may be upper or lower case.) 
3.2.1.3 Running the Program. Press " $\mathrm{R}$ " to have the computer run the program for the selected combination. All error messages appear in the upper left-hand corner of the screen, above the start date/time. Figure VI-3 shows the user-input screen without any error messages.

A few quality checks are performed before the program will list the requested data. It first checks to see if the amount of time is greater than zero (i.e., that the start date/time is less than the end date/time). If it is not, a message to check them will appear.

It then checks for the existence of the start and end files. If one or both do not exist, "Check Start/End Dates - File Not Found" is printed on the screen. If a file is missing between the start and end files, the data will appear as null values $(-9999$. or -99.$)$ in the output. A message will be displayed on the screen reflecting this occurrence.

Finally, WXLIST checks to make sure all station/channel combinations are viable and that none are blinking. If there are combinations that do not exist, "Check Station ( $\mathrm{s}$ )/Channel ( $\mathrm{s}$ )" is printed to the screen.

The program will return to the input screen after it has finished listing the requested data. Parameters can then be changed and the program run again without termination. If data are sent to the file WXLIST. OUT, data from each successive run will be appended to the previous run's output until the program is terminated.

If you decide to terminate the program but want to save the output file, change its name in DOS or in PE2 with the COPY or the RENAME command (see subsection 3.3.6 or type "RENAME WXLIST.OUT [new path, filename]" on the PE2 command line). Note: the next time WXLIST is run, the old output file WXLIST. OUT from the previous run will be erased. Messages created by WXLIST that are helpful for debugging purposes are found in the file WXLIST. XXX in the HANDAR subdirectory. This file is also erased when the program is rerun.

3.2.1.4 WXLIST Presets and the Preset File (WXLIST. PRE). An option that makes selecting common station/channel combinations easier is the use of 10 preset combinations. By pressing $\langle a 1 t-1\rangle$ through $\langle a l t-0\rangle$, you can set up a specific station/channel configuration for the program to list.

The presets may be changed by editing the preset file WXLIST [S] . PRE, where $[S$ ] is a site indicator letter ( $T$ for Tooele, $E$ for Edgewood, $L$ for Lexington, and $P$ for Pine Bluff, and J for Johnston Island. To edit this file, type PE2 WXLIST [ $\mathrm{S}$ ] . PRE from the HANDAR subdirectory. Important: WXLIST [S]. PRE needs to be copied to the 
default preset filename of WXLIST. PRE using the DOS COPY command (see subsection 3.3.6) for the program to read the most recent changes before it is run.

You can also change the default preset file WXLIST. PRE from within the program by striking $\angle F 2>$. This will take you into PE2 to view or edit this file. If you change anything here while running the program, you should copy or rename WXLIST. PRE back to the site-specific file WXLIST [S] . PRE after terminating the program to avoid losing those changes.

The preset file consists of a title (WXLIST PRESET FILE), followed by the preset definitions. For each preset, the keystroke name is preceded by its ASCII equivalent, e.g., 120 is the ASCII equivalent of $\langle a 1 t-1\rangle$. The next line gives the number of channels $(0-10)$. The next lines must be equal in number to the number of channels. They consist of station/channel combinations-one per line, separated by commas. For example, if <alt- $-1>$ was for Station 1, Channel 1 (Battery), the preset definition would look like this:

$$
\begin{array}{rc}
120, & <a l t-1> \\
1, & \text { Number of Channels } \\
1,1, & \text { Station, Channel }
\end{array}
$$

To disable a preset, change the number of channels to zero and delete the lines that follow until the beginning of the next preset definition. If you try to use this preset later, a message "Preset not defined" will appear on the screen above the start date. Exit PE2 in the usual manner to return to the iriput screen.

3.2.1.5 WXLIST Initialization File (WXLIST. INI). The initialization file provides the program with information on screen colors, cursor position, and screen design. Only the screen colors should be changed. Cursor position and screen design should remain as they are.

The input screen colors can be changed by changing the first few lines in the WXLIST. INI file. Four color parameters may be changed: the base text (now blue), the changeable parameter highlight (now green), the current-parameter highlight (now white), and the wrong station/channel indicator (now blinking green). The brightness and color parameters are listed in pairs separated by commas. Table VI- 12 shows how they appear in the WXLIST. INI file.

The first number sets color brightness- 0 for dull, 1 for bright. The bright form of most colors shows up best on the black background. The 5 in color parameter \#4 sets up the blinking. Changing these specifications is not recommended. 
The second number in each pair sets the color of the text according to the codes given in Table VI-13.

Save the WXLIST. INI file only with NOTABS as follows. When finished editing, press $\angle F 3>$ then type "WXLIST. INI NOTABS" after the word "FILE" and press $<$ return>. If this is not done, the screen will appear in disarray when you try to run the program (unless the second line of your PE2. PRO file says "s blankcompress of $\mathrm{f}^{\prime \prime}$, per subsection 3.4.6). The input screen (Figure VI-3) is also located within the WXLIST. INI file, and the program expects to read it in a certain format.

\subsubsection{WXSUM.EXE}

To create the *. HR files containing hourly averages of all parameters for each day, it is necessary to run the WXSUM program. (For AQ values, it is also necessary to run AQHRS.)

Table VI-12. WXLIST screen display color parameters.

\begin{tabular}{cl}
\hline Colors & Description \\
\hline 1,34 & Base text \\
1,32 & Lowlighted \\
1,37 & Highlighted \\
5,32 & Wrong channel for station (blinking) \\
\hline
\end{tabular}

Table VI-13. WXLIST screen display colors.

\begin{tabular}{clcl}
\hline Code & Color & Code & Color \\
\hline 30 & Black & 34 & Blue \\
31 & Red & 35 & Magenta \\
32 & Green & 36 & Cyan \\
33 & Yellow & 37 & White \\
\hline
\end{tabular}


Because of the specific characteristics of each CHAWS site, WXSUM is unique at each site and is given a unique name, as shown in the following list:

$\begin{array}{ll}\text { Tooele } & \text { WXSUMT } \\ \text { Edgewood } & \text { WXSUME } \\ \text { Pine Bluff } & \text { WXSUMP } \\ \text { Lexington } & \text { WXSUML } \\ \text { Johnston Island } & \text { WXSUMJ }\end{array}$

The operation of all the WXSUM programs is identical. The only difference among the programs is the form of the hourly average data tables.

Before running WXSUM, you should indicate, by selecting a start and end date, which data period is to be averaged. Look into the WXOBS subdirectory (see 3.3.2 for "DIR" instructions) to find the *. WX files that correspond to that period. If the *. WX files are not all there, copy them from the archive floppies (see 3.3.6 for "COPY" instructions). When all *.WX files for the desired period are in the WXOBS subdirectory, make sure enough room exists for the files to be created by the WXSUM program. (The size of these files is shown in Table VI-2.) If you do not think enough room exists, copy the excess *. WX files to archive floppies or select a shorter period to run WXSUM.

To run WXSUM, make the default device $C$ and the default subdirectory HANDAR (see 3.3.2 for details). Now, start WXSUM from the Slave 1 keyboard by entering "wxsum" plus the site suffix, as above. Below is an example for Lexington-Blue Grass Army Depot:

$$
\begin{array}{r}
\mathrm{C}: \text { < Enter> } \\
\text { cd } \backslash \text { handar }<\text { Enter> } \\
\text { WXSUML }<\text { Enter }
\end{array}
$$

After the last command, wait for the program to display a "user-interface" screen. As shown in Figure VI-4, the screen has places to change the input parameters for "System Configuration", "Start Date", "End Date", and "Send Data to:". The use of the TAB, Up and Down arrows, and $<$ PgUp $>$ and $<$ PgDn $>$ keys to change parameters is the same as in 3.2.1.1.

Use the Tab Right key to move the highlight to the Start Date. The Julian date appears to the right of the calendar date. Change this date as required by pressing the keys discussed above.

Next is the "File Exist?" column, which states whether or not the file for the specified date exists. As you change the date, the program will automatically change the answer to the question and the file name to the right. " $\mathrm{Y}$ " means yes, 


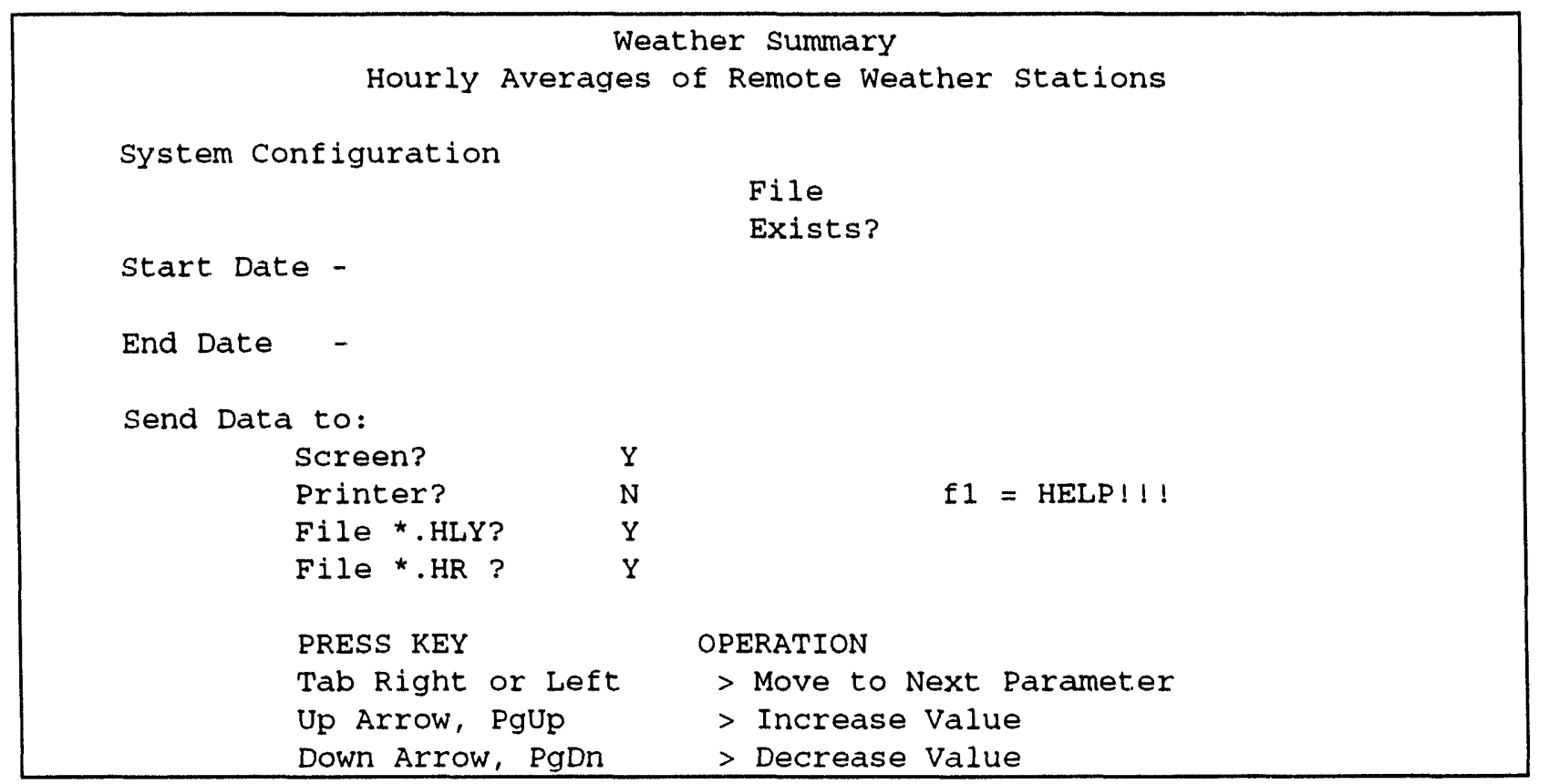

Figure VI-4. WXSUM user-input screen display.

it exists in the WXOBS subdirectory and " $\mathrm{N}$ " means no, it does not exist in that directory. Check other directories or add the file from the archive floppies.

Just before you run the program, decide where to direct the output. Because screen output takes much longer to run, it is not recommended unless you need to check hourly averages as they are being computed. Because the printer is a very slow device, printed output of the tables is also not suggested. It is much faster to save the tables in *. HLY files to be printed at a later time or reviewed in an editor such as PE2.

The hourly averages are saved in binary form in " $T$ [julyrss]. HR" files, where jul is the Julian date, $y r$ is the year, and ss is the site identifier, which is $\mathrm{T} 2$ for Tooele, P2 for Pine Bluff, L3 for Lexington, E2 for Edgewood, and J2 for Johnston Island. WXSUM puts the * . HLY and *. HR files in the WXOBS subdirectory. Select an output mode by pressing the up or down arrow keys until a " $\mathrm{Y}$ " or " $\mathrm{N}$ " appears.

For additional help, press the following function keys:

F1-Write a help file WXSUM. HLP.

F3-Write a listing of the * WX files.

F4-Write a listing of the *. HLY files.

F5-Write a listing of the *. HR files.

When you are satisfied with the start and end dates and the output modes, press $R$ to run the program. WXSUM first checks to see that the start date is before or the same 
as the end date. If it is not, the operator is warned by a message found at the top of

- screen; otherwise, the program continues to run. It finds the start date, computes hourly averages, makes tables, and sends them to their selected destinations. After the last hour of the last day, the program closes all open files and stops. The * . HLY and *. HR files should appear in the WXOBS subdirectory.

The * . HLY tables list the hourly average values of wind speed ("WSpd") and direction ("Wdir"), wind direction standard deviation, (also called sigma theta or "SigThe"), temperature ("Temp") relative humidity ("RHum"), and battery voltage ("Batt") for all the stations at the site. Each level is listed for the multi-level towers. The "NOTES" at the bottom explain other symbols besides numbers that may appear in the columns of the table. For instance, "-..-" means there are no instruments at this location.

The values U-STAR and T-STAR represent logarithmic vertical profiles of wind and temperature. They are important measures of atmospheric stability.

\subsubsection{The AQ Hourly Translation Program (AQHRS)}

Although WXSUM may have been run to give hourly averaged meteorological data for a given period, the $A Q$ values need to be calculated from the averaged raw voltages, and the calibration data need to be removed before they can be used. For this purpose, it is necessary to run $A Q H R S$, which writes translated $A Q$ data to the *. HR files (see Table VI-1). AQHTAB (see below) then reads hourly data from these files to generate tables.

The AQHRS program asks you to input the year and starting Julian date for which the program is to be run (see Appendix I-C for Julian date vs calendar date). It will then look for the ${ }^{*}$.WX file for the first day requested followed by succeeding days until the current day, at which time it terminates with the message, "NO MORE T[JULYR] T2.WX FILES THRU CURRENT TIME; PROG TER".

If one of the *. WX files does not exist, it simply prints a message onto the screen "NO FILE FOR JULIAN DATE = " and continues with the next day. This message and other operational messages are all written to the output file "AQHRS. XXX", which may be reviewed by using an editor program such as PE2. 


\subsubsection{The AQ Hourly Tabulation Program (AQHTAB)}

A schematic diagram of the AQHTAB program is presented in Figure VI-5. To start this program, type "aqhtab" <Enter>. Then after it responds "ENTER YEAR, MONTH $(0,0$ TO STOP)", enter the year and the numerical value of the month for which the program is to be run. It then asks whether or not to "PRINT ALL TABLES?", to which you should type " $y$ " for yes or " $n$ " for no, followed by <Enter>. Note: the program does not print output tables directly. Instead, it writes them to an output file. A sample output table is presented in this chapter in Table VI-4.

If you answer " $\mathrm{y}$ " to the above question, $\mathrm{AQ}$ tables for all stations and pollutants are written to the file $A Q$ [mony $r$ ] . TAB, where "mon" is the 3-letter abbreviation for the month and " $y r^{\prime}$ " is the last two digits of the year. For the " $n$ " answer, you are asked to "ENTER AQ STATION NUMBER ([station list])", and then to "ENTER CHANNEL NUMBER $(3,7,8$, or 9$)$ " for required pollutants. The table requested will then be written to the output file "AQHR. TAB".

After $A Q H T A B$ has run for the month discussed above, it will again ask you to "ENTER YEAR, MONTH $(0,0$ to stop)". If you want to run AQHTAB for another year and/or month, enter them as before. If you answer " $n$ " to the "PRINT ALL TABLES?" question on two or more adjacent runs, the output tables will be listed in order on the currently active "AQHR. TAB" file. Only one such file can exist at once, however, so if you terminate the program and run it again, the existing file with that name will be erased. Any time you answer the YEAR, MONTH question with " 0,0 ", you will stop the program and return to DOS.

The "([station list])" given after "ENTER AQ STATION NUMBER" will vary from one site to another. It is found on the initialization file $A Q H T A B$. INI (see next subsection). The channel numbers will not vary between stations or sites. They are 3 for $\mathrm{NO}$ (nitrogen oxide), 7 for $0_{3}$ (ozone), 8 for $\mathrm{SO}_{2}$ (sulfur dioxide), and 9 for $\mathrm{NO}_{\mathrm{x}}$ (all nitrogen oxides). The $\mathrm{NO}_{2}$ concentrations can be calculated by subtracting the $\mathrm{NO}$ from the $\mathrm{NO}_{\mathbf{x}}$.

Numbers in the output tables are rounded to the nearest whole part per billion $(\mathrm{ppb})$. However, " $<1$ " is substituted for " 0 " to avoid the illusion of a zero concentration, which will not occur in nature. If an actual zero appears in a table, the analyzer is indicating at least slightly on the low side. Even concentrations of $0.1 \mathrm{ppb}$ are converted to " $<1$ ", not zero. 


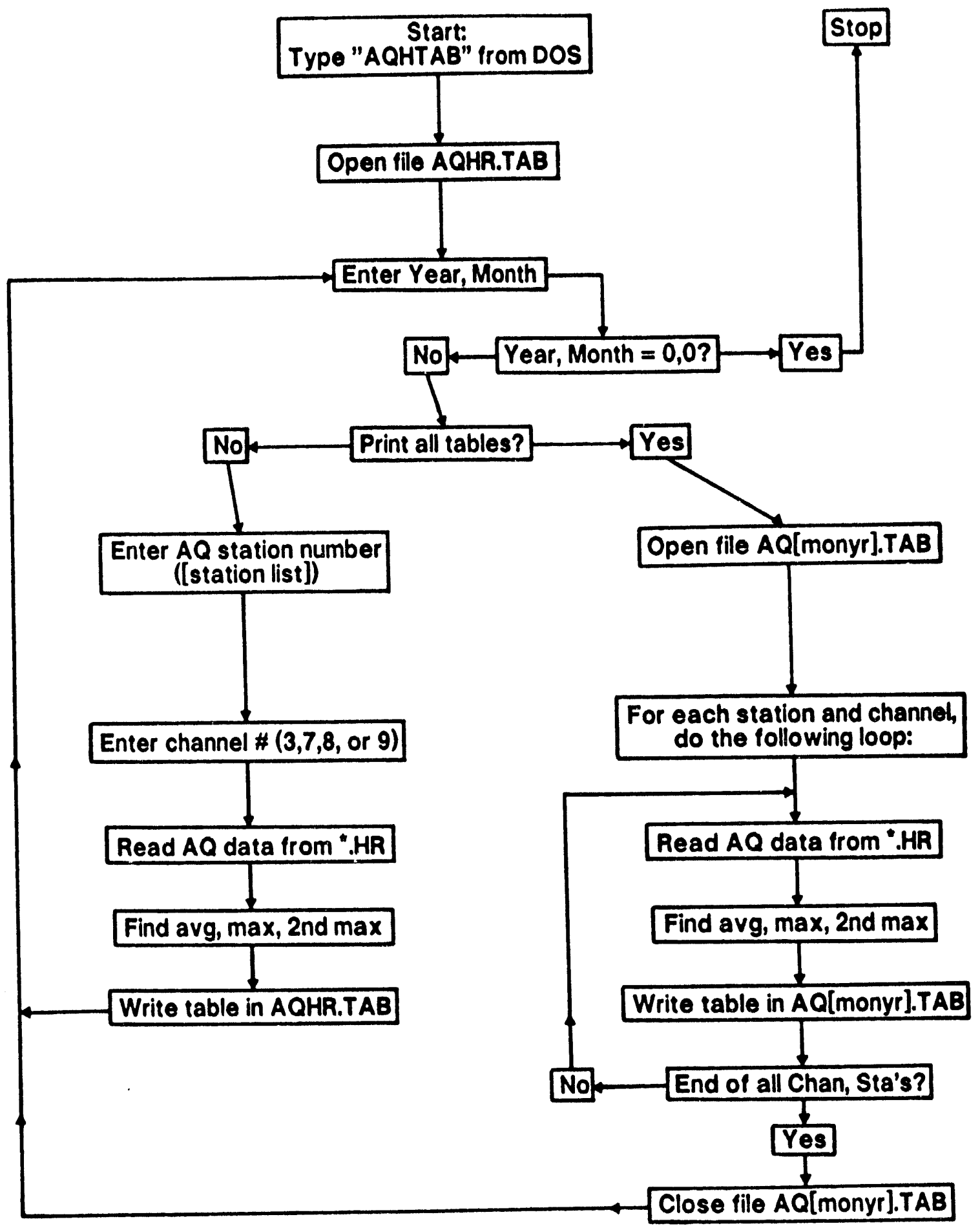

Figure VI-5. $A Q H T A B$ user-input flow chart. 
If there is a problem with any analyzer, and it generates false negative values, these will not appear as negative in these tables but as zeros. The values from this analyzer should be checked with an on-site printer per Section 4.2.

\subsubsection{The AQHTAB Initialization File ( $A Q H T A B . I N I)$}

The purpose of the $A Q H T A B$ initialization file, $A Q H T A B$. INI, is to provide sitespecific information to the $A Q H T A B$ program. It should not need editing or changing because the $A Q$ station configuration is not expected to change.

The first line describes $A Q H T A B$. INI as an initialization file (Table VI-14). The second line gives the screen input request line for $\mathrm{AQ}$ station numbers. These numbers

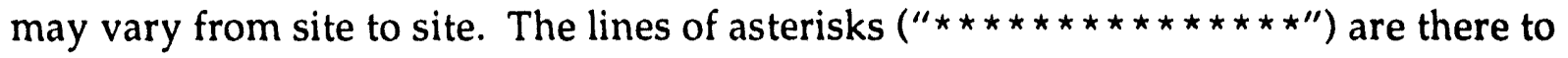
separate logical data blocks. The SITELOC line gives the site location to be printed out at the top of the tables. This is followed by the number of AQ stations located at that site. This number should equal the number of lines given in the next logical block below. These lines give the station number followed by the station name (in quotes). Notice that the numbers "Station 1", "Station 2", etc. will not necessarily agree with the station numbers in the first column. They simply list the AQ stations in numerical order. To examine this file, enter the HANDAR directory (if not already there) by typing "cd $\backslash$ handar" <Enter>. Now type "pe2 aqhtab. ini". The file should then appear on the screen.

\subsubsection{The Data Recovery Analysis Program (RECOV)}

The RECOV program is not part of the data train and does not need to be run until it is time to examine the data base for the amount of data recovery. At that time, start it by typing "RECOV" <Enter>. When it asks for the "YR, START DATE, END DATE", type the last two digits of the year followed by the beginning and ending Julian dates, inclusive (see Appendix I-C for Julian date vs calendar date). It creates an output file "RECOV. OUT" that has a page for each day of data recovery. Use PE2 (Section 3.4) to examine this output file. It should only be printed by striking $\langle F 7><$ Enter $>$ in PE2 (not from DOS) after making some changes described in Section 4.5. A sample output table printout of such a RECOV. OUT file appears as Table VI-5. Its application is described in Sections 4.2 and 4.5 . 
Table VI-14. Initializing file for AQHTAB (AQHTAB. INI) (for Tooele Army Depot, South - Site).

\begin{tabular}{|c|c|}
\hline Actual WXGRAPH. INI line & Short Description \\
\hline $\begin{array}{l}\text { AQHTAB INITIALIZING FILE } \\
\text { "ENTER AQ STATION NUMBER }(1,3,5 \text {, or } 7) \text { ", INPUT } 1\end{array}$ & $\begin{array}{l}\text { File description } \\
\text { Input command (asked of user). }\end{array}$ \\
\hline 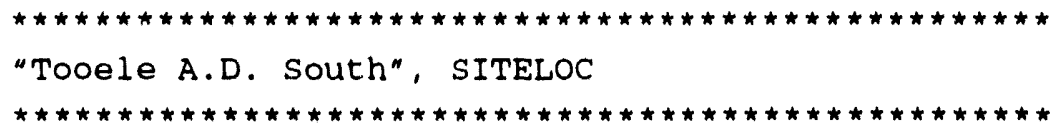 & Line to identify site \\
\hline 4, Number of AQ Stations & TOTAL no. of AQ stations \\
\hline $\begin{array}{ll}\text { 1. "East" } & \text {, AQ Station } 1 \text { Name } \\
\text { 3, "South" } & \text {, AQ Station } 2 \text { Name } \\
\text { 5, "West" } & \text {, AQ Station } 3 \text { Name } \\
\text { 7, "North" } & \text {, AQ Station } 4 \text { Name }\end{array}$ & $\begin{array}{l}\text { Use any word that will } \\
\text { uniquely identify which } \\
\text { stations you want. Do not } \\
\text { confuse Ch. \# with Sta. \#. }\end{array}$ \\
\hline
\end{tabular}

\subsection{Disk Operating System (DOS) Primer}

This section summarizes the basic DOS commands used to edit and process data and operate programs from the CHAWS system. It contains only reminders and does not replace the DOS manuals. Familiarity with DOS from the DOS manuals and practice with the DOS commands is recommended before running programs on the CHAWS system.

Some DOS commands start programs through simple entry of the program name, while others print out, copy, or delete files, create or change directories, etc. When commands (other than PRINT) list filenames preceded by a path (see 3.3.2), the path is not needed if the same subdirectory is already active.

\subsubsection{Entering Commands}

Before entering any DOS commands, you must enter the DOS mode. When booted, the Slave 1 terminal keyboard should enter this mode automatically. If you are already running PE2, enter DOS with <Ctrl>-" $d$ ". Type "exit" and press the $<$ Enter $>$ key to return from DOS to PE2. 
DOS commands can also be done on the host keyboard, but you must terminate (type "quit" or "exit") or complete most programs before typing the DOS command. Exit LOGIT or GRAPHIT between data polls with <Ctrl>-<Break> (<SCroll lock>).

Confirm that you have entered DOS by looking for the DOS prompt character on the left side of the screen. It may start with a word or two describing the terminal, location, or the program normally run on that terminal (such as "D2 PC"). In any case, it will end with the DOS prompt symbol ( $>$ ). Once you see this symbol, you may enter a DOS command after it on the same line.

You execute most commands with <Enter>. Spacing can be important; you need at least one space between the command and the file acted upon. DOS commands are not case-specific; they may be executed in either upper or lower case. Do not type the brackets "[ ]" shown in the sample commands below. They are only there to designate a specific name to be typed in.

\subsubsection{Use of Directories}

Directories and subdirectories are groups of files listed together on a device. To see $v$ nich directory you are in, type "cd" $<$ Enter $>$.

The computer will respond with a path:

"[dev]: \[directory] \[subdirectory]"

A table of contents for a subdirectory can be obtained by typing

"dir [dev]: \[directory] \[subdirectory]" <Enter>.

(There cannot be a space wherever a backslash (" $\backslash$ ") appears.) After this command, the computer will display a table of contents for the specified path (device, directory, and subdirectory) or, if none is specified, the currently active path.

The screen will display a table showing the filenames, element names, number of bytes per file, and the date and time created. At the bottom will be the number of files listed, followed by the number of bytes free (available on disk). This command may be done from the command line of PE2 (without the top and bottom lines of information).

To change directories, use the DOS " $C D$ " command:

$$
\text { "cd \[directory] \[subdirectory]" <Enter>. }
$$

For example, change to the HANDAR directory by typing "Cd $\backslash$ HANDAR" $<$ Enter>. There is no need to specify the current directory-only the directory you wish to change to. To call up the root directory, type "cd।". 


\subsubsection{Starting a Program}

Programs that do not start automatically when the system is booted may be started from DOS. Simply type the program name following the DOS prompt. If you get a message such as "Bad command or file name", it probably means you misspelled the file or program name or you are in the wrong directory (see 3.3.2). Most CHAWS programs can be run from the root directory, which should eliminate this problem.

\subsubsection{Terminating a Program}

All single-cycle programs (those that operate on only one data set without rerunning for the next time increment) should terminate automatically. Some of these are described in Section 3.2. Programs described in Section 3.1, however, have loops that permit them to continue to run for each succeeding time increment. To terminate either type of program, press $\langle\mathrm{Ctr} l\rangle$ and $\langle$ Break $\rangle$ ( $\langle$ Scroll Lock $\rangle$ ) simultaneously. This may need repeating. Any input-output operation will stop after the device buffer is empty. If all else fails, reboot the system by pressing $\langle C t r l\rangle$, $<A l t>$, and $<$ Del $>$ simultaneously (WARNING-this will erase all volatile memory). Most programs should stop running from either procedure. LOGIT will resume operation after a reboot on the host computer.

\subsubsection{Printing Out a File}

Print out a file by typing:

"\print [directory] \[subdirectory] \[filename]. [ext]" <Enter>.

The computer may prompt you to enter the name of the list device. Simply striking <Enter> again will send the printout to the default device, which should be the primary printer attached to the system. Some programs can be requested to print out data or files from inside the program. This includes PE2, where $\langle F 7\rangle$ is used.

PRINT. COM should not be used when NTNX has been installed on the HOST computer. Use SPOOL from the host or SPRINT from a slave. These files are located in either the root directory or the $\mathrm{C}: \backslash \mathrm{BIN}$ directory.

Make sure the printer is turned on, that it is on line with the cables connected, and that it has plenty of paper. If the printer runs out of paper, no printout is lost. The 
PRINT command (or the WRITE command in the program) will interrupt its execution until the paper is refilled.

\subsubsection{Copying a File with the DOS Copy Command}

To copy from device 1 to device 2 use the following command:

"COPY [dev1] : [filenam1] . [ex1] [dev2] : [filenam2] . [ex2]" <Enter>.

Devices can be any letter but must refer to a data-access device such as a hard or floppy disk or a tape drive. The filenames and extension names can (but need not) be changed in the process.

When copying to or from a specific directory or subdirectory, be sure to include the path in front of the filenames given above.

If you want to copy all the possible extensions of a given filename, use " $\star$ " in place of the extension. The same applies to filenames, such as all the * EXE or * . TXT files. This asterisk acts as a "wild card" and copies every name in that location. It substitutes only for filenames or extension, however-not paths, directories, or subdirectories.

As an example, if you wish to copy all the *. TXT elements on device A to *. DOC elements of the same filename on device $B$, for instance, type

$$
\text { "copy } a:{ }^{*} \text {.txt b: *.doc"<Enter>. }
$$

The entire contents of a floppy disk drive or directory may be copied with

"copy $[\operatorname{dev} 1]:{ }^{*}{ }^{*}[\operatorname{dev} 2]:$ " < Enter $>$.

\subsubsection{Deleting a File}

Use the "del" command followed by the filename and extension:

"del \[directory] \[subdirectory] \[filename] . [ext]" <Enter>. The filename is deleted from the file-access table, and the data may be written over by other files. If the data have not yet been written over, there are ways of getting them back, but such procedures are beyond the scope of this manual.

\subsection{Examination and Editing of ASCII Files (PE2)}

PE2 (Personal Editor, Version 2) is a word-processing and file-editing program that can be used to examine and (when necessary) change ASCII files associated with the CHAWS system. What follows is a general description of the PE2 program and a 
few commands. For details on these items and many other commands, refer to the PERSONAL EDITOR I Manual, ${ }^{1}$ which is available at the CHAWS sites.

Before running PE2, see if the files PE2 . EXE and PE2. PRO are on the active subdirectory. It is easiest to run PE2 if they are. However, files on any subdirectory may be processed. No directory or subdirectory needs to be specified if the processed file is on the currently active subdirectory. PE2 may be run from any subdirectory if PE2. EXE is in the $C: \backslash B I N$ directory.

\subsubsection{Entering PE2}

Activate the PE2 program for any filename. ext from DOS by typing "pe2 \[directory] \[subdirectory] \[filename] . [ext]" <Enter>. The screen will display a work area for text followed by a command line for entering the commands discussed in the following subsections. Enter the work area or return to the command line with the $<$ Esc $>$ key.

A new file may be created in the same manner, specifying the new filename and the path (device, directory, and subdirectory) unless the current path applies. In that case, simply type "pe2 file. nam" where " $\mathrm{file}$ " is the name of the file and "nam" is the extension.

A status line showing the path and filename accessed appears under the command line near the bottom of the screen. If any changes are made to any line in the work area, the status line changes from white to red upon leaving the line of changed text.

A remark line may appear under the status line. If it says "new file", the filename above is new and the work area is blank except for the "—-Top of File_-" and "—Bottom of File_-" markers. This may happen when you are trying to examine an existing file. If so, the filename has been misspelled or you did not specify the right device, directory, or subdirectory.

The message "Profile or macro file not found" on the remark line (below the status line) means the PE2. PRO file is not in the active subdirectory. The CHAWS host computer should have it in the root directory, but it also must be in the active subdirectory to avoid the above message display. If the display appears, you may still edit a file, but the PE2. PRO presets cannot be used. If you wish to use the presets, leave $P E 2$ by striking $\langle F 3>$ or $\langle F 4>$. Now copy $P E 2$. PRO to the active subdirectory (see 3.3.6). 


\subsubsection{Use of the Edit Command and Function Keys}

The procedure above allows one to edit a single file. Other files may be edited concurrently by typing

$$
\text { "e \[directory] \[subdirectory] \[filename] . [ext]" }
$$

on the command line. As above, the directory and subdirectory need not be specified if the file is on the active subdirectory. You may edit as many files as you wish. If the available memory is full, a spill file is created.

The function keys $(\langle F \#\rangle)$ perform many actions for $P E 2$. One can toggle back and forth between files with the $\langle F 8>$ key. Use $\langle F 2\rangle$ to save and $\langle F 3\rangle$ to save and quit a file, each followed by $<$ Enter $>$. $<F 4>$ will quit a file without saving it. $<F 5>$ will delete an entire line, and $\langle F 6\rangle$ will delete the part of a line at and to the right of the cursor. Use $\langle F 7\rangle\langle$ Enter $>$ to print out a file. $\langle F 9\rangle$ and $\langle F 10\rangle$ both add a line. $<F 9>$ puts the cursor to the far left, while $<F 10>$ puts it below the beginning of the line above. Use the insert mode to add text and the replace mode to write over text. This mode is shown in the lower right-hand corner of the screen, just after the line and column numbers. (NOTE: Before saving a file, be sure you do not need any deleted text from the . UNNAMED file (see 3.4.5).)

The uses of the function keys and other editing features are explained in Figure VI-5. The PE2. HLP file can also be obtained by striking $\angle F 1>$ (if you have it in the currently active subdirectory) and printed out with $\langle$ F 7$\rangle\langle$ Enter $\rangle$. It contains slightly more detail than Figure VI-6.

\subsubsection{Setting Margins}

Margin presets are defined at the bottom of the PE2. PRO file. These help the user set the margins quickly by the use of the $\angle A 1 t>-[n u m b e r]$ keys together. The presets currently have the left margin in column 1 and the right margin in the column for 10 times the number of the key. Pressing $<A l t>-7$, for instance, will give you margins in columns 1 and 70 . <Alt $>-0$ will set them at 1 and 100 (see also subsection 3.4.6).

If custom margins are required, use the SET MARGINS command on the command line. The three numbers following the command designate the left margin, right margin, and paragraph indentation margin, respectively. For a standard text in columns 10-75, with a 5-space paragraph indentation, use

$$
\text { "set margins } 107515 \text { " <Enter>. }
$$




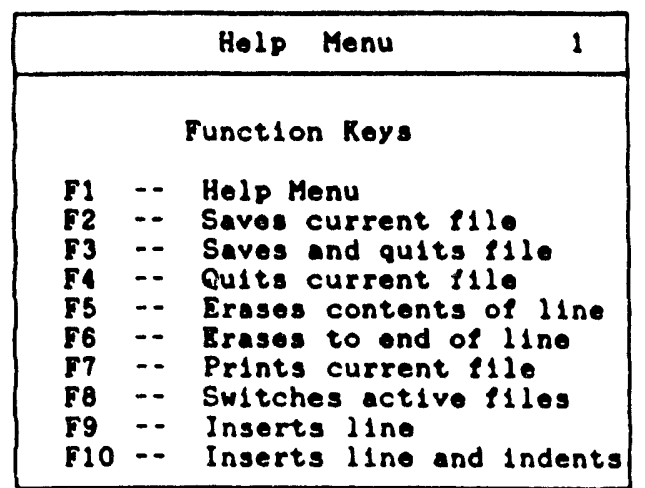

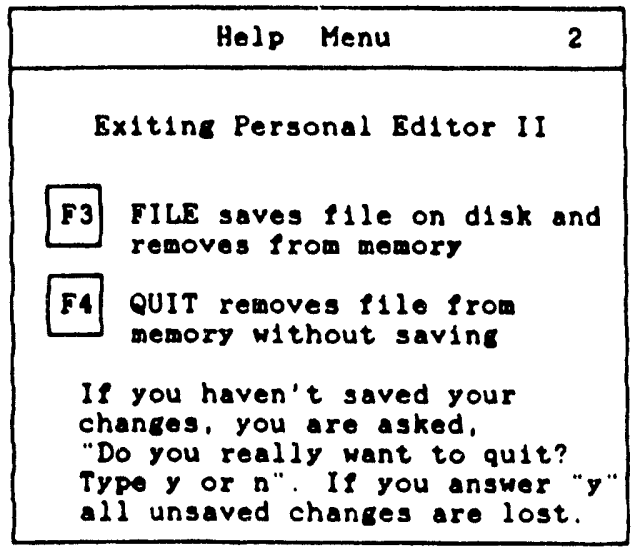

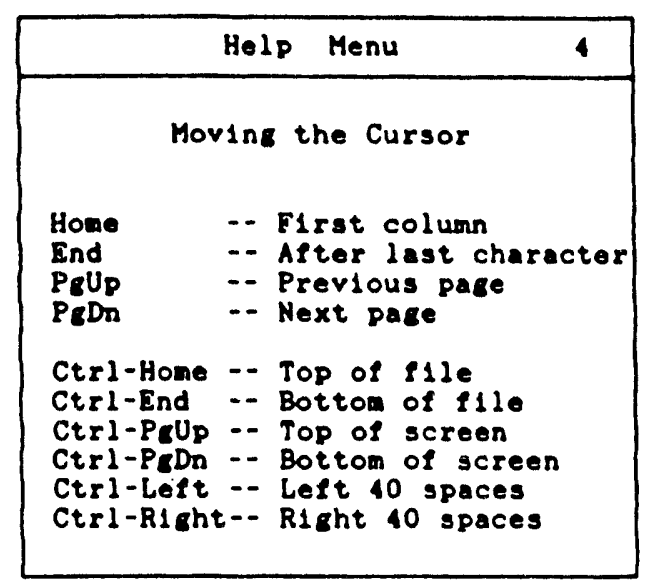

Note: For more detalls, see PE2.HLP 11le or PE2 Reference Manual
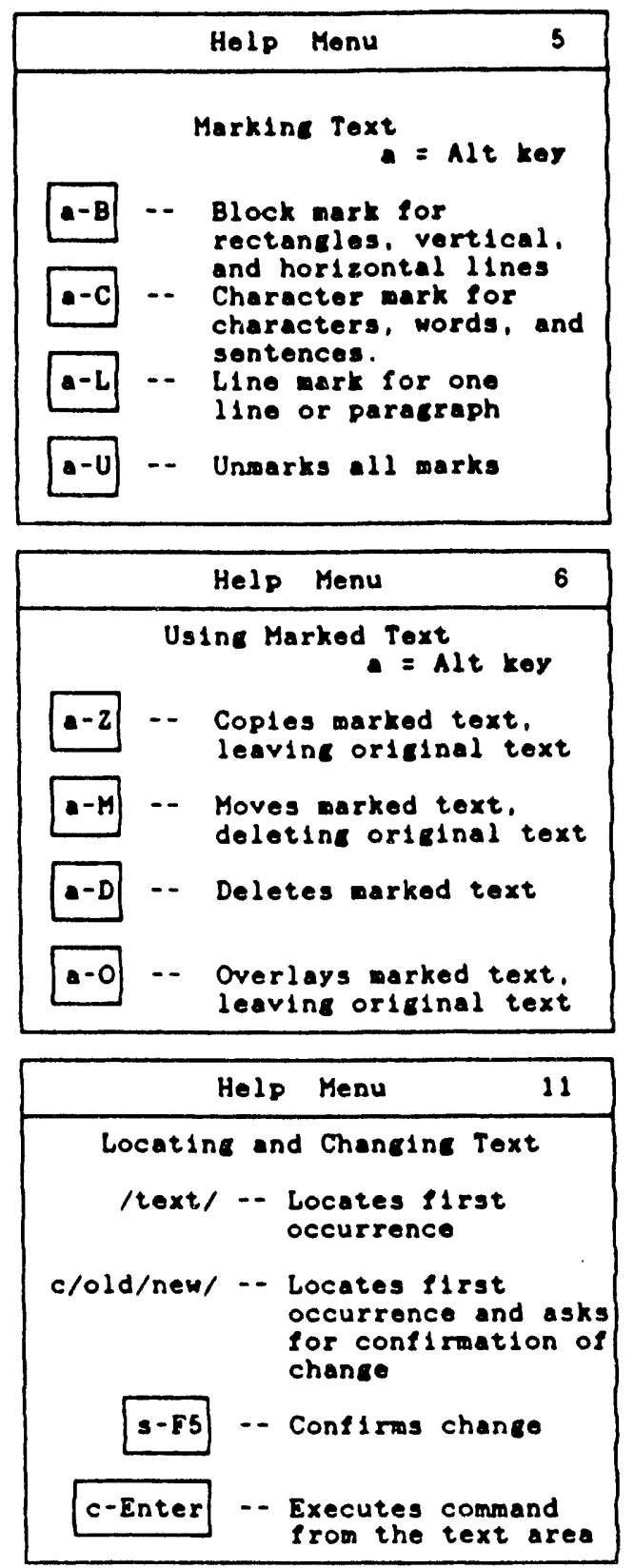

Figure VI-6. Summary of PE2 commands. 


\subsubsection{Working with Marked Text}

1

Text is highlighted so that it can be moved, copied, or deleted. To edit an existing file, mark (highlight) the text as detailed in Figure VI-5. The commands you use the most for editing data files are $\langle A l t\rangle-b$ (to mark a block) and $\langle A l t\rangle-d$ (to delete). The block command $(\angle A I t>-b)$ will mark a rectangle in between the two places where it is used. $\angle A I t>-C$ is used to mark text along the reading path between its two occurrences. It is best for moving or editing prose. $<A l t>-L$ will mark an entire line, or a series of lines if used twice.

The marking techniques discussed above can be used to delete, print out, or perform other activities upon certain portions of an output file. One $<A l t>-b$ command can be used to mark the upper left corner of the area to be deleted, while the second can be used at the lower right corner, and $\langle A I t\rangle-d$ can be used to delete the marked area. The command "[print mark]" can be used to print only the marked area.

Move marked text with $<A \perp t>-m$. Copy marked text with $<A \perp t>-z$. Both of these commands will displace original text to the right (not below or above), whether in Insert or Replace mode. The $\langle A 1 t>-0$ command overlays the marked text on top of existing text. To alleviate complications when working with tabular files, set the margins as wide as possible before using $\langle A 1 t\rangle-m$ or $\langle A 1 t\rangle-z$. The following is a summary of marked text commands:

$<A 1 t>-m$ Move text from old to new location. Move old text in new location to right, or below if $<A I t>-L$ used.

$<A l t>-z$ Copy text from old to new location. Move old text in new location to right, or below if $<A l t>-L$ used.

$<A I t>-0$ Copy text from old to new location. (Only with $<A l t>-b$.) Replace existing text with new text in new location.

Figure VI-6 has the "bare bones" instructions for PE2 editing. Complete instructions are given in PE2 . HLP, a printout of which is available by pressing $<$ F $7><$ Enter $>$ when that file is on the screen. 


\subsubsection{Search and Change Commands}

Any word, number, phrase, or other character string can be quickly found in a file by typing it after a "/" on the command line, then pressing <Enter>. If you leave spaces before or after the string, it will look for these as well. The program will se ch the entire file starting with the current cursor location.

You may change a character string by typing a SMALL (lower case) " $\mathrm{C}$ " and a space before the delimiter (" $/$ " or another character not in the string). In this case, follow the old character string with another delimiter, the new string, and another delimiter. If you want the change to occur for every string after the cursor, type a " $\star$ " following the last delimiter. If you want to go backwards from the cursor, type "- $\star^{\prime \prime}$; if you want the changes to occur in the marked area only, use " $\mathrm{m}^{\prime \prime}$ or " $-{ }^{*} \mathrm{~m}$. A more detailed explanation appears in the PE2 manual.

\subsubsection{Retrieving Deleted Text}

If you have changed a given line but have not left it, you may restore the line to the way it was when you entered it by pressing $\langle$ Shift $>-<F 4>$. If you mark and delete text, you can get it back by entering the . UNNAMED file. This file is entered with $<C t r 1>-u$ and contains the last five changes to all files in memory up until the time it was last saved. They may be copied back to the text using the move command $\langle A 1 t\rangle-$ $\mathrm{m}$ described in 3.4.4.

If you have gone beyond the last five changes, you can get the text back only if you quit $(<F 4>)$ the file without saving it. Now re-enter it with edit " $e$ ", and you will have the file back as it was when you last saved it.

\subsubsection{Editing the PE2. PRO File}

This file contains preset margins and other specifications that will not ordinarily need to be changed. However, it is sometimes desirable to customize them by editing this file, just as is done with the initialization files *. INI described in 3.1 and 3.2.

Use the editing procedure described above to edit PE2 . PRO. The "blankcompress" value in the second line can be turned off to avoid having to save certain files with NOTABS. However, many files will then require more than twice the storage space. The margins assigned upon entry to a file are usually defined on the third line. The $<A 1 t>$-[number] margin presets appear near the bottom of the file. 
Edit them as required to make format'ing of text easier. Other key definitions appear

- but are not likely to need changing. They may be changed if necessary.

\subsubsection{Entering DOS-Like Commands from PE2}

Entering DOS-like commands from PE2 is very simple. PE2 has a few DOS-like commands of its own, such as "DIR", "CD", "RENAME", "SAVE" (<F2>), "FILE" ("SAVE" and "QUIT") ( $\angle F 3>)$, and "PRINT" $(<F 7>)$. These can be entered on the command line, including directory names when needed. The command "DIR", however, does not give header and footer information (such as number of files and total bytes used) when requested from PE2 , ; it does in DOS.

To enter DOS from PE2, type <Ctr1: -d. Type "exit" to return to PE2. Your PE2 work file will still be in the work area, even if you did not save it.

\subsection{DATA TABULATION, INTERPRETATION, AND ARCHIVING}

It is essential that a permanent record be kept of the CHAWS AQ and meteorological data. These data are produced in file and tabular form by the software discussed in Sections 2 and 3 . This section explains how to interpret, document, and store these data.

\subsection{Data processing and quality assurance}

Meteorological data are averaged by the HANDAR DCP and put through preliminary QA editing by the RDCATCH program (run by the LOGIT or GRAPHIT batch files). Once meteorological data are displayed in graphic or tabular form by WXGRAPH, WXSLIST, WXSUM, or other programs, they have had some basic processing.

Any $A Q$ data gathered, however, remain in the form of averaged, uncalibrated voltages until they are translated to parts per billion ( $\mathrm{ppb}$ ) by the AQHRS program (see 2.4.3). Voltages are translated as follows:

$$
\mathrm{ppb}=\text { Volts } \times 100 . \quad \mathrm{ppm}=\text { Volts } / 10 .
$$

The AQHRS program uses the first of these formulas to obtain $\mathrm{ppb}$.

When reading the following subsections, then, keep in mind that the *. Wx files contain data for 5- and 15-minute averaging periods that have had preliminary quality assurance, but only the meteorological data are translated into the proper units. The *. HR files from the WXSUM output contain hourly data of the same quality as the *. WX 
files. *. HR files that are created by AQHRS, however, have the proper units for ALL the data, both meteorological and air quality.

\subsection{Interpretation of the Tabular Data}

Tables of averaged (avg) meteorological (MET) and AQ data are created by the following programs:

- WXLIST-WXLIST.OUT (5- and 15-minute averaged MET data or AQ volts),

- WXSUM-T[julYr]L3. * . HLY (hourly averaged MET data)

- $A Q H T A B-A Q$ [monyr] . TAB (hourly averaged AQ data)

- $\quad$ KECOV- RECOV. OUT (data recovery for each 15-minute period)

Several precautions need to be taken when reviewing and interpreting these data. First of all, the parameter values given represent the average values over periods of an hour (except for WXLIST. OUT, where the shortest period is still 5 minutes). Do not assume that the wind directions or speeds include all possible winds within that hour. Wind can vary a lot even within 5 minutes, while temperature, humidity, and even air-pollutant levels may vary considerably within an hour. It is important to note that hourly data are what are generally used in government and industry, but for your own purposes, remember that short-term variations, which may have further implications for your activities, will not necessarily appear in the data base-especially in the hourly data. Short-term peak values will not appear in most of the tables discussed in this section.

Also, most of the instruments need regular maintenance, servicing, and calibration. If they are not calibrated regularly, the data output will not be reliable. (The U.S. Army has its own calibration specifications, with most Army equipment being calibrated at Redstone Arsenal, Alabama. The calibration procedures for most of the equipment at the CHAWS sites are detailed in the owner's manuals, with some discussion of the AQ equipment in UCRL-CR-105428, the Johnston Island Air Quality Monitoring Systems User's Guide. ${ }^{2}$ )

Moreover, it is difficult for the untrained person to find suspect data. One has to know whether a persistent wind direction, for instance, is real or a false reading from a stuck vane. Wild temperature fluctuations are less common than wind fluctuations but can happen under certain conditions.

Finally, remember that false negative $A Q$ values are reported as zero in the data files and tables. In the $A . \mathrm{QHAB}$ output tables, " $<1$ " means any value between 0 and 0.5 parts per billion. Actual concentrations may be close to zero, but at least a few ppb (say 
3 to 10 or more) are usually present. If a " 0 " appears in these tables, it means the

- concentration as reported in the data is exactly zero or below, but the instrument is at least slightly out of calibration. Rather than show these false negative values, tables produced by WXLIST will show zero instead. Be aware of the percentage of zeros you see in the output. If it is over about half, the following step is essential.

We highly recommend that a printer be installed in each air-quality instrument shelter to obtain direct printout summaries of the air-quality data at least every 3 to 4 days (twice a week). This printer will obtain data directly from the air-quality systems, in which the false negative values will appear as a negative value. The elimination of zeros by the HANDAR software will not have taken place, and these negative values can be used to re-calibrate the analyzers as necessary. (For details, see Iohnston Island Air Quality Monitoring Systems User's Guide: System Description and Standard Operating Procedures, UCRL-CR-105428.2)

\subsection{Archiving of Tables}

Each of the tables created by $A Q H T A B$ and RECOV should be printed and kept in a binder. Printing and archiving bulky WXLIST. OUT printout or the * HLY tables (see subsections 3.2.1 and 3.2.2) is not recommended but may be done at the option of the user. Recommended procedures for storing these tables are as follows.

\subsubsection{WXLIST}

WXLIST. OUT output tables, printed at the option of the user only for very short periods of episodic conditions, potential release conditions, or interesting meteorological events, are stored by event or chronologically in a large 3-inch binder. 
* . HLY tables (if desired), are stored chronologically in 3-ring looseleaf binders

by the year. An entire year would be from about 2200 to 4400 pages (depending on the site) and require 3 to 5 large 3 -inch binders.

\subsection{3 $A Q H T A B$}

Monthly $\mathrm{AQ}^{*}$.TAB tables (Table VI-4) are stored chronologically in a 3-ring looseleaf binder. An entire year fits in a $11^{\prime} 2$-inch binder.

\subsubsection{RECO?}

RECOV. OUT tables (Table VI-5) are stored chronologically in a 3-ring looseleaf binder. Using the output described in Section 4.5, tabulate each day's percentage datarecovery rate by hand. Now, insert the results in front of the RECOV. OUT tables for that month. An entire year of these tables fits into a 11/2-inch binder.

Procedures for running the programs that create these tables appear in 3.2, and program applications and examination of the data are discussed below.

\subsection{Archiving of Data Files (*.WX, *. HR)}

Raw 5- and 15-minute averaged data should be archived on 51/4-inch floppy disks in the ${ }^{*}$. $W X$ form, while processed data should be saved in the *. HR form after running WXSUM (and AQHRS for sites with AQ data). The ASCII files " * . HLY" are easily reproduced with the WXSUM program and do not have to be kept. (If you want to keep them, you can also keep the printed output tables as discussed above.)

\subsubsection{Archiving of the 15-Minute Data Periods (*. wX Files)}

*. WX files are created by the RDCATCH program (see 2.3.6). Before archiving them, make a preliminary search to ensure all data obtained are in one place. Check the hard disk and other floppy disks at your base for any missing files. If you can not find certain days or periods, call LLNL and the ASL at White Sands Missile Range to see if they are available. 
Use the DOS COPY command (subsection 3.3.6) to store the * WX files in

- consecutive order, fitting as many onto each 1.2-M byte floppy disk as possible. For Tooele, for example, 17 * . Wx files should fit easily onto a 1.2-M byte floppy disk. Files should be stored on 1.44-M byte disks where available.

If you find any missing files at a later time, copy them onto the floppy disks using the COPY command in DOS. Delete the older *. WX files from the floppy disk,if the available storage is exhausted. It is helpful to keep a DIR listing of the contents of each floppy disk in its sleeve. Write the percentage of data recovery on this list when available (see 4.5).

Construct a label for each floppy disk as in Figure VI-7 after being sure you have all the possible files for that period. You can use the figure or the file "CHAWSLAB. $[Y r]$ " for the format and even type labels beforehand if you prefer, leaving the dates, Julian dates and floppy disk numbers blank. Fill these in as you store the * Wx files. The project and file type should appear on the top line, with the site name on the second line.

Inclusive dates and Julian days appear on the third and fourth lines. The last line should contain a disk number, preceded by the site initial (" $\mathrm{J}$ " for Johnston Island, " $E$ " for Edgewood, " $P$ " for Pine Bluff, etc.) and should be labeled in consecutive order. Remember to put your initials in the lower right corner of the label.

When you have a year's worth of data or have filled a floppy diskette box (whichever comes first), prepare a label for the box. This label should have the same basic format as the individual disks, with the addition of the 4-digit year number at the top of the label. If a box spans 2 years of data, put the last two digits of the year at the end of the Julian date numbers for clarity (i.e., "27486", as for the *. HR files in Figure VI-7, part B).

Before permanent storage, all diskettes should be write-protected. This is done by wrapping a small piece of tape around the indented portion of the disk on the upper right side. Small 1 - by $1 / 2$-inch pieces of tape are provided in each diskette box for this purpose.

\subsubsection{Archiving of the Hourly Datn Periods (*. HR File's)}

Hourly averages of the meteorological data are to be computed at least monthly using the WXSUM program and organized into files or tables. These tables may be saved in up to three different ways: displayed on the screen at run time, 
SHORT-TERM * .WX FILES

\begin{tabular}{l} 
CHAWS *WX flles \\
Tooele A.D. South \\
15 Apr -6 MaY 86 \\
Juldan: $105-125$ \\
T01, Init \\
\hline
\end{tabular}

CHAWS .WX files

Tooele A.D. South

23 May - 8 June ' 86

Julian: $143-159$

* T03, Init

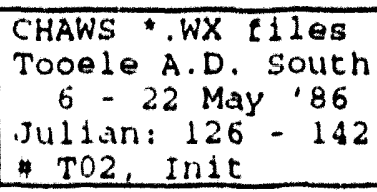

\section{LONG-TERM *.HR FILES}

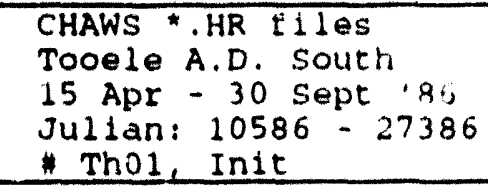

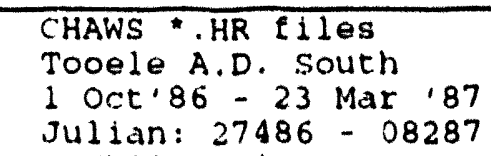

Figure VI-7. Sample labels for *. WX and * . HR files.

printed by a printer at run time, or saved in * . HLY files (see 3.2.2). The most convenient way to use the results is to save them as *. HLY files and examine them on the screen for any suspect data periods (remember that any AQ data gathered will not appear in these tables and so cannot be examined at this stage). Only the suspect data periods or phenomena of interest should be printed out and kept in a binder, as discussed above.

When running WXSUM for the first time, answer yes to the "File *. HR:" question on the user-input screen, which then stores the data in vialry form. These binary files are added to the WXOBS subdirectory, along with the *. HLY files (if 
requested) and the *. WX files. If you have $A Q$ data, run $A Q H R S$ as discussed in 3.2.3. The * . HR files may then be read by programs like AQHTAB.

Store the *. HR files on 1.2-M byte floppy disks unless $1.44-\mathrm{M}$ byte disks are more convenient. If the 1.2- $\mathrm{M}$ byte disks are used, 161 such files will fit on a disk for the Tooele site. A year could be stored on two disks.

Labels of the *. HR files are similar to those for the *. WX files (see Figure VI-6). If a floppy disk or disk box includes data spanning two years, designate the range of Julian dates by putting the last 2 digits of the year at the end of each Julian date. An example is shown in the figure. Remember to put the years at the top of the box label as well.

\subsection{Data Recovered (RECOV)}

When compiling a data base, it is essential to keep track of the daily and monthly percentages of data recovery. For periods of low recovery, it is also helpful to look at the status of each instrument. For these purposes, you should run the RECOV program, which keeps track of each 15-minute period for each station and channel, reads the raw *. WX files, tallies the valid and missing (" $M$ ") data periods, and creates the file "RECOV. OUT". One such file is shown in Table VI-5.

Start this program as described in 3.2.6 and run it for each day (i.e., each *. wX file). The "RECOV.OUT" file should be printed each day, separated, and inserted into a three-ring binder as discussed previously.

Prepare each "RECOV. OUT" file for printing by inserting the correct printercontrol characters. The program generates certain characters in the upper left corner of the screen. Although these characters cannot be reproduced here in printed text, they do change the printer parameters. Where the RECOV program has written " $A<2$ ", use $<A 1 t-9>$ (9 from numeric keypad) in PE2 to change this to something that looks close to "AO<2". This is done by typing "C/A $/ A<A 1 t-9>/ *$ " $<$ Enter $>$ (four spaces after $A$ ) on the command line. Now print the files using only PE2 by striking <F7> <Enter>. 

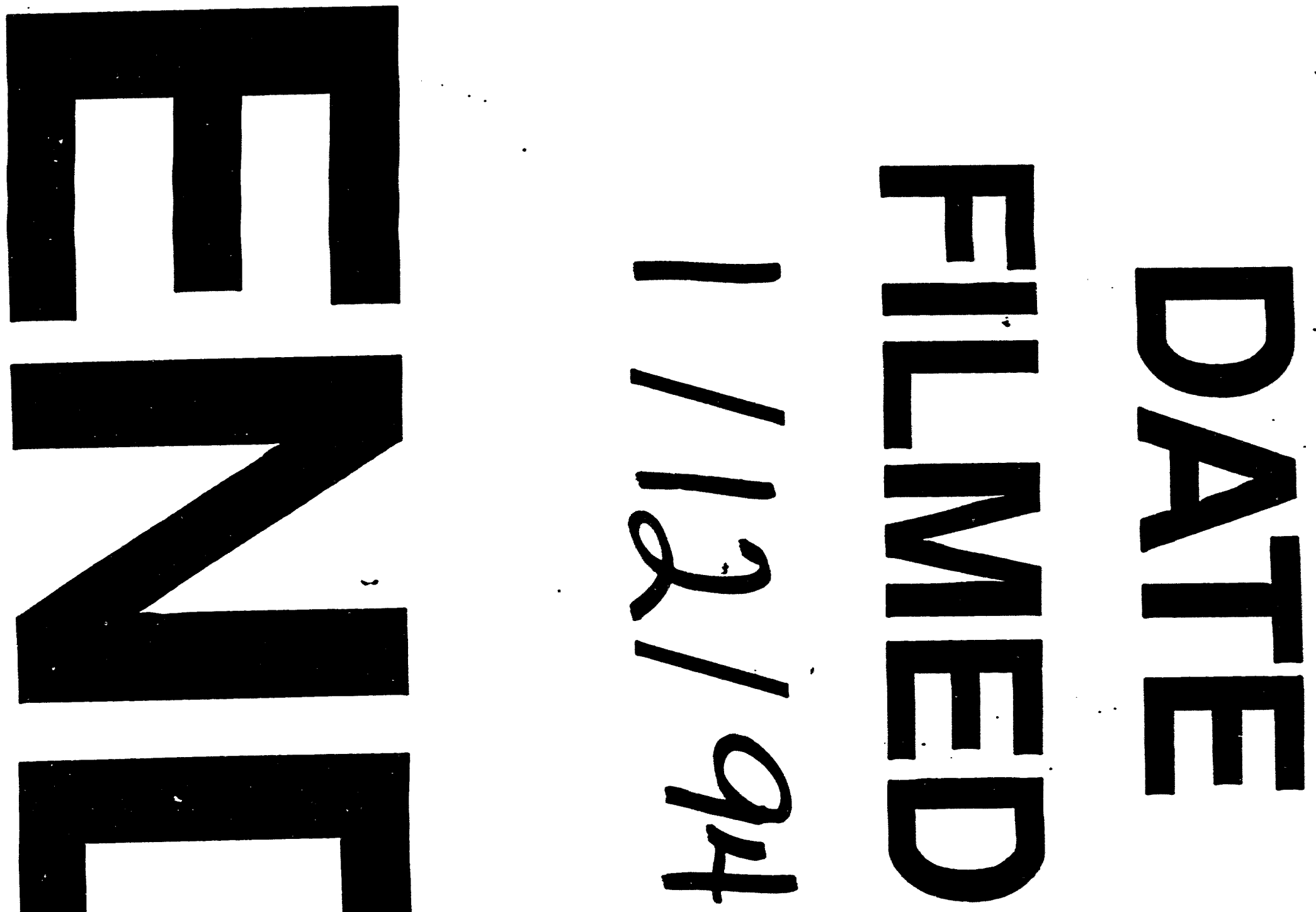


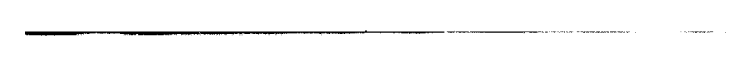
s.

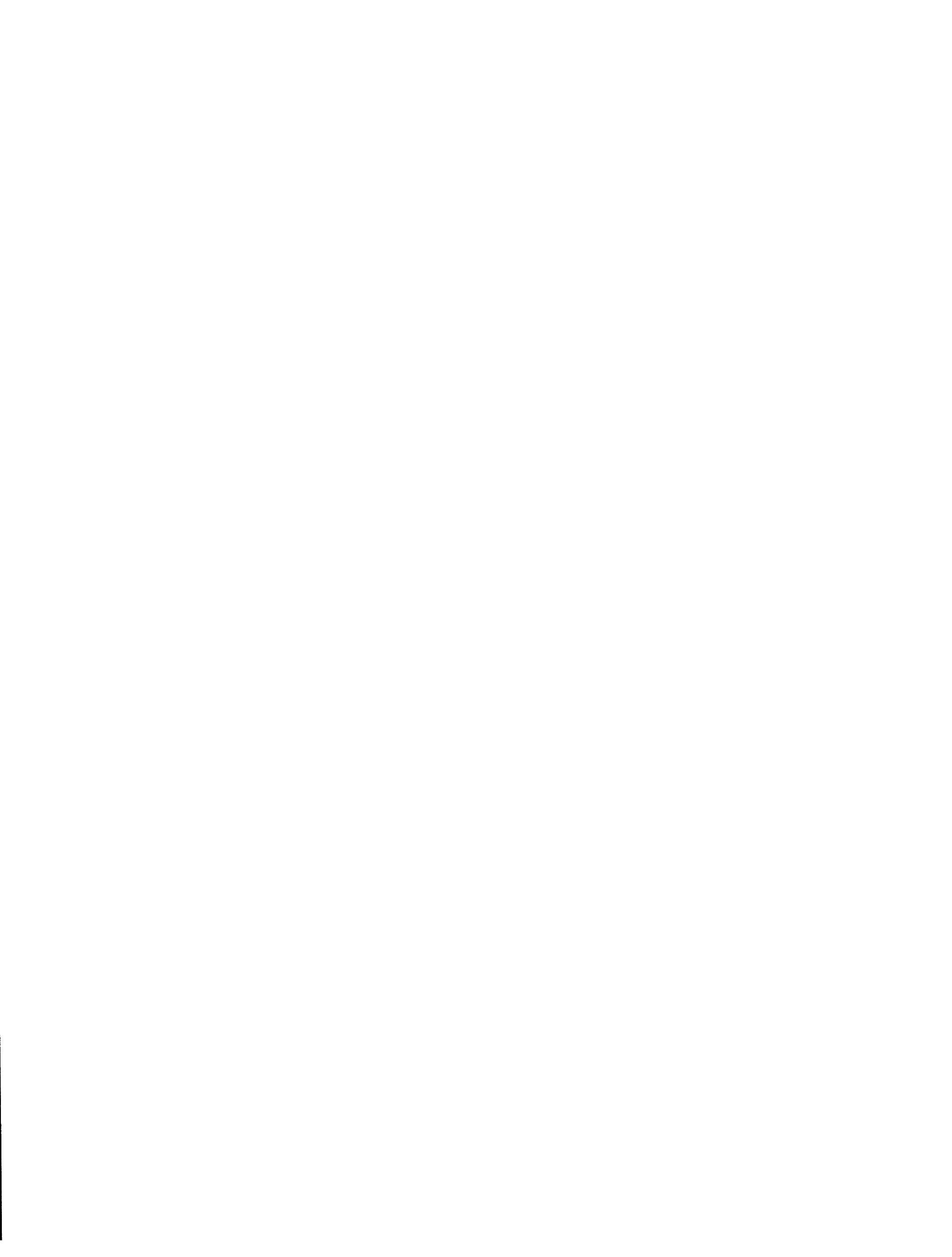

